\title{
norden
}

\section{Environmental compensation}

Key conditions for increased and cost effective application

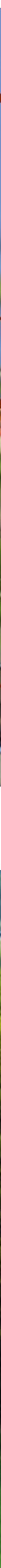







\section{Environmental compensation}

Key conditions for increased and cost effective application

Anders Enetjärn, Scott Cole, Matleena Kniivilä,

Svein Erik Hårklau, Linus Hasselström, Tryggve Sigurdson and Johan Lindberg

TemaNord 2015:572 
Environmental compensation

Key conditions for increased and cost effective application

Anders Enetjärn, Scott Cole, Matleena Kniivilä, Svein Erik Hårklau, Linus Hasselström,

Tryggve Sigurdson and Johan Lindberg

ISBN 978-92-893-4335-0 (PRINT)

ISBN 978-92-893-4337-4 (PDF)

ISBN 978-92-893-4336-7 (EPUB)

http://dx.doi.org/10.6027/TN2015-572

TemaNord 2015:572

ISSN 0908-6692

(C) Nordic Council of Ministers 2015

Layout: Hanne Lebech

Cover photo: ImageSelect

Print: Rosendahls-Schultz Grafisk

Printed in Denmark

This publication has been published with financial support by the Nordic Council of Ministers. However, the contents of this publication do not necessarily reflect the views, policies or recommendations of the Nordic Council of Ministers.

\section{www.norden.org/nordpub}

\section{Nordic co-operation}

Nordic co-operation is one of the world's most extensive forms of regional collaboration, involving Denmark, Finland, Iceland, Norway, Sweden, and the Faroe Islands, Greenland, and Åland.

Nordic co-operation has firm traditions in politics, the economy, and culture. It plays an important role in European and international collaboration, and aims at creating a strong Nordic community in a strong Europe.

Nordic co-operation seeks to safeguard Nordic and regional interests and principles in the global community. Common Nordic values help the region solidify its position as one of the world's most innovative and competitive.

\section{Nordic Council of Ministers}

Ved Stranden 18

DK-1061 Copenhagen K

Phone (+45) 33960200

\section{www.norden.org}




\section{Contents}

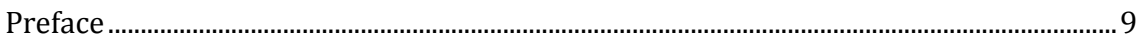

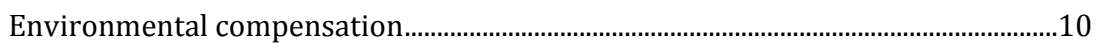

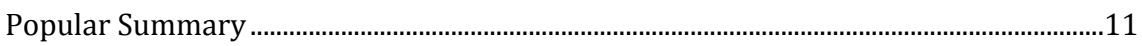

Introduction and background ...................................................................................1

Environmental Compensation in the Nordic Countries.............................................12

Benefits, Costs, and Risks..............................................................................................13

Key issues in developing a compensation framework ...............................................14

Recommendations for increasing the use of compensation .....................................14

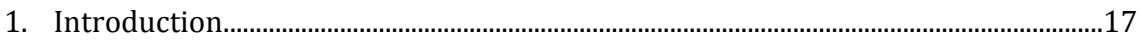

1.1 Background ...............................................................................................................17

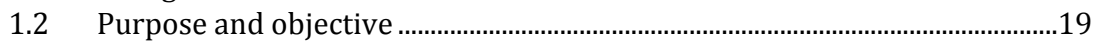

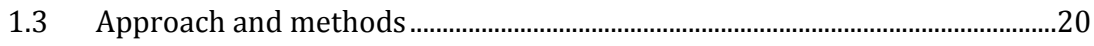

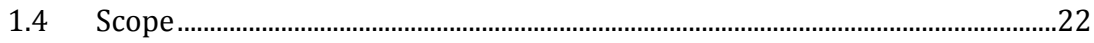

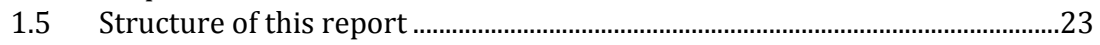

2. The Concept of Environmental Compensation ...........................................................25

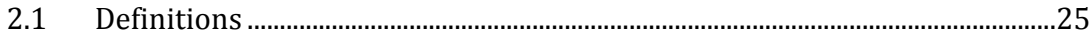

2.2 Method for compensation scaling.....................................................................30

2.3 Nordic environmental compensation example.................................................37

3. Benefits, costs, and risks of compensation .................................................................4

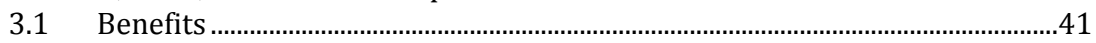

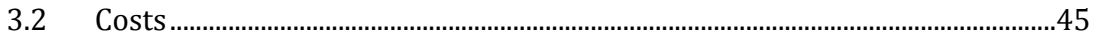

3.3 Linking Benefits and Costs.................................................................................55

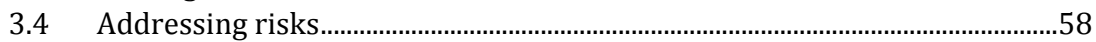

4. Environmental compensation in the Nordic countries ..............................................61

4.1 Drivers for environmental compensation......................................................61

4.2 Experience and status of Environmental Compensation..................................73

$4.3 \quad$ Key challenges.........................................................................................................94

5. Key issues in developing a compensation framework ..............................................103

5.1 Environmental compensation as part of the planning and

regulatory process ........................................................................................103

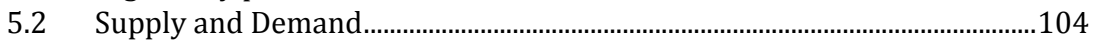

5.3 Cost-effectiveness considerations ..................................................................107

6. Recommendations for increasing the use of environmental compensation

in Nordic countries ....................................................................................................127

6.1 Stimulate supply of, and demand for, compensation ....................................128

6.2 Clarify and supplement compensation guidelines and legal

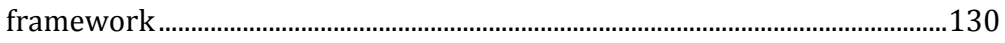

6.3 Strengthen Nordic cooperation ....................................................................132

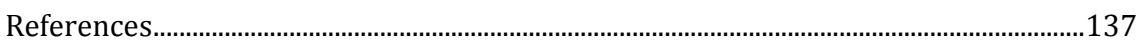

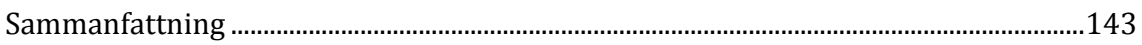




\section{List of boxes, figures and tables}

Box 2.1: BBOP definition.

Figure 2.1. Compensation within the mitigation hierarchy (inspired from BBOP) 29

Box 2.2. BBOP Mitigation hierarchy

Figure 2.2. Equivalency Analysis scales a compensatory credit such that its

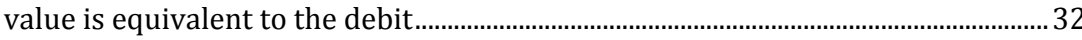

Box 2.3. BBOP Best practice principles ............................................................................... 34

Figure 2.3. Decidous forests are focus habitats in measuring the debit, identifying possible credits and scaling compensation in the Swedish Nordic Iron Ore Ludvika mining project.

Figure 2.4. Impact and environmental compensation in the Swedish Nordic Iron Ore Ludvika mining project.

Figure 3.1. Cost categories that can be affected in a compensation framework 46

Table 3.1. Summary of major cost categories associated with environmental compensation.

Figure 3.2. Timeframe of compensation costs. ................................................................. 50

Figure 3.3. Distribution of costs for compensation project Botnia Line railway

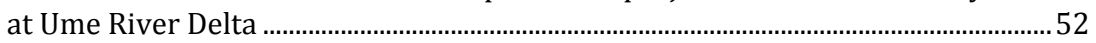

Table 3.2. Illustration of the range and magnitude of compensation costs....................53

Table 3.3. Cost of compensation related to total cost of development project..............55

Table 4.1. Examples of implementation of mitigation hierarchy and compensation in Swedish legislation.

Figure 4.1. Wetlands and meadows restoration and restored temporarily flooded arable land in central parts of compensation area at Ume River Delta, with new railway Botnia Line through the area. This picture covers one of five new nature reserves

Box 4.1: Railway Bothnia Line, Ume River delta ................................................................... 78

Box 4.2: Railway Bothnia Line, Öfjärden ........................................................................... 79

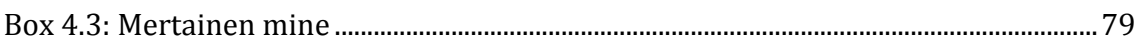

Figure 4.2. Felling of old growth forest in impact area of Mertainen mine. The retained trees will be removed seperately and relocated to the compensation area to improve conditions for species depending on dead wood substrate.

Figure 4.3. Highway E45 and railway along river Göta Älv ................................................ 81

Box 4.4: New highway E45 and railway along Göta Älv River, Gothenburg................... 81

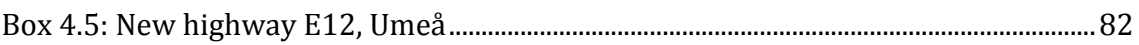

Figure 4.4. Compensation measures along new highway E12 aimes to create several small wetland, meadow, stream, sand and grazed habitats between existing farmland to the north (right) and a stream to the south (left), as well as improve recreational use and public access 
Figure 4.5. Providing a new breeding habitat for sand martin is one of the compensation measures in the compensation plan for new highway E12..............84

Box 4.6: New tailings expansion, Aitik mine.

Figure 4.6. Old growth dead wood debris, like the old log on the ground in this picture, is a key priority substrate that will be moved from the impact area to improve conditions in the compensation area

Box 4.7: New highway E18 Hamina-Vaalimaa................................................................87

Box 4.8: Merikoski hydro power station.............................................................................87

Box 4.9: Rudus - voluntary nature conservation program...............................................88

Box 4.10: Highway E6 expansion Hamar ..........................................................................90

Figure 4.7. Northern part of Åkersvika with existing highway E6 and suburbs of city of Hamar prior to the proposed expansion of the highway and associated compensation

Box 4.11: Various hydro power projects............................................................................91

Box 4.12: Armed forces training field..............................................................................

Figure 4.8. Búðarháls hydro power plant.........................................................................93

Box 4.13: Búðarháls hydro power plant............................................................................93

Figure 4.9. In all Nordic countries there is a need for clear guidelines for assessing damage and scaling compensation . .100

Figure 5.1. Environmental compensation should be considered when applying the mitigation hierarchy in all stages of the planning of a project, from public land use planning to decomissioning. This would create incentives to improve avoidance, minimization and restoration

Figure 5.2. Like the chicken and the egg problem, both supply and demand must be present from the beginning. If the business community sees clear incentives for environmental compensation, the implementation will gain momentum

Figure 5.3. Cost reducing benefits of Dissemination of experiences..............................108

Figure 5.4. Cost reducing benefits of Regional management/Land use plans ............109

Figure 5.5. Cost reducing benefits of Administrative systems.......................................110

Figure 5.6. Cost reducing benefits of clear guidelines......................................................111

Figure 5.7. Cost reducing benefits of Best Management Practices.................................111

Figure 5.8. Cost reducing benefits of flexibility in key compensation variables ........113

Figure 5.9. Cost reducing benefits of Habitat Banking ..................................................120

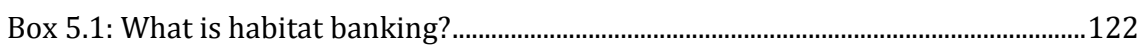

Box 5.2: Exploring habitat banking in Finland and Sweden ...........................................123

Box 5.3: Alternatives to Habitat Banking: Pros and Cons ................................................124

Figure 5.10. Cost minimization strategies and their effect on the compensation cost categories. 



\section{Preface}

Environmental compensation as a policy instrument to stop the loss of biodiversity and ecosystem services has recently gained much attention by researchers and policy makers alike. Failure to meet biodiversity targets together with increasing pressure from human activities has sparked new interest in this potentially useful tool. Environmental compensation has already been implemented in various countries, although limited in scope. Experiences from these implementations are mixed and tend to stress the importance of certain principles in order to achieve the overall objective of halting biodiversity loss.

This report has been commissioned by The Nordic Council of Ministers in order to better understand the conditions for increased and cost efficient use of environmental compensation in the Nordic countries. Responsible working groups are Environment and Economy (MEG) and Terrestrial Ecosystems (TEG).

The report presents the current use of environmental compensation in the Nordic countries together with some thoughtful recommendations on how to increase its use in a cost efficient and equitable manner. We think this contribution is timely and wish to support the present discussion about compensation with sound evidence-based results.

A group of consultants led by Enetjärn Natur was chosen to write the report. The group includes EnviroEconomics Sweden, Pellervo Economic Research PTT, Hårklau NRM Services and Enveco. The authors of the report are responsible for the content as well as the recommendations, which do not necessarily reflect the views and positions of the governments in the Nordic countries.

August 2015

Fredrik Granath

Chairman of the Working Group on Environment and Economy under the Nordic Council of Ministers 


\section{Environmental compensation}

\section{Key conditions for increased and cost effective application}

\section{Prepared by}

- Anders Enetjärn, Enetjärn Natur.

- Scott Cole, EnviroEconomics Sweden.

- Matleena Kniivilä, Pellervo Economic Research PTT.

- Svein Erik Hårklau, Hårklau NRM Services.

- Linus Hasselström, Enveco.

- Tryggve Sigurdson, Enetjärn Natur.

- Johan Lindberg, Enetjärn Natur.

\section{Illustrations}

- Susan Enetjärn, Enetjärn Natur.

\section{Reference group}

- Ian Dickie, eftec, Great Britain.

- Lena Gipperth, Göteborg University, Sweden.

- Fabien Quétier, Biotope, France.

- Martin Szaramowicz, Compensation Agency Brandenburg, Germany. 


\title{
Popular Summary
}

\author{
Introduction and background
}

Environmental impacts are increasing due to human activities related to residential and commercial development, energy infrastructure, mines, rail and road construction, dredging, marinas, docks, piers as well as agriculture, forestry, fisheries, etc.

The overuse and over-exploitation of the benefits nature provides us - such as biodiversity and ecosystem services (sometimes referred to as "natural capital") - is the direct result of our failure to put a price on these benefits. As a result, the global economic system creates poor incentives for public and private entities to incorporate these valuable goods and services into their daily decision-making.

One way of addressing these impacts is to require environmental compensation measures that offset the loss associated with the damaged resources. Environmental compensation is provided in the form of resource-based (not monetary) payments that protect, enhance, restore or otherwise improve similar resources. We distinguish between two types of compensation: biodiversity offsets focus on the loss and gain of ecological functions, habitats, and species while ecosystem service offsets take a broader aim and include human use of resources. While we suggest a primary focus on biodiversity offsetting, a consideration of human use concerns is motivated to ensure equity for victims of environmental damage.

While compensation represents a valuable tool for policy makers it should be applied within the context of the mitigation hierarchy, which suggests that environmental impacts should first be avoided, then minimized, and finally restored where possible. After these initial measures have been undertaken, any residual impacts can be compensated for based on a variety of different compensation scaling methods.

This study is timely given that Nordic governments and the EU have embraced the Polluter Pays Principle (PPP) and the main principles of the mitigation hierarchy. Further, a number of EU Directives require compensation for environmental impacts and current EU policy developments suggest that compensation will become increasingly relevant, 
not the least because of the No Net Loss Initiative expected as Action 7 under Target 2 of the EU Biodiversity Strategy to 2020.

While actors in the Nordic countries acknowledge a need for increased use of compensation, the legal provisions vary. Further, the current scope of compensation remains limited, the use of established frameworks and guidance is un-common, and few of the countries are benefiting from the lessons learned from compensation approaches elsewhere. The lack of an overall framework and clear guidance for regulators makes the use of compensation as a policy tool difficult to predict and potentially ineffective.

This report for the Nordic Council of Ministers provides decisionmakers at the national level in Nordic countries with an overview of key conditions for increased, flexible and cost-effective application of compensation and outlines of potential frameworks.

\section{Environmental Compensation in the Nordic Countries}

Our review of existing compensation efforts found significant variation in the legal support for, and use of, compensation between Nordic countries. Several recent initiatives in Sweden, some of which were proposed voluntarily by developers and municipalities, places that country slightly ahead of the others. In total, the Swedish compensation projects have protected more than 3,500 ha of land. Norway is in a start-up phase and has initiated its first pilot project on compensation for a major highway project. Finland has weak legal support for compensation, but is investigating options for increasing the use of habitat banking as a mechanism to facilitate the future supply of compensation credits. Although there are success stories in Denmark related to restoration and habitat creation in general, no formal compensation projects have been identified. In Iceland, compensation is required in some cases, e.g. a hydro power plant compensated the loss of vegetated land through the restoration of eroded land.

Nordic countries have faced several key challenges related to their initial work with compensation. A common Nordic challenge is the lack of clear guidelines. In 2015, the Swedish EPA will be the first Nordic authority to develop and publish guidelines. Lack of clear guidelines leas to project delays, which subsequently leads to higher costs for compensation. Further, a relatively low degree of flexibility in applying compensation has resulted in high costs for scaling and selection of suitable areas and methods for compensation. Land access for compensation appears 
to be a major challenge, particularly in Norway where there is strong legal protection of cultivated areas. A specific challenge connected to boreal ecosystems is the long delivery time before restored habitats come "on-line". Finally, there is no mechanism for comprehensive feedback among authorities in Nordic countries, which means that many opportunities are lost for sharing experiences and reducing costs.

In short, Nordic legislation does not support the use of environmental compensation and is not designed to achieve No Net Loss of biodiversity and ecosystem services.

\section{Benefits, Costs, and Risks}

The benefit of requiring compensation is that society no longer bears the cost of un-repaired environmental damage. Instead, those causing the damage face incentives to avoid damages as a result of having to pay for compensation.

Compensation requirements cost society money, including transaction costs, scaling costs, investment costs, and long-term management costs. An understanding of these financial costs is key for informing the development of a cost-effective compensation framework, i.e., a framework that helps to reach the No Net Loss goal at the lowest cost to society.

One way of conceptualizing the costs of providing compensation is to consider the total cost of implementing a compensation project as a percentage of overall project development costs, which we find may vary from 1 to $5 \%$. Despite the uncertainty in these estimates, they nonetheless provide two important messages for policy makers.

- First, for a relatively small cost society can make a significant investment in the provision of biodiversity and ecosystem services. Further, this compensation investment represents a significant improvement over the "business as usual" approach where nature exploitation is essentially free.

- Second, even if the compensation investment does not fully offset the costs of environmental damage, it nonetheless represents a step in the right direction. 
Nonetheless, there are certain risks associated with compensation, e.g., compensation policies may be abused ("license to trash"), some types of environmental injuries are difficult to offset, restoration results may be uncertain, and/or compensation may lead to changing landscapes. The most important strategies for addressing these risks are (1) clear guidelines on what is and is not acceptable and (2) strong adherence to the mitigation hierarchy.

\section{Key issues in developing a compensation framework}

We identify several issues that need to be considered in developing a future compensation framework in Nordic countries including:

- How best to integrate compensation into existing regional planning processes. While full integration will reduce transaction costs, it is also important to maintain separate decision-making processes related to: (1) permit approval (should it be built?) and (2) compensation (how best to offset the residual impact?).

- How best to ensure the two prerequisites for a successful compensation system: stimulation of demand for, and supply of, compensation credits.

- The identification of key trade-offs in defining a future compensation framework, in particular the balance between increased flexibility on the one hand (to keep compensation measures as cost-effective as possible) and a strong focus on reaching the No Net Loss objective.

\section{Recommendations for increasing the use of compensation}

In this report we make a number of recommendations for the Nordic Council of Ministers and decision-makers at the national level in Nordic countries on how to increase the use of environmental compensation. While the ultimate goal should be to reach No Net Loss of biodiversity and ecosystem services, we believe a realistic short-term goal of increasing compensation should be based on an "acceptable level of loss." The recommendations incorporate international best practice and are applicable to all Nordic countries. Three main recommendations are detailed together with nine recommended actions: 
1. Stimulate supply of, and demand for, compensation:

- Require compensation now to stimulate demand.

- Establish pilot habitat banks to increase supply.

- Develop compensation pilots using existing regulatory drivers.

2. Clarify and supplement compensation guidelines and legal frameworks:

- First: Rely on existing legal frameworks and improve existing implementation.

- Second: Consider improvements to legal frameworks.

- Implement environmental compensation within existing spatial planning processes.

3. Strengthen strategic Nordic cooperation on compensation:

- Share experiences and lessons learned.

- Create a common Nordic interpretation of the No Net Loss concept.

- Start cooperation on transboundary development projects.

Finally we note that there has been an evolution in thinking about environmental values. While this shift may be driven in part by explicit changes in environmental regulations across countries, it also includes an implicit change in social norms about what is and what is not acceptable in terms of our impact on global ecosystems - and what we should do to repair or offset these impacts. One result of this change is increased requirements for environmental compensation in countries like the US, Germany, Australia, France, and England. More recently, this change in social norms related to ecosystem services can even be seen in the Nordic countries, in particular Sweden.

Changes in social norms tend to occur slowly over time, as has been seen in similar shifts in citizens' preferences or mindsets on issues like smoking in public places, child labor or wearing seatbelts. This shift in how we view biodiversity and ecosystem services can even be seen in the private sector. For example, at a recent Swedish conference on environmental legislation a mining business representative suggested that "Environmental compensation is a reasonable and natural expectation when a company's development negatively impacts areas of high environmental value." 1

${ }^{1}$ Anders Forsgren, Boliden Mineral, at Miljöbalksdagarna (19-20 March 2015) In Swedish: "Ekologisk kompensation är rimligt och naturligt att genomföra vid anspråktagande av mark med höga naturvärden." 



\section{Introduction}

\subsection{Background}

Impacts on the environment, including on ecosystem goods and services, are increasing due to human activities such as residential and commercial development, energy infrastructure, mines, rail and road construction, dredging, marinas, docks, piers as well as agriculture, forestry, fisheries, etc. Despite advanced planning frameworks and environmental standards in the Nordic countries, the cumulative environmental impacts over time are reaching unprecedented levels. Since most development projects have residual negative impacts and no environmental compensation is required, society is steadily losing important environmental resources and implicitly under-valuing these resources. This is costly from a social welfare point of view as it leads to a shortage of the valuable benefits that nature provides us, including biodiversity and ecosystem services (sometimes referred to as "natural capital").

One way of addressing these impacts is to require environmental compensation measures that protect, enhance, restore or otherwise improve the damaged or scarce resources.

But why do we need compensation requirements in the first place? The overuse and over-exploitation of nature's benefits is the direct result of our failure to put a price on biodiversity and ecosystem services. As a result, the global economic system creates poor incentives for public and private entities to incorporate nature's benefits into their daily decision-making.

Economists refer to this dis-incentive to conserve the supply of nature's benefits as a market failure. As explained in chapter 3.1.1, environmental damage from certain actors ("polluters") imposes a negative external cost on society. If polluters faced incentives to consider these external (environmental) costs in their decision-making process, they would "internalize" them and thus consider the resulting environmental impact. This is the idea behind the Polluter Pays Principle (PPP).

From a policy perspective there are several instruments that can address these types of environmental impacts and resulting market failures. They can generally be grouped into four categories (Sterner 2003, Cole et al. 2014): regulation (which mandates a certain level of 
environmental control by law), information sharing (which aims to change actors' behavior), technology support (which encourages R\&D to solve environmental challenges), and economic-based instruments (which influences how actors experience the costs and benefits of their choices). A key attribute to consider when choosing between alternative instruments, or selecting specific policy approaches, is costeffectiveness: a cost-effective approach ${ }^{2}$ is one that reaches a given objective - in our case, No Net Loss - at the lowest possible cost to society (see chapter 5.3).

Compensation is a policy instrument that combines several of these approaches. It relies first and foremost on a regulatory driver that requires polluters to consider the environmental consequences of their decisions. If properly implemented through the mitigation hierarchy (see chapter 2.2), compensation requirements provide information to polluters on how their actions impact biodiversity and ecosystem services and how compensation measures can offset those impacts. The fact that polluters are required to consider environmental values suggests that an economic-based approach is also at work: polluters face an incentive to internalize environmental impacts by considering the cost of compensation projects. Further, economic-based approaches may be used to deliver off-setting compensation credits in a cost-effective manner through habitat banking (see chapter 5.3.7).

This study, funded by the Nordic Council of Ministers, is timely. For example, both the Nordic governments and the EU have embraced the PPP and the main principles of the mitigation hierarchy. The PPP suggests that those causing environmental damage should be responsible for the costs of repair, while the principles of the mitigation hierarchy provides a theoretical framework for addressing environmental impacts that arise from a development project: first avoiding impacts, then minimizing, then mitigating and restoring and, ultimately, compensating for any remaining and unavoidable impacts. The Nordic countries have also signed the UN Convention on Biological Diversity (CBD), the Ramsar wetlands convention and other obligations that prescribe compensation as part of the mitigation hierarchy. ${ }^{3}$ EU Directives such as the Habitats Directive, the Birds Directive, the EIA Directive, the SEA Directive and the Environmental Liability Directive require compensation for environmental impacts and current EU policy developments suggest that

\footnotetext{
2 In our report we consider a "cost-effective" measure to be equivalent with a cost-efficient one.

3 Text of CBD does not provide for compensation. However, guidelines dealing with compensatory measures have been developed under the Convention.
} 
compensation will become increasingly relevant. For example, compensation is described in the No Net Loss Initiative (NNL) expected as Action 7 under Target 2 of the EU Biodiversity Strategy to 2020 (European Commission 2011). Together, these initiatives suggest that environmental compensation is an increasingly salient policy tool to help protect our natural capital.

While actors in the Nordic countries acknowledge a need for increased use of compensation as a policy tool (SOU 2013; Samferdselsdepartementet 2013), the legal provisions vary, with only some of the countries undertaking compensation projects. Further, the current scope of compensation remains limited, the use of established frameworks and guidance is un-common, and few of the countries are benefiting from the lessons learned from compensation approaches elsewhere. A recent Swedish EPA report (Naturvårdsverket 2015) found that very few development projects demanded compensation in Sweden, which has led to negative impacts on the environment. Importantly, the lack of an overall framework and clear guidance for regulators make the use of compensation as a policy tool difficult to predict and potentially ineffective.

The regulatory and other drivers for compensation vary across the Nordic countries. Generally, compensation is driven by (1) explicit legal protection of certain habitats, species or protected areas and (2) concerns associated with some human activities that are known to have impacts on biodiversity (e.g., mines, roads). Although the lost values caused with "large footprint" projects may be significant, the biggest threat to biodiversity is often the accumulation over time of projects in "everyday landscapes", ${ }^{4}$ which contributes to substantial cumulative losses (IEEP 2014).

\subsection{Purpose and objective}

The purpose of this study is to provide Nordic Council of Ministers, specifically the Working Group on Environment and Economy (MEG) and the Terrestrial Ecosystem Group (TEG) and decision-makers at the national level in Nordic countries with an overview of key conditions for increased, flexible and cost-effective application of compensation and outlines of potential frameworks.

\footnotetext{
4 The term "everyday landscapes" is used for all areas without formal protection or with relatively lower conservation value (See Chapter 1.4).
} 


\subsection{Approach and methods}

To analyze compensation frameworks, we rely on certain approaches for data collection and apply relevant methods and theories.

Our information collection relies on literature and expertise on the state of the art internationally (e.g., EU, US, Germany, Australia, France, UK) and within Nordic countries. We focus specifically on the challenges and opportunities for implementing compensation in the Nordic countries. For example, we consider the nascent implementation of compensation measures in Sweden and the preliminary considerations for applying compensation in Finland and Norway.

Our report benefits from a diverse team of experts that reflect both practical experience in developing and applying compensation on an international level and interdisciplinary nature of compensation itself (e.g., ecologists and economists). We rely on the REMEDE toolkit approach to compensation scaling (Equivalency Analysis), which was developed in the US over the last 30 years and recently adapted for use in the EU. The team's experience also includes several on-going and relevant compensation-related projects as well as discussions with policy makers and other Nordic stakeholders involved in compensation.

The methodological starting point for this analysis is the economic concept of compensating individuals (and ultimately society) for losses, which is an inherently human-centric, or anthropocentric, concept. Because we assume that environmental compensation is motivated by a concern over society's well-being, we rely on theories from welfare economics. Welfare economics is the study of how well society is doing. While it is frequently measured in terms of income (e.g., GDP in a particular country), this is only a proxy for "welfare", which refers more broadly to general prosperity and quality of life and may consider such factors as e.g., human health, access to education, level of pollution, access to nature, etc. The anthropocentric approach used in this report assumes that welfare is based on individual preferences for goods and services, which necessarily includes levels of biodiversity and ecosystem services. 
Assessing welfare implications of environmental change requires the merging of ecological theory - which observes, measures, and quantifies ecological changes - with economic theory. Our approach requires explicit terminology that distinguishes between environmental and welfare changes (Roach and Wade 2006). Specifically, we make a distinction between:

- Environmental injuries, which are measured by ecologists and capture the biophysical changes: e.g., loss (or gain) of flora and fauna (biodiversity), habitats, or the contamination (or restoration) of water, soil or air.

- Economic damages, which are measured by economists and capture how the environmental injury affects social well-being. Examples include: reduced enjoyment of habitat and species, increased cost of wastewater treatment, property damages from sea level rise or coastal erosion, flood damages from extreme weather events, reduced recreational opportunities, loss of food production, etc.

Interdisciplinary cooperation between ecologists and economists is crucial for determining the appropriate scale (i.e., size and extent) of compensation payments designed to offset economic damages from environmental injury.

Our anthropocentric approach relies on so-called "instrumental values", i.e. the value of nature to society (and not the intrinsic value of nature itself). Instrumental values are relevant to policy makers who face decisions about when to require compensation and how much. These decision-making challenges require information about environmental values (monetary or otherwise) to assess the inevitable trade-offs in how society should spend limited resources to protect the environment. While compensation aims to restore instrumental values it may also, to some extent, protect intrinsic values.

The benefits to society provided by both biodiversity and ecosystem services are captured by instrumental values, with ecosystem services more directly connected to human use. For example, injury to a wetland not only leads to a decline in species composition (biodiversity) and a reduction in nutrient cycling but may also impact human enjoyment of these resources, such as recreational swimming, hiking, fishing, paddling, etc. ${ }^{5}$ The focus on both ecological function and human use (both

${ }^{5}$ Compensation in general should address total welfare losses resulting from environmental injuries, which includes both consumer surplus losses (e.g., the public's loss of biodiversity values or ecosystem services like 
motivated by a human-centric approach) is supported by various compensation-related policies. For example, the Business and Biodiversity Offsets Program (BBOP) includes both "equity (fairness to users)" and "involvement of stakeholders" in their criteria for best practices and includes, among other things, consideration of "people's use and cultural values" in their definition of biodiversity offsets. Further, the EU's definition of No Net Loss aims to prevent a decline in both "biodiversity and ecosystem services". 6 The US definition of environmental damage also includes references to "the services nature provides society". ${ }^{7}$

\subsection{Scope}

This report focuses on the Nordic countries, primarily Sweden, Norway, and Finland, but to some extent also covers Denmark and Iceland. The report considers relevant and on-going policy efforts in the EU and how these may affect the future development of compensation frameworks in Nordic countries.

The report focuses on everyday landscapes, as suggested by the NCM invitation to tender, but applies to other areas too. We define everyday landscapes as terrestrial, freshwater, and marine habitats experiencing environmental loss and being outside of protected landscapes. Our focus on everyday landscapes is consistent with the European Commission (EC)'s development of the NNL, which was recently described in a policy proposal document as an initiative that should aim to "extend the reach of EU nature law beyond existing protected areas" (EC NNL Working group 2013). This report will, however, consider relevant experiences of implementing compensation in protected landscapes in Nordic countries and beyond.

With our human-centric approach we define compensation to cover impacts to both biodiversity and ecosystem services. Biodiversity offsets generally focus on the loss of ecological functions, habitats, and species (and generally rely on biophysical metrics to scale compensation), while ecosystem service offsets have a broader aim and include recreational and

recreational swimming, fishing, boating, etc.) and producer surplus losses (e.g., loss of private profits to commercial fishing industry, tourism companies, etc.). However, "environmental compensation" addresses environmental injuries and their impact on consumers (social profits), and is paid in resource terms. In contrast, producer surplus losses are addressed through civic compensation and are paid in monetary terms. We do not address civic compensation in this report.

${ }^{6}$ Action 7 under target 2 of the EU Biodiversity Strategy to 2020 seeks to "ensure no net loss of biodiversity and ecosystem services".

${ }^{7}$ NRD Natural Resource Damage Assessment (http://www.epa.gov/superfund/programs/nrd/nrda2.htm). 
cultural human use of resources (and rely on a combination of monetary and or non-monetary scaling metrics). While the primary focus should be on biodiversity offsetting, a consideration of human use concerns vis a vis an "ecosystem services lens" is motivated to ensure equity for victims of environmental damage. We discuss some of the pros and cons of these alternative viewpoints in chapter 5.3.6.

Our suggestion for key issues to consider in a compensation framework and our set of recommendations applies primarily to ex ante compensation but the results are equally relevant for ex post compensation schemes. An ex ante scheme demands that compensation is agreed to prior to an anticipated environmental injury (e.g., from an infrastructure project), while an ex post scheme demands compensation for an injury that has already happened (e.g., an unexpected chemical release, as under the EU's Environmental Liability Directive). The results of this study are particularly relevant for governments that wish to ensure consistency between, and flexibility and cost-effectiveness for, future ex ante and ex post compensation schemes.

\subsection{Structure of this report}

The remainder of this report is structured as follows:

Chapter 2 provides illustrations and definitions of key concepts like environmental compensation, biodiversity offsets, No Net Loss, the mitigation hierarchy, and other guiding principles.

Chapter 3 provides an overview of the costs and benefits of environmental compensation and underscores the fact that providing compensation may in fact be cheaper than not providing it, especially when the welfare losses associated with environmental injury are high.

Chapter 4 summarizes the status of compensation in Nordic countries and highlights some of the current challenges and results from the nascent use of compensation.

Chapter 5 provides policy makers with a discussion of key issues to consider in developing a compensation framework.

Chapter 6 provides our own recommendations on a path forward for the increased use of compensation, including specific suggestions for how to develop a cost effective and flexible application, and how Nordic countries might be able to cooperate in this area. 



\section{The Concept of Environmental Compensation}

This chapter defines key concepts and definitions in building a compensation framework.

\subsection{Definitions}

\subsubsection{Economic compensation}

As noted in chapter 1.3, our starting point is inherently human-centric. Thus, the fundamental basis for environmental compensation is the economic concept of compensating individuals (and ultimately the public) ${ }^{8}$ for their welfare losses. Welfare may be impacted by e.g., loss of income, loss of free time (recreation), loss of access to education, health care, or environmental resources. In theory, these types of impacts could be compensated with a variety of different mechanisms, such as money, private goods or services, or even public goods such as biodiversity or ecosystem services. The amount of economic compensation required to ensure an individual is "no worse off" than he/she was prior to some injury is inherently subjective, as it depends on an individual's preferences about what they are willing to substitute (e.g., gain for loss).

\subsubsection{Environmental compensation for impacts to biodiversity and ecosystem services}

Environmental compensation is a particular type of economic compensation where the compensation mechanism is restricted to be resource-based: i.e., victims cannot be compensated with money (even if they prefer it, see Jones and Pease 1997). Rather, resource loss must be

8 In theory, compensation is assessed on an individual level, but then the results should be aggregated. See Johannsson 1991. 
compensated with resource gain. ${ }^{9}$ Further, biodiversity offsets represents a specific type of environmental compensation that relies on biophysical measures of loss and gain. This type of compensation has specific aims and goals (see Box 2.1) and generally addresses the loss of non-use values. As we discuss above (chapter 1.4), we also consider an additional category of environmental compensation that addresses the loss of ecosystem services separately from biodiversity loss. These types of losses tend to address use values and may be measured in monetary or non-monetary terms but, like biodiversity compensation, must be provided in terms of restored resources and/or improved access for the enjoyment of resources.

\section{Box 2.1: BBOP definition 10}

\section{BBOP definition}

Biodiversity offsets are measurable conservation outcomes resulting from actions designed to compensate for significant residual adverse biodiversity impacts arising from project development after appropriate prevention and mitigation measures have been taken. The goal of biodiversity offsets is to achieve No Net Loss and preferably a net gain of biodiversity on the ground with respect to species composition, habitat structure, ecosystem function and people's use and cultural values associated with biodiversity.

This report uses the term "environmental compensation" (or simply "compensation") to refer to both biodiversity offsets or compensation of ecosystem services losses. ${ }^{11}$ Our use of the term refers to actions that aim to replace environmental values on an equal basis (as a minimum No Net Loss). Further, we assume it may address both pure ecological impacts such as to biodiversity and habitat as well as impacts on human use such as recreation. Finally, we assume that compensation is linked to a specific and recent human activity that leads to (or will lead to) environmental injury in the short term, rather than more general ecological restoration activities aimed at repairing historic losses that have accumulated over the past centuries. Finally, compensation refers only to the

\footnotetext{
${ }^{9}$ Note further that resource-based compensation cannot be provided to specific individuals, but rather to society as a whole. In other words, it can only be provided in aggregate. See Cole 2011.

${ }^{10}$ Business and Biodiversity Offsets Programme (BBOP). 2012

11 The terms equivalent to "environmental compensation" used in different Nordic languages include for instance "ekologisk compensation" (Sweden), "ekologinen kompensaatio" (Finland) and "økologisk kompensasjon" and "fysisk kompensasjon" (Norway).
} 
final step of the mitigation hierarchy (see chapter 2.2), but is inevitably affected by the preceding steps.

We highlight below several definitions of compensation used by different countries.

\section{Sweden}

Environmental compensation ("ekologisk compensation") is defined by the 2013 Swedish governmental investigation on ecosystem services (SOU 2013:168) and clearly incorporates a No Net Loss component:

"Environmental compensation is defined as the requirement that those who cause environmental injury to the natural environment - including public resources such as species, natural habitats, ecosystem functions, and user values - should offset these losses by creating new values with the explicit aim of avoiding a net loss. Environmental compensation should only be implemented after all other reasonable environmental measures have been taken in the affected area (i.e., to avoid or minimize impacts)."

\section{France}

France reformed its Environmental Impact Assessment process in 2012 and published guidance on applying the mitigation hierarchy. It states that the outcome of applying the hierarchy should ensure that the overall quality of the environment is maintained or improved, with "quality" being defined broadly or specifically depending on the applicable regulations in that specific context. These include impacts on protected species, wetland functions, priority habitats etc. (Quétier et al. (2014)).

\section{Norway}

The Norwegian governmental investigation on ecosystem services (NOU 2013:10), the government working group considering offsets in the transportation sector (Arbeidsgruppe, 2013) and the study commissioned by this working group (Hårklau et al., 2013) base their definition of compensation on the BBOP definition of biodiversity offsets. The Norwegian biodiversity legislation does not provide an explicit definition of compensation but refers to compensation as something a project developer may be required to bear the costs of and comprises the safeguarding, establishment or development of an area corresponding to the area impacted by the project. 


\section{Great Britain}

British Defra uses the following definition of biodiversity offsetting, which incorporates a No Net Loss (Defra Sept. 2013):

"Biodiversity offsets are conservation activities that are designed to give biodiversity benefits to compensate for losses - ensuring that when a development damages nature (and this damage cannot be avoided) new, bigger or better nature sites will be created."

EU

The EU Biodiversity Strategy to 2020 seeks to "ensure No Net Loss of biodiversity and ecosystem services". The European Parliament adopted a resolution in 2012, urging the Commission to "develop an effective regulatory framework based on No Net Loss, also utilizing the standards applied by the Business and Biodiversity Offsets Program". The resolution also referred to the importance of applying such an approach to all EU habitats and species not covered by EU legislation.

Action 7 under target 2 of the EU Biodiversity Strategy to 2020 is composed of two complementary sub-actions. Action 7 a foresees that the Commission will develop a methodology for assessing the impacts of EU funded projects, plans and programs on biodiversity by 2014 . Action $7 \mathrm{~b}$ specifies that the Commission will carry out further work with a view to proposing by 2015 an initiative to ensure there is No Net Loss of ecosystems and their services (e.g. through compensation or offsetting schemes).

The Commission will develop an impact assessment on the policy options for the No Net Loss initiative. As foreseen in the EU Biodiversity Strategy to 2020, the No Net Loss initiative is still expected in 2015 but may be delayed.

\section{Mitigation hierarchy}

Compensation should be seen as one of several tools in the tool box to enhance conditions for biodiversity and one that should only be used under certain conditions. The Business and Biodiversity Offsets Program (BBOP) among others, advocates for strict adherence to the mitigation hierarchy (BBOP 2012). This hierarchy views the role of compensation as a "last resort", after all reasonable measures have been taken to avoid, minimize, and mitigate the impacts of a development project and then to restore biodiversity on-site. The unavoidable residual impacts are those that should be compensated. Compensation should not act as a tool that justifies projects that have been inadequately planned in terms of avoidance, minimization, mitigation or on-site restoration of project impacts. 
In fact, in many cases the avoidance and minimization of impacts is less costly than trying to repair damages afterwards.

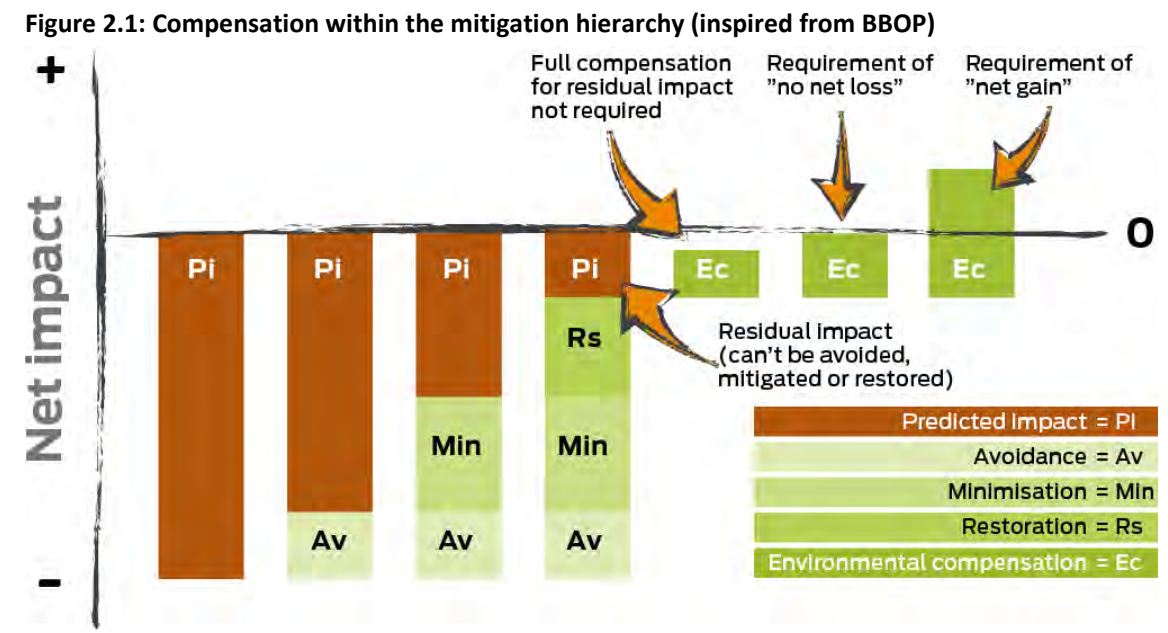

The approach of the mitigation hierarchy enables a development project to work towards No Net Loss of biodiversity, and ideally, a net gain. The application of the mitigation hierarchy, and how far each step should be pursued before turning to the next, is one of the key issues for consideration in the design of environmental compensation.

\section{Box 2.2. BBOP Mitigation hierarchy}

\section{BBOP Mitigation hierarchy}

The mitigation hierarchy, based on BBOP's definition, can be described as:

\section{Avoidance}

Measures taken to avoid creating impacts from the outset, such as careful spatial or temporal placement of elements of infrastructure, in order to completely avoid impacts on certain components of biodiversity.

\section{Minimization}

Measures taken to reduce the duration, intensity and/or extent of impacts (including direct, indirect and cumulative impacts, as appropriate) that cannot be completely avoided, as far as is practically feasible.

Rehabilitation/restoration

Measures taken to rehabilitate degraded ecosystems or restore cleared ecosystems following exposure to impacts that cannot be completely avoided and/or minimized. 


\section{Compensate}

Measures taken to compensate for any residual significant, adverse impacts that cannot be avoided, minimized and / or rehabilitated or restored, in order to achieve No Net Loss or a net gain of biodiversity. Offsets can take the form of positive management interventions such as restoration of degraded habitat, arrested degradation or averted risk, protecting areas where there is imminent or projected loss of biodiversity.

Note: It can admittedly be challenging to distinguish between measures aimed at minimization and those aimed at compensation.

\subsection{Method for compensation scaling}

The BBOP standard, and available guidance in a number of countries, recommends an explicit analysis and comparison of biodiversity losses associated with residual impacts, on the one hand, and biodiversity gains, associated with compensation measures, on the other. The terms and concepts used for Equivalency Analysis are helpful in developing such an analytical framework. This method has been applied in various ex ante and ex post compensation scenarios and is explicitly highlighted in the ELD, which provides the most thorough guidance for compensation scaling in the EU. The REMEDE Toolkit (Lipton et al. 2008), was developed to help EU Member States comply with environmental compensation requirements and describes how to scale compensation under several EU Directives ${ }^{12}$ using the Equivalency Analysis method.

In the Toolkit, scaling of environmental compensation involves three steps (Lipton et al. 2008; Cole 2012; Cole and Dahl 2013a):

1. Measure the debit (loss). Assess the environmental injury and the subsequent economic damages over time.

2. Identify credits (gains). Identify feasible compensation projects designed to improve the injured resource over time.

3. Scale compensation. Determine "how much is enough" compensation to ensure equivalence over time between debit and credit.

12 See e.g., the Environmental Liability Directive, the Habitats and Birds Directives, the Environmental Impact Assessment and Strategic Environment Assessment Directives. 
The scaling process is illustrated in Figure 2.2, which requires an interdisciplinary assessment of value - across time, space, and other relevant dimensions. A properly scaled compensation project ensures that the value of the debit (shaded area) is equivalent to the value of the credit over time (shaded area). This requires an estimate of the value of nonmarket resources such as biodiversity and some ES, which in turn may require non-market valuation techniques. These techniques may rely on monetary or non-monetary currencies, ${ }^{13}$ but the actual compensation payment must be in resource terms. A key assumption underlying compensation scaling is that the public is willing to substitute the value gained from a restored, enhanced, or protected resource for the temporal loss in value of the injured resource.

The Y-axis shows the value of the resource or the services it provides, while the $\mathrm{X}$-axis illustrates the passage of time. The debit captures the welfare loss from the environmental injury ("economic damages") while the credit captures the welfare gain from a compensation project.

In the REMEDE framework, the welfare loss (debit) is frequently referred to as the "interim loss" because it represents an interim period of time during which the resource fails to provide the baseline level of value. For example, a wetland may fail to provide a certain level of biodiversity or ecosystem services following an oil spill, but this value may eventually return due to natural recovery or active rehabilitation. Importantly, even if this resource fully recovers at some point in the future ("recovery date" in Figure 2.2), a welfare loss has nonetheless occurred during this interim period of time.

Note that in some cases environmental injuries may lead to interim losses that are essentially permanent, i.e., recovery does not occur in the foreseeable future. For example, land development projects (roads, shopping centers, energy infrastructure) may cause a biodiversity and/or ecosystem service debit that lasts forever. In this case, the term "interim" may be less appropriate because this value is lost every year "in perpetuity". But even if this value never returns to its baseline level, we can nonetheless estimate a finite value ${ }^{14}$ for this debit and therefore use it to scale the size of an appropriate credit.

\footnotetext{
13 The environmental economics literature on the techniques and methods for non-market valuation is extensive and a summary is beyond the scope of this analysis. For a review see Freeman et al. 2014 14 Even infinite losses can be quantified in finite terms if we rely on a discount rate, as in the REMEDE Model. For example, in the case of a monetary metric, we know that a perpetual annuity for retirement can be valued in finite terms (otherwise a price could not be established for this type of financial instrument, which provides a constant financial payment every year "forever"). The same logic applies in the case of a nonmonetary metric that captures the value of an annual loss that lasts "forever". See Cole 2013 for more technical details.
} 
Figure 2.2: Equivalency Analysis scales a compensatory credit such that its value is equivalent to the debit

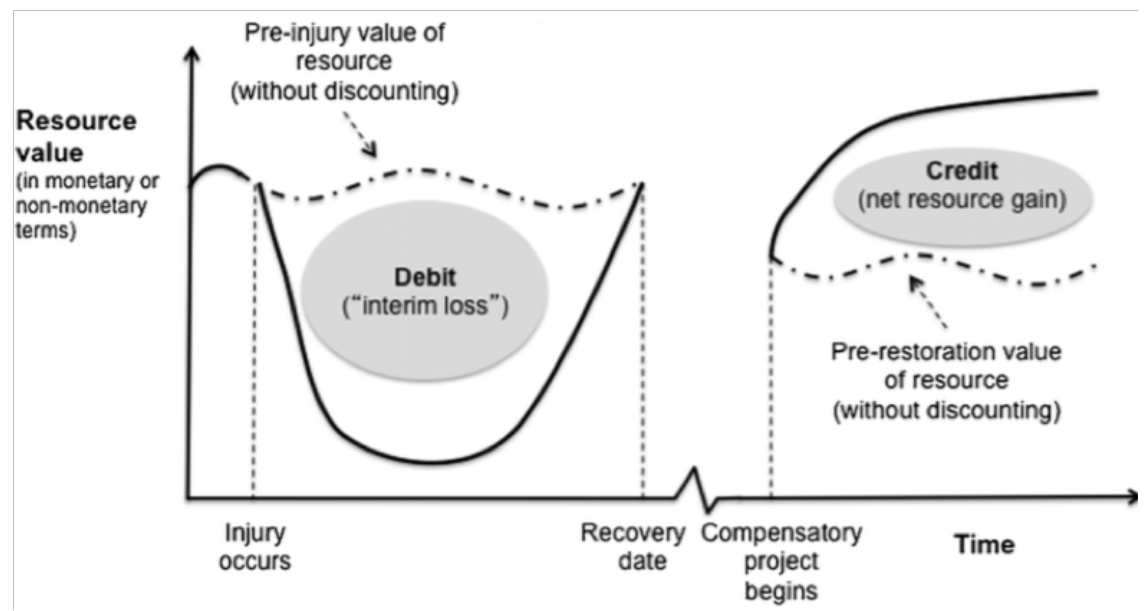

The currency for measuring value may be monetary or non-monetary (Y-axis). Even if the resource recovers to the pre-injury value, an "interim loss" of welfare accrues to the public over time (X-axis). In some cases (e.g., land development) this loss is permanent rather than "interim", but in the loss can nonetheless be quantified in finite terms and compensated through a credit.

Source: Cole and Lie Dahl 2013.

\subsubsection{Measure the debit (loss)}

The first step in measuring the debit is to assess the biophysical change that arises over time from the damaging activity. This may be measured in terms of hectares of habitat, number of individuals of a species, amount of a habitat structure (e.g. dead wood debris), diversity or distribution of species, quantity or quality of water, etc.

Second, this biophysical change in terms of quality and/or quantity must be interpreted to determine the impact on human welfare. In some cases, this metric is in monetary terms (e.g., the lost recreational value in EUROS from a pollution event) but in other cases, the biophysical change is used directly as the metric. For example, a Habitat Equivalency Analysis (HEA) assumes that acres lost (non-monetary metric) represents a proxy for proportional and linear changes in society's overall welfare (Zafonte and Hampton 2007, Cole 2012). This approach, which has also been developed in an ex-ante context under the name "Habitat Hectares" in Victoria, Australia (Parkes et al. 2003; McCarthy et al. 2004 and in Sweden (see Box 4.3 Mertainen mine) captures an affected area of a certain constant environmental quality. Other approaches (1) capture the quantity and quality of an affected space through a percent service loss 
of habitat hectares or (2) capture the quantity and time loss of a specific species such as the number of bird-days lost (see Box 4.1 Railway Bothnia Line, Ume River delta, and Cole and Dahl 2013a).

The (monetary or non-monetary) metric captures the welfare loss that accrues during the "interim time" that the resource (or the ecosystem services it provides) is below the baseline (which may be permanent in the case of land development, see above). Note that Figure 2.2 is drawn under the assumption that the resource returns completely to the baseline level at the "recovery date" but the Equivalency Analysis method can also handle cases where recovery is incomplete, delayed or linked to a permitted injury, e.g., permission to build an infrastructure project (see Lipton et al. 2008 or Moilanen et al. 2008).

\subsubsection{Identify possible credits (or gains)}

The same metric used to quantify the debit is also used to quantify the gains (credit) to the public from a compensation project, which must represent an additional and quantifiable improvement over the compensation site's current and future baseline condition. Without generating additional gains, losses to biodiversity or ecosystem services are not offset, leading to a "net loss" of social welfare (see Box 2.3 BBOP Best practice principles). In general, there are two mechanisms for achieving an additional gain: restoration (including rehabilitation, enhancement, re-creation) or conservation (protection provided by land acquisition or land use restrictions). In both cases, demonstrating additionality against a counterfactual ("what would have happened without the compensation action?") is essential, and may be particularly challenging to prove in the case of conservation of existing natural values.

In theory the present value of the credit must be equal to the present value of the debit. When using monetary metrics (which is common when capturing human use impacts like recreation), the value of the loss is often equated to the cost of providing equivalent resource or services, even if this may underestimate the actual value (Zafonte and Hampton 2007, see Environmental Liability Directive 2004, Annex II). For example, the value lost to sports fishermen from a damaged lake is sometimes compensated with a credit that is valued in terms of the costs of providing improved fishing access or fish production at a nearby site.

The compensatory credit may be provided by the "polluter" directly through an in-situ project or may be provided by a third party contracted by the polluter (e.g., habitat bank). 


\section{Box 2.3. BBOP Best practice principles}

\section{BBOP Best practice principles}

BBOP (2009) defines the goal of biodiversity offsets as to "achieve No Net Loss and preferably a net gain of biodiversity on the ground with respect to species composition, habitat structure, ecosystem function and people's use and cultural values associated with biodiversity." The design and implementation of biodiversity offsets should fulfill BBOP's ten principles (BBOP 2009, p. 7-8) which, most importantly, emphasizes the mitigation hierarchy as a fundamental part of the BBOP Standard on Biodiversity Offsets (BBOP 2012). The BBOP ten principles are relevant for the Nordic countries when establishing compensation frameworks, but nonetheless a certain amount of flexibility is needed, as we discuss in Chapter 5.

\section{Adherence to the mitigation hierarchy}

A biodiversity offset is a commitment to compensate for significant residual adverse impacts on biodiversity identified after appropriate avoidance, minimization and on-site rehabilitation measures have been taken according to the mitigation hierarchy.

\section{Limits to what can be offset}

There are situations where residual impacts cannot be fully compensated for by a biodiversity offset because of the irreplaceability or vulnerability of the biodiversity affected (see chapter 3.4 risks).

\section{Landscape context}

A biodiversity offset should be designed and implemented in a landscape context to achieve the expected measurable conservation outcomes taking into account available information on the full range of biological, social and cultural values of biodiversity and supporting an ecosystem approach.

\section{No Net LosS}

A biodiversity offset should be designed and implemented to achieve in situ, measurable conservation outcomes that can reasonably be expected to result in No Net Loss and preferably a net gain of biodiversity (which ultimately benefits society's welfare).

\section{Additional conservation outcomes}

A biodiversity offset should achieve conservation outcomes above and beyond results that would have occurred if the offset had not taken place. Offset design and implementation should avoid displacing activities harmful to biodiversity to other locations. 


\section{Stakeholder participation}

In areas affected by the project and by the biodiversity offset, the effective participation of stakeholders should be ensured in decision-making about biodiversity offsets, including their evaluation, selection, design, implementation and monitoring.

\section{Equity}

A biodiversity offset should be designed and implemented in an equitable manner, which means the sharing among stakeholders of the rights and responsibilities, risks and rewards associated with a project and offset in a fair and balanced way, respecting legal and customary arrangements. Special consideration should be given to respecting both internationally and nationally recognized rights of indigenous peoples and local communities.

\section{Long-term outcomes}

The design and implementation of a biodiversity offset should be based on an adaptive management approach, incorporating monitoring and evaluation, with the objective of securing outcomes that last at least as long as the project's impacts and preferably in perpetuity.

\section{Transparency}

The design and implementation of a biodiversity offset, and communication of its results to the public, should be undertaken in a transparent and timely manner.

\section{Science and traditional knowledge}

The design and implementation of a biodiversity offset should be a documented process informed by sound science, including an appropriate consideration of traditional knowledge.

\subsubsection{Scale compensation}

Scaling compensation assesses equivalence in value between debit and credit. As noted above, these biophysical changes can be valued using monetary or non-monetary approaches, with the latter becoming increasingly more popular. Importantly, when scaling compensation the metrics used on the credit side should be the same as the one used on the debit side. Scaling should account for uncertainty in providing credits, as explained in the BBOP Principle Point 4, which states that measures should "reasonably be expected to result in No Net Loss."

Time is relevant in many aspects. The time at which a loss or gain occurs is an important variable that affects equivalence. For example, some compensation benefits are not realized until far in the future (e.g., 
restoration projects may take years before delivering benefits), some legal requirements insist that compensation benefits are in place before damaging development project are undertaken, or in other cases, past damages may need to be valued in today's prices. One way of accounting for discrepancies in time (for both monetary and non-monetary metrics) is to rely on a discount rate (Cole and Kriström 2008).

Time affects value because it is assumed that society generally prefers to benefit from an (ecosystem) service now, rather than in the future, all things equal. For example, the loss of biodiversity or the loss of recreational opportunities today has a greater negative impact on an individual's welfare than a similar loss that occurs in the future. The reverse is true for a gain, which is valued higher if it occurs today than if it occurs in the future.

Thus, a compensation assessment of credits and debits that are delivered at different times must account for how time affects how an individual (or society) values a resource or service. A discount rate, which reduces the value of future impacts (debits/credits) relative to the present, provides a solution by ensuring that losses and gains far in the future are valued lower in today's (present) value. The practical implication is that discounting debits and credits encourages polluters to provide credits today, rather than in the future. The reason is that a discount rate penalizes polluters for a delay in providing compensation - i.e., all else equal, a developer will have to provide more environmental compensation if the benefits occur far in the future relative to compensation alternatives that provide benefits sooner.

The correct level of discount rate to use in a scaling analysis is ultimately a subjective decision, but to ensure consistent project appraisal many countries have developed guidance that recommend the use of specific discount rates (See e.g., 6\% in Norway in NFD (2005); see e.g., $4 \%$ in Sweden in SIKA (2009) and SEPA (2003); see e.g., 3\% and 7\% in US in NOAA (1999)). For example, a relatively higher discount applies a higher penalty for delay. Where decisions on compensation are sensitive to the choice of discount rate, results of analysis using multiple discount rates should be presented to reflect this.

The issue of time also arises in a non-scaling context when considering the horizon for long-term management of a compensation credit (see e.g., chapter 4.3.1 with experiences on long term management in the compensation scheme for the railway Bothnia Line, Ume River delta). 


\subsection{Nordic environmental compensation example}

To illustrate environmental compensation connected to development in the everyday Nordic landscapes together with early steps of the mitigation hierarchy, we outline a Nordic case. Other Nordic compensation projects are presented briefly in textboxes in chapter 4.2 .

Nordic Iron Ore, a mining and exploration company, plans to re-open and develop a medium sized iron ore production at two sites near the small town of Ludvika, county of Dalarna, central Sweden. Although the exploration sites are situated outside protected conservation areas, mining will have a negative impact on the surrounding natural areas and lead to the loss of valuable habitats both directly and indirectly, including 3 ha deciduous and coniferous forest on limestone, 14 ha deciduous forest, 4 ha of stream habitat and 21 ha of lake Norsen, formerly a reservoir for early mining activity.

Figure 2.3: Deciduous forests are focus habitats in measuring the debit, identifying possible credits and scaling compensation in the Swedish Nordic Iron Ore Ludvika mining project

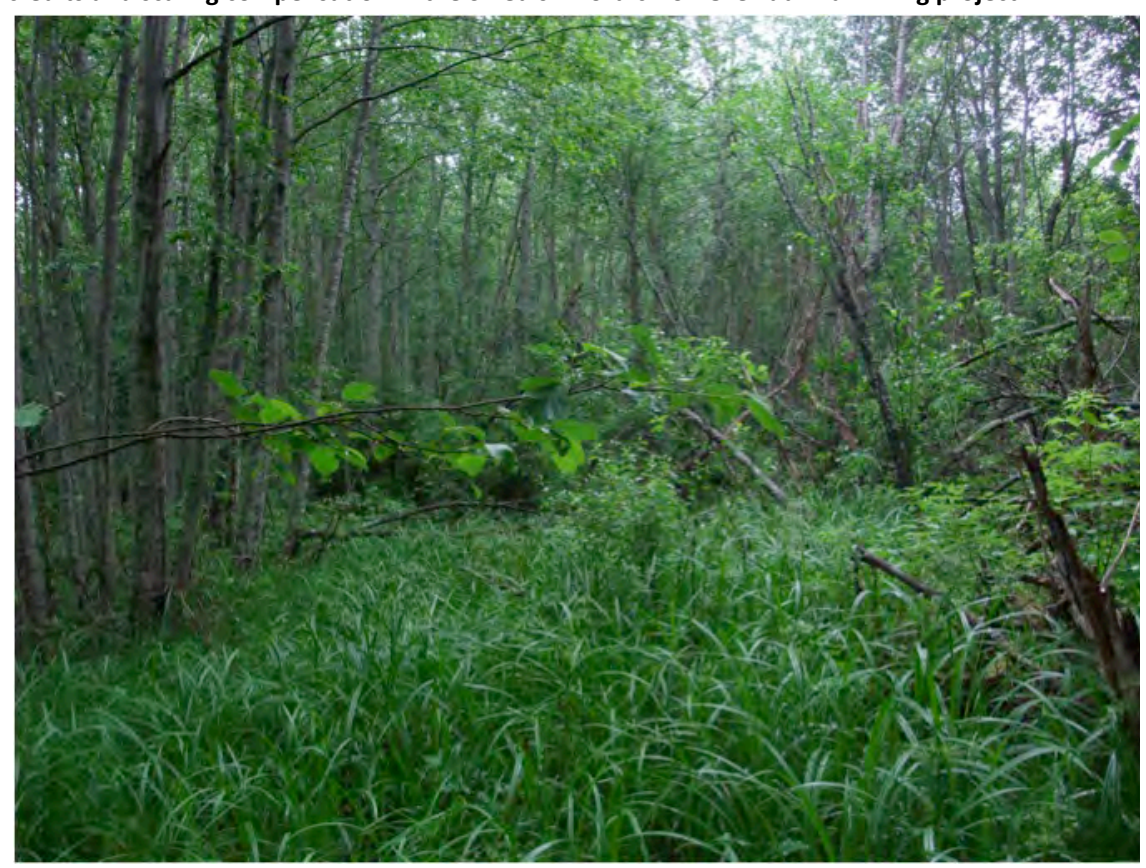

Source: Anders Granér. 
The County Administrative Board of Dalarna and Ludvika municipality requested that Nordic Iron Ore minimize the environmental impact as much as possible and compensate for the remaining loss. As the area has earlier been used for mining it was important to localize as much as possible of the development on earlier mining sites, according to the first steps of the mitigation hierarchy; avoidance and minimization. The mine will be underground, which minimizes visual impact. Finally restoration will take place after the closure of the mine.

The request to compensate was based on the Swedish Environmental Code (chapter 16, article 9). In March 2014, the Environmental Supreme Court decided the terms and conditions for the mining permit which required compensation and in December 2014, Nordic Iron Ore submitted a compensation plan (Nordic Iron Ore 2015) to the County Administrative Board of Dalarna.

A compensation plan, which describes the compensation areas and proposed conservation measures, was produced by an independent ecology consultancy (Enetjärn Natur) and is based on data from field surveys, species observations, GIS-analyses and expert knowledge. The compensation plan was discussed and revised after a series of meetings with representatives of Nordic Iron Ore, the County Administrative Board, Ludvika municipality and landowners.

The development of the compensation plan followed these steps:

1. Adherence to the mitigation hierarchy.

2. Hearings with authorities.

3. Selection of metrics to quantify losses and gains.

4. Adequate estimation of impact.

5. Benchmarking with reference habitats in surrounding landscape.

6. Field surveys to identify compensation possibilities.

7. Data analysis and calculations to decide on proposed compensation.

Challenging aspects of the plan included the selection of adequate parameters for quantifying the value of nature, balancing the losses and gains of natural values, and agreeing on land access, liability and financial compensation between landowners and Nordic Iron Ore. Compensation was scaled using biodiversity metrics at the different sites. In deciduous forest habitats eight different metrics were used, including amount of dead wood, amount of deciduous trees, number of breeding birds, etc. 


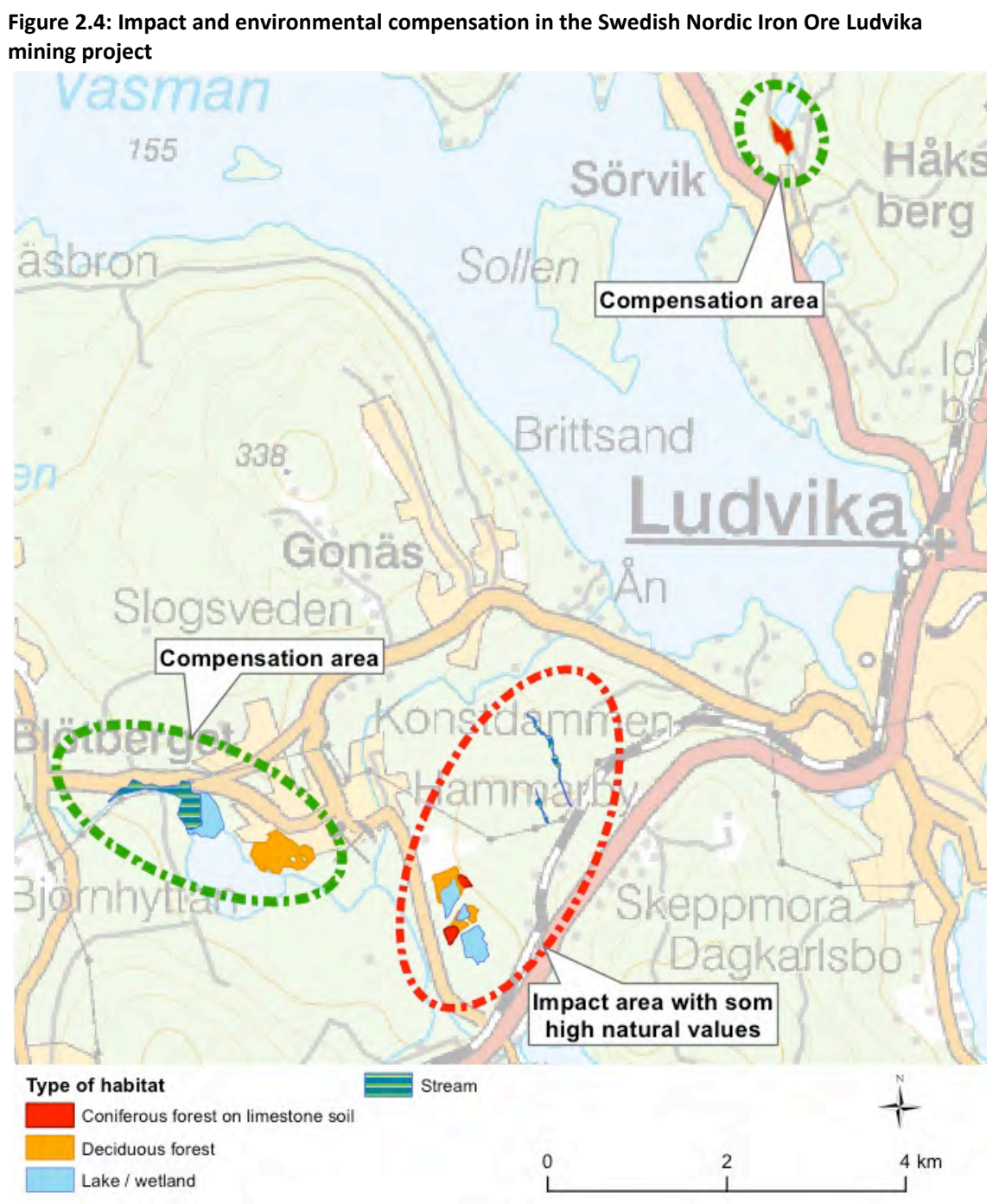

Data for each metric was collected during field surveys in both impact area, reference habitats and possible compensation areas. Reference habitats are areas with high conservation values in the surrounding landscape. Calculations defined a quality value that could be used for scaling compensation relative to impact. The compensation plan points out four areas in the vicinity of the proposed mining sites, i.e. the measures consist of on-site compensation. 
The total compensation area measures 51 ha:

- Biodiversity management of 5 ha deciduous and coniferous forest on limestone.

- Biodiversity management of 20 ha deciduous forest.

- Restoration of 10 ha of open water lake habitat.

- Conservation of 16 ha riparian forest and stream habitat.

The estimated compensation costs are EUR 110,000 to 270,000 for acquisition of land and approximately EUR 110,000 to 160,000 for carrying out conservation measures and monitoring compensation sites for 20 years (the life of the mine). Further, a servitude contract between the landowner and Nordic Iron Ore guarantees protection of the compensation sites for 50 years.

Deciduous forest, coniferous forest on limestone and meandering streams are species-rich habitats that are generally under threat in Sweden. Compensation projects aimed at restoring these habitat types facilitate conservation work at sites that previously lacked protective status.

The compensation area is in total nearly 10 ha larger than the impact area for precautionary reasons to ensure No Net Loss of biodiversity in the area. A number of conservation measures are listed in the compensation plan that will lead to the development of existing natural values and improvement of habitat for birds, bats and conservation of rare species. Forestry measures are proposed to create a diverse forest structure, including the improvement of growth conditions for deciduous trees, increasing the amount of deadwood, creating small forest openings and a varied forest edge, and creating small water-filled hollows that attract a wide range of species. The compensation area includes not only stream habitat itself but also part of the adjacent deciduous forest. At the lake incorporated in the compensation plan, reed will be removed (reed is a trivial habitat, widespread on Swedish lakes) to make the area more attractive to birds, transforming it from a wetland to more open waters.

Conservation work in the compensation areas is planned before mining operations start and the conservation outcome will be preliminarily monitored for at least 10 years. Monitoring will be based on a range of indicator variables that are commonly used for assessing biodiversity values of natural habitats such as species abundance and richness, and measures that capture structural diversity in forest stands. 


\section{Benefits, costs, and risks of compensation}

This chapter discusses some of the benefits, costs and risks of compensation and addresses the following questions:

-What are the key benefits to society of requiring compensation?

- What are the key categories of costs associated with compensation and which costs can be affected in a compensation framework?

- What is the potential range and magnitude of these costs based on past experience?

- What are the potential risks associated with compensation and what strategies exist to address these?

\subsection{Benefits}

The primary benefit of requiring compensation is to address a market failure (a negative externality) by encouraging actors to internalize the cost of environmental damage in the decision-making process. In addition, a number of indirect benefits demonstrate how compensation may also provide value to different actors, each of whom may perceive benefits differently.

\subsubsection{Primary benefit: internalizing external costs}

The primary benefit of compensation is to reduce the social welfare loss associated with a continued decline in the benefits nature provides us: biodiversity and ecosystem services. Compensation helps to reduce this decline by implicitly "pricing" these benefits and creating an incentive for actors to incorporate these values into their daily decision-making. The failure to price nature's benefits leads them to appear "value-less" under the current business as usual scenario. 
From an economic perspective, a compensation requirement is motivated by the need to address a market failure referred to as an externality. ${ }^{15}$ A negative externality arises when the production or consumption of a good or (ecosystem) service imposes a cost on a third party not directly involved in the market. In our case, a negative externality arises because private and/or public actors fail to account for the cost of environmental damage on society in their own private decision-making process (e.g., the decision to build a road or other project). If developers ("polluters") faced incentives to consider these external environmental costs on society - i.e., were required to pay for offsetting compensation projects - then they would "internalize" these costs and make decisions that are better from a social perspective. This is the idea behind the Polluter Pays Principle (PPP), which suggests that from an equity perspective, the burden of preventing or removing pollution (or environmental damage) should be shifted from the government to those causing the pollution.

A strong regulatory driver for compensation makes the externalities associated with environmental damage more explicit, either in monetary or non-monetary terms. In much the same way that pollution-trading schemes assign costs to pollutants and thus make a clearer connection between emissions and human welfare, compensation requirements ensure that the decision-making process explicitly considers the value provided by un-developed "natural" landscapes, and thus makes a clearer connection between land use impacts and human welfare. The cost of providing compensation provides an incentive to use less land for development or to re-direct development to lands with relatively lower biodiversity and/or ecosystem service values.

Requiring developers to address their own impacts also saves taxpayers money, which is consistent with the fairness objective of the PPP. Finally, a compensation requirement based on the PPP has the potential to be a cost-effective instrument for reaching NNL, as discussed in chapter 5.3 .

${ }^{15}$ Another common market failure, which is also relevant in our case, is the fact that biodiversity and ecosystem services are considered public goods. These types of goods suffer from poorly defined ownership rights and non-rivalry (i.e., consumption by one individual does not reduce the amount available for others to consume). The market failure associated with public goods leads them to be over-consumed and under-produced. 


\subsubsection{Indirect benefits}

In addition to the primary benefit of improving social welfare, properly scaled compensation may also lead to indirect benefits to other actors including governments, companies, communities and NGOs (see e.g. ten Kate et al., 2004).

\section{Potential for additional ecological and human use benefits}

By striving for internalization of environmental damage costs, compensation requirements are likely to secure more environmental values relative to today's business as usual baseline. However, to the extent that a net gain can be achieved through scaling, compensation may also lead to a net contribution to both ecological and human use values.

A net gain in ecological values like biodiversity may be further augmented from the complementary effect that compensation can have on conservation planning. For example, compensation may stimulate and improve the implementation of national or regional conservation plans and help to secure more continuous habitats. These larger (and linked) conservation areas may also lower monitoring and auditing costs and improve connectivity. 16

A net gain in human use values may be particularly important in densely-populated urban areas where green space is lost and everyday landscapes are degraded from development (EEA 2006, Naturskyddsföreningen 2007, Riksdagen 2010). To realize these human use benefits compensation projects must ensure improved access for users to sites that are restored or enhanced. Without access, the compensation credit will not generate additional values associated with e.g., recreation, health, well-being, etc. The fact that compensation can benefit human use in urban areas motivates compensation strategies in fastgrowing cities in Sweden (pers. comm. Jennie Wehrmann) and even addresses conflicts in environmental objectives (see below).

\section{Reduced need for environmental investments}

When environmental damage costs are internalized and compensation is applied consistently in the long-term it reduces the need for public and private environmental investments, i.e., important and costly projects that provide "substitute" ecosystem services such as dam construction (flood control), wastewater treatment plants (water quality), artificial pollination (crop production), etc. By reducing these opportunity costs,

${ }_{16}$ Proposed environmental compensation in the case study Aitik Mine (see Box 4.6) will improve connectivity between two already protected areas. 
compensation ensures that society's financial resources are available for more productive social investments by both private and public entities.

\section{Reduced conflicts in development planning}

Politicians (and other decision-makers) can benefit from an additional tool in their tool-box to ensure that society's interests are well balanced in carrying out development projects that require comprehensive consultation, studies and plans. For example, compensation helps to address the conflict between the need for additional housing in growing urban areas and the need for green spaces; alternatively the conflict between regional development (infrastructure, tourism, mining) and conservation values or reindeer herding. Projects that identify more viable alternatives that include compensation can reduce conflict levels and the time it takes to achieve regulatory approvals. The Bothnia Line Ume River Delta Project was initially characterized by widespread protests from stakeholders. But today stakeholders cooperate on the Board that oversees the compensation fund, which is responsible for the long-term conservation management of the area.

When compensation helps to address conflicts in development planning it leads to both nature conservation and economic development benefits.

\section{Improved awareness of environmental values}

Well-designed guidance for compensation measures may play an outreach and communication role for developers and stakeholders. Besides improving predictability of the decision-making process itself, guidance will also help highlight the lost value of biodiversity and ecosystem services and thus motivate local governments, planning boards, and other regulatory agencies to demand compensation as a means for reaching No Net Loss targets. Earlier consideration of environmental compensation options in the planning process can also create incentives for public authorities and developers to do more to reduce impacts in the preceding steps of the hierarchy (i.e., avoidance, minimization and on-site restoration), which helps to reduce the costs of compensation. This has been the case with the compensation system in Victoria, Australia (ten Kate, pers. comm.).

Further, this awareness of environmental values may provide more information to private companies to help them better understand the potential private benefits of improved environmental decision-making. This, in turn, may lead to strategic decisions by companies that also lead to social benefits, e.g., it may motivate private companies to undertake voluntary compensation that otherwise wouldn't have been 
undertaken (leading to a net benefit). This reduces the need (and cost) of future conservation funded by taxpayers. Further, it may encourage investors to consider environmental issues in their investment strategies (ten Kate et al. 2004).

\section{New business opportunities for landowners}

Offsets present business opportunities for landowners by providing opportunities for investing in the ecological restoration or conservation of their land e.g. through Habitat banks (see Boxes 5.1-5.3). By selling compensation to developers, landowners can benefit privately while also benefiting the public by increasing the supply of biodiversity and ecosystem services.

\section{International advantages for Nordic companies}

By developing a compensation framework in Nordic countries a key knowledge base will be built up that ultimately benefits Nordic companies, who can then export their know-how. See chapter 6 .

\subsection{Costs}

Costs are relevant when building a flexible and cost-effective compensation framework, but can also be relevant when comparing to the benefits of demanding compensation. Based on a review of the literature, case studies, and our own practical experience we summarize cost categories and, based on available data, provide an illustration of the potential range and magnitude of costs that have arisen under today's frameworks for environmental compensation. Improved frameworks are expected to reduce the range and magnitude of these costs.

\subsubsection{Costs overview}

In theory, the total cost of environmental damage should include not only the financial costs associated with assessing and repairing it, but also the social and environmental costs that arise during the time the environment is injured (see "interim loss" in chapter 2.2). However, this report only focuses on the financial costs of assessing and providing compensation, which are the most relevant costs in the sense that they can be affected in the design of a flexible and cost-effective compensation framework. 


\subsubsection{Cost categories}

To capture the costs that can be affected in the future design of a compensation framework, we identify four cost categories: transaction, scaling, investment, and long-term management costs. Although there may be some overlap in the sense that some costs could reasonably be assigned to more than one category, we believe that this categorization nonetheless provides structure to our cost assessment and thus helps to identify key costs that can be minimized in our proposed framework.

Importantly, most costs are incurred by the developer in the short term, but some are incurred by society in the long term. Money spent by developers represent an opportunity cost in the sense that these resources are not available for other potentially productive purposes like schools, hospitals etc. However, this is balanced by the fact that these costs create proper incentives for the developer (see "Benefits" above) and by the fact that the public now avoids the costs of unrepaired environmental damage via the Polluter Pays Principle. The public may also face some short-term costs (e.g., funding an agency to oversee the compensation system), and even some long-term monitoring costs, but a portion of these costs can be re-cooped through administration fees on developers. Further, long-term monitoring costs paid by taxpayers could be reduced through economic instruments that pay landowners to ensure delivery of biodiversity and ecosystem services.

These costs are illustrated in Figure 3.1 and summarized in Table 3.1. Further, these costs are spread across different time periods as shown in Figure 3.2.

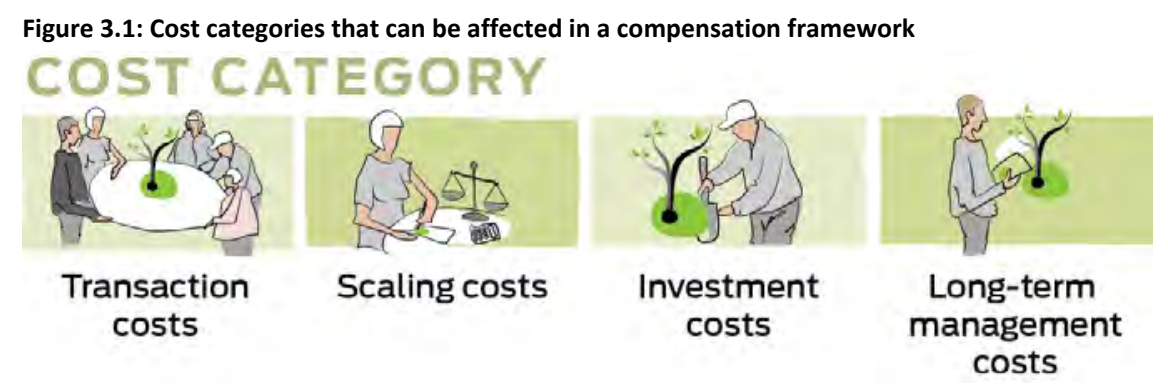




\section{Transaction costs}

Transaction costs represent the activities of the decision-making process itself, rather than any specific measuring or field work. The transaction costs include communication between stakeholders, negotiating compensatory proposals, obtaining necessary permits/permission, reviewing compensation and monitoring plans, review of appeals and final permit approval. Note that transaction costs always occur early in the process (see Figure 3.2). These costs are generally incurred by all stakeholders involved in the process, but are experienced most by the developers in terms of project delays, which can result in significant financial costs to both business and society.

In contrast to the other three cost categories below, which lead to biodiversity and ecosystem service benefits, transaction costs do not provide direct environmental value, but rather represent the time necessary to reach agreement among stakeholders. These costs are necessary to ensure coordination and efficient allocation of resources in the other cost categories and thus add value in that sense. However, transaction costs are more diffuse and difficult to standardize. In contrast, the other cost categories can be standardized by unit (e.g., per hectare, per tree planted, per mile of coastline restored), which can be helpful when comparing costs across alternative compensation projects or when assessing the proportion of total compensation costs represented by transaction costs. Finally, they are not easily scaled to the size of impacts and/or the compensation. 
Table 3.1: Summary of major cost categories associated with environmental compensation

\begin{tabular}{|c|c|}
\hline Cost category & Description \\
\hline \multicolumn{2}{|l|}{ Transaction costs } \\
\hline $\begin{array}{l}\text { Paperwork and administration of compensa- } \\
\text { tion system, necessary communication } \\
\text { needed to move the process forward }\end{array}$ & $\begin{array}{l}\text { Administrative review, permit application and ap- } \\
\text { proval process, judicial review (if needed), signing } \\
\text { contracts, project delay }\end{array}$ \\
\hline \multicolumn{2}{|l|}{ Scaling costs } \\
\hline \multirow{3}{*}{$\begin{array}{l}\text { Assessing damage and determining appro- } \\
\text { priate compensation }\end{array}$} & Assessing damage (data collection, report writing) \\
\hline & Identifying compensation projects (search costs) \\
\hline & $\begin{array}{l}\text { Scaling compensation (determining appropriate } \\
\text { scale and scope of compensation project) }\end{array}$ \\
\hline \multicolumn{2}{|l|}{ Investment costs } \\
\hline \multirow[t]{3}{*}{$\begin{array}{l}\text { “One-up" investment costs of carrying out } \\
\text { the compensation project }\end{array}$} & $\begin{array}{l}\text { Land acquisition }{ }^{a} \text { and investment (may include op- } \\
\text { portunity costs of using land for compensation) }\end{array}$ \\
\hline & $\begin{array}{l}\text { Financing for land acquisition, restoration, financial } \\
\text { guarantees and/or insurance }\end{array}$ \\
\hline & $\begin{array}{l}\text { Construction (machine and labor costs for active } \\
\text { restoration, rehabilitation, replacement of re- } \\
\text { sources) }\end{array}$ \\
\hline \multicolumn{2}{|l|}{ Long term management costs } \\
\hline \multirow[t]{4}{*}{$\begin{array}{l}\text { Ensuring proper operation and compliance } \\
\text { with project objectives }\end{array}$} & $\begin{array}{l}\text { Operation and maintenance (including administra- } \\
\text { tive and possible financial costs) }\end{array}$ \\
\hline & Monitoring \& follow up \\
\hline & Compliance checks (audit) \\
\hline & $\begin{array}{l}\text { Contingency costs (money put aside at start of pro- } \\
\text { ject to pay for unexpected repair or re-design costs) }\end{array}$ \\
\hline
\end{tabular}

\footnotetext{
${ }^{a}$ These costs that are not always needed in a typical compensation project. For example, some compensation projects do not require land purchase or, loans or, for those that do, property rights may be secured in other ways (e.g., easements or covenants).

Source: Lipton et al. (2008); Naturvårdsverket (2008); Naturvårdsverket (2010) - see Chap. 4.2 and Appendix 3; Conway et al. (2013).
}

\section{Scaling costs}

Scaling is the process of assessing the environmental injury (see Figure 2.2) and determining an appropriate scale of offsetting compensation. Scaling requires significant data collection, analysis, and report writing, all of which demands input from economic and ecological experts. Data collection costs are associated with determining pathways for injury (what is/will be damaged? how?), who is responsible, and what type of 
compensation is possible. Compensation planning costs include project identification, site selection, scaling, etc. and are usually summarized in a final compensation plan and report. These costs are generally incurred by the developer, but local agencies may be involved in the approval process. Scaling costs are often embedded within the cost of undertaking studies - notably environmental impact assessments - and designing environmental management plans for projects, i.e., there is rarely a stand-alone task of designing and scaling compensation. ${ }^{17}$

\section{Investment costs}

Compensation project costs represent the costs of carrying out the compensation project itself and generally include labor and capital costs associated with landscape restoration and/or the purchase and protection of land. These costs are incurred with the goal of improving the flow of biodiversity and ecosystem services and may be undertaken by the developer himself or by a third party (see e.g., habitat banking below). ${ }^{18}$ The price of land should, in theory, capture the opportunity cost of using land for compensation, instead of for some other type of productive use, and may also include other administrative costs like title and ownership, negotiation, and final purchase. These costs are incurred by the developer.

\section{Long-term management costs}

Management costs are associated with proper long term operation during the project lifetime as well as ensuring compliance with compensation project objectives. As such, these costs are spread over the full lifetime of the project. This includes regular operation and maintenance according to the project plan, as well as the monitoring, reporting and verification to ensure the plan delivers expected benefits. These costs include skilled labor (data collection) and site visits. It may also include establishment of a contingency fund that sets aside money up front to cover unforeseen costs that may arise at a future date, often ranging from 20 to $40 \%$ of total project costs (Jones 2011). Management costs are the responsibility of the developer, including the costs of audits or other compliance checks. ${ }^{19}$

\footnotetext{
17 This can be a problem when it slows the adoption of new or improved methods for addressing impacts, such as appropriately designed and scaled compensation.

${ }^{18}$ Although these are referred to as financial costs today, they may also represent possible investment costs if incurred by a habitat bank or other entrepreneur that plans to sell these services as a credit in the future to a buyer that is required to compensate (see Box 5.1 on Habitat Banking).

${ }^{19}$ In some cases (when it is legal to do so) it may be more efficient for developers to contract management costs to a 3rd party. One way of doing so is to provide an endowment fund that supports long-term management and is financed over time as revenues from the development project are realized. These funds should
} 
Figure 3.2 provides a summary of when key costs occur over time and demonstrates that monitoring costs are spread over the long-term, while the other cost categories are generally occurred early in the process. Management costs far into the future may be relatively lower in present value terms due to the impacts of discounting future financial flows, although this effect depends on the discount rate applied and the timeframe considered.

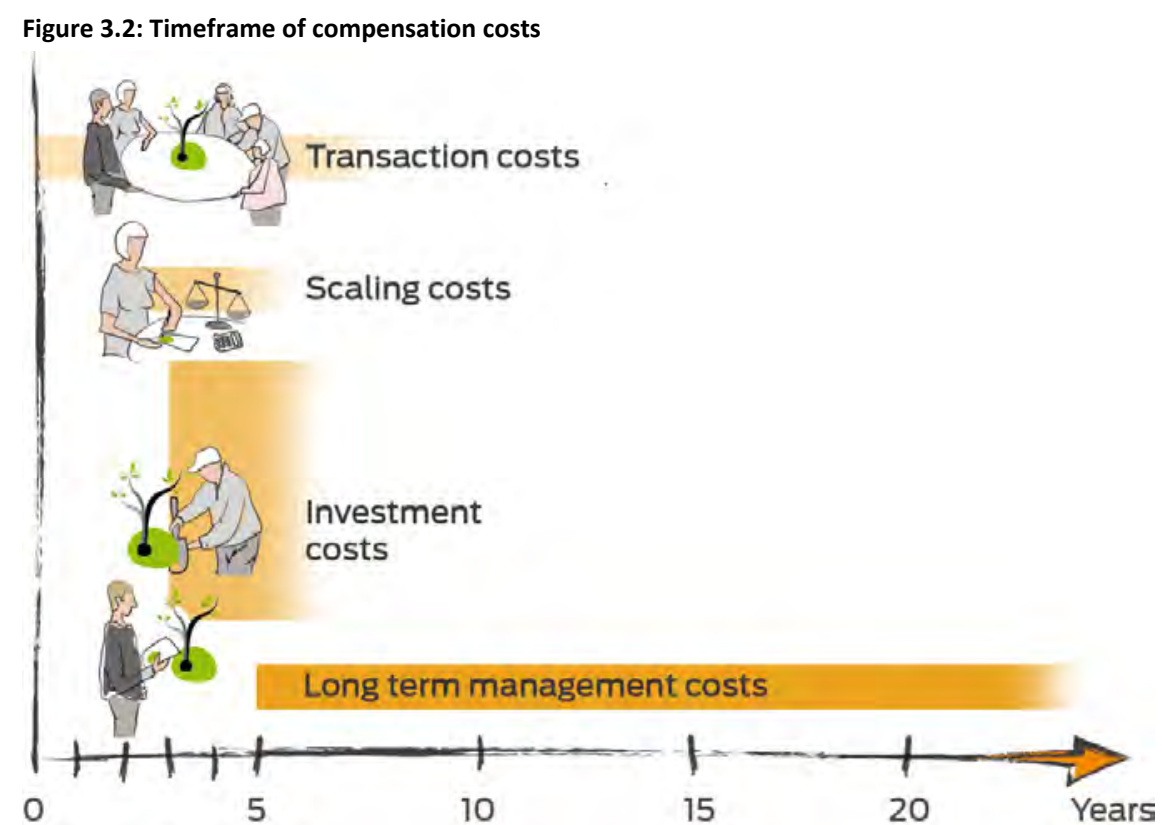

Our development of ex ante compensation costs categories can be compared to the costs that "responsible polluters" are liable for under an $e x$ post scheme. ${ }^{20}$ Experiences from ex post schemes are relevant in our case because they pre-date ex ante schemes ${ }^{21}$ and because they are based on explicit legal doctrine rather than evolving policy such as NNL. Ex post schemes in the EU and US require that responsible polluters pay for the following compensation-related costs (see Cole 2013):

be established in advance and should be a part of legal agreement for development. Developers that perceive risk could insure themselves.

${ }^{20}$ As noted in the introduction ex post schemes demand compensation for an injury that has already happened (e.g., an unexpected chemical release).

${ }^{21}$ Ex post compensation has been required since the early 1980s in the US (English et al. 2009) and has been required in the EU since 2007 under the Environmental Liability Directive. 
- Component \#1: Financial cost of immediate clean-up and response.

- Component \#2: Financial costs of restoration aimed at speeding resource recovery so that the resource returns to (or toward) the "pre-injury" baseline.

- Component \#3: Environmental and social costs that arise from the injury (see e.g., interim loss in Figure 2.2) which are often estimated using economic valuation methods that measure the monetary or non-monetary value associated with the environmental injury.

- Component \#4: Financial costs of assessing the damages, including data collection, expert assessment, compensation planning, longterm monitoring, etc.

Our assessment of compensation cost categories in Table 3.1 covers ex post components \#1, \#2, and \#4. As noted, we exclude costs captured in component \#3 ("environmental and social" costs) as these cannot be affected by the design of compensation in such a framework. However, these costs are still highly relevant when comparing the costs and benefits of compensation (see chapter 3.3).

\subsubsection{Illustrative examples of costs}

While a comprehensive and empirical assessment of per unit costs for compensating different types of environmental loss is beyond the scope of this study, we nonetheless provide illustrative cost examples from compensatory projects in Scandinavia and elsewhere (Table 3.2). These numbers give a rough illustration of the wide range and magnitude of compensation costs and are standardized across projects as best as possible on a per hectare basis. The intention was to collect data on the distribution of costs across the four categories identified above, but we could only obtain reliable estimates of total compensation project costs. This underscores the importance of further study into compensation costs and to ensure accurate collection of cost information as compensation is implemented in the Nordic countries in the coming years.

One exception to the lack of data was the Ume River Delta railway project, which separated costs into transaction, project, and management costs as shown in Figure 3.3. As shown, investment costs represent the largest share of total cost, but both transaction and management costs are significant. However, this illustration should not be interpreted to imply any general conclusions about compensation cost distribution, as such costs can vary significantly across compensation projects and, 
based on report data we have obtained, it is difficult to know exactly what is included in each cost category.

Figure 3.3: Distribution of costs for compensation project Botnia Line railway at Ume River Delta

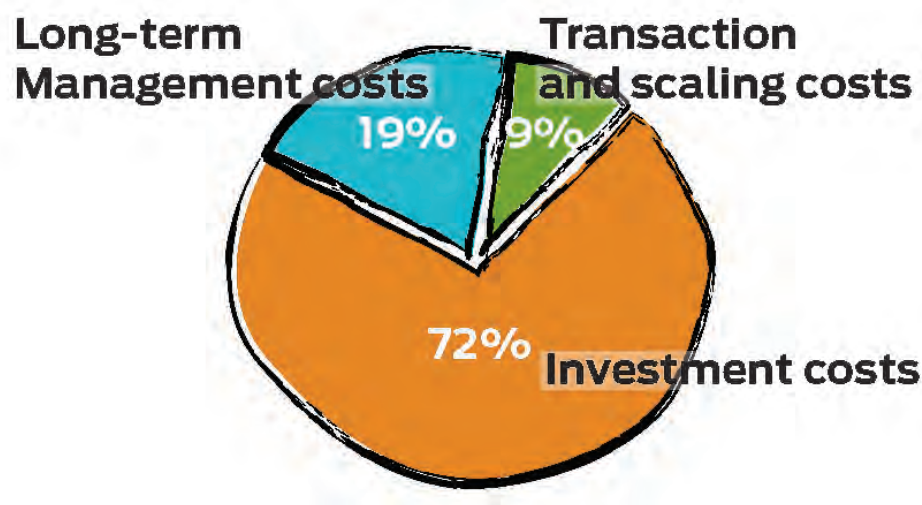

An analysis by Conway et al. 2013 suggests that:

“...The costs of purchasing or securing rights to land, the administrative and transaction costs of determining offset requirements and entering legal agreements, and the allocation of funding to long term management and monitoring all add significantly to the overall costs involved."

The challenges of quantifying per unit costs of compensation include the following:

- Variation. Costs for planning and implementing compensation at a particular site can vary considerably from case to case and from country to country and may be a function of many variables such as e.g., the nature and extent of the compensation requirements, transaction costs, legal requirements, scarcity of the damaged resource, availability of similar resources for restoration or land acquisition, labor rates, etc.

- Lack of data on distribution of costs across cost categories. There are many challenges in identifying which of the four cost categories identified above are most dominant because: (1) many projects do not keep good records of specific activities undertaken and the costs of each; (2) there is a disproportionate amount of data on investment costs (frequently called restoration costs), because these 
data are easier to track, but only represent a portion of overall compensation costs; (3) Transaction costs are inherently very difficult to measure and are likely underestimated in the literature. However, one would expect habitat banks to keep detailed records in order to better understand the transaction costs they face as a business - even if some are managed in a non-profit setting (see costs for Australia's BushTender program); and (4) even when costs data were available for a given compensation project, the project summaries rarely use consistent cost estimation methodologies, which made it difficult to compare the magnitude of costs across categories. For example, one project might consider an activity to be a transaction cost while another might consider the same activity to be a scaling cost, and detailed data were not available to adjust for this. As a result we were unable to identify which cost category tends to dominate.

Table3.2: Illustration of the range and magnitude of compensation costs

\begin{tabular}{|c|c|c|c|c|}
\hline Country & Project & Cost per hectare ${ }^{a}$ & Compensation type & Notes \\
\hline Sweden & $\begin{array}{l}\text { Railway Botnia } \\
\text { Line, Ume River } \\
\text { Delta, Umeå }\end{array}$ & EUR 28,200 & $\begin{array}{l}\text { Wetlands and } \\
\text { forests creation/ restoration }\end{array}$ & $\begin{array}{l}\text { EUR } 14 \text { mil. total, of which } \\
\text { EUR } 2.7 \text { mil. for long term } \\
\text { management }\end{array}$ \\
\hline Sweden & $\begin{array}{l}\text { New highway E45 } \\
\text { and railway along } \\
\text { Göta River, } \\
\text { Gothenburg }\end{array}$ & EUR 14,000 & $\begin{array}{l}\text { Wetlands and meadow habitats } \\
\text { restoration }\end{array}$ & $\begin{array}{l}\text { EUR } 4.2 \text { mil. total, of which } \\
\text { EUR } 2.6 \text { mil. for long term } \\
\text { management }\end{array}$ \\
\hline Sweden & $\begin{array}{l}\text { Railway Botnia } \\
\text { Line, Öfjärden }\end{array}$ & EUR 5,400 & $\begin{array}{l}\text { Wetlands and deciduous forests } \\
\text { restoration }\end{array}$ & \\
\hline Sweden & $\begin{array}{l}\text { New highway } \\
\text { E12, Umeå }\end{array}$ & EUR 35,400 & $\begin{array}{l}\text { Creation of small landscape for } \\
\text { habitats and species }\end{array}$ & \\
\hline Sweden & $\begin{array}{l}\text { (not-project } \\
\text { specific) }\end{array}$ & DKK $1.1-2.3 \mathrm{mil}$ & $\begin{array}{l}\text { Seagrass restoration in marine } \\
\text { Environment on Sweden's west } \\
\text { coast }\end{array}$ & $\begin{array}{l}\text { Includes labor, materials, site } \\
\text { selection, and long-term } \\
\text { monitoring, excludes transac- } \\
\text { tion costs (Estimated 2014) }\end{array}$ \\
\hline Finland & $\begin{array}{l}\text { Forest biodiversi- } \\
\text { ty conservation } \\
\text { programme } \\
\text { (METSO) }\end{array}$ & EUR $3,980-5,150$ & $\begin{array}{l}\text { Public land acquisition costs or } \\
\text { payments to private forest } \\
\text { owners for conserving their land } \\
\text { permanently (includes no resto- } \\
\text { ration or other measures) }\end{array}$ & $\begin{array}{l}\text { Costs range depending on } \\
\text { form of acquisition: from } \\
\text { purchase by state to perma- } \\
\text { nent easements on private } \\
\text { land }\end{array}$ \\
\hline Finland & $\begin{array}{l}\text { New highway, } \\
\text { E18, Hamina- } \\
\text { Vaalimaa }\end{array}$ & NA & $\begin{array}{l}\text { Ecosystem creation for different } \\
\text { species, e.g. flying squirrel. }\end{array}$ & \\
\hline Norway & $\begin{array}{l}\text { New highway E6, } \\
\text { Åkersvika, Hamar }\end{array}$ & NA & $\begin{array}{l}\text { Inclusion and restoration of } \\
\text { areas neighboring a wetland } \\
\text { nature reserve are currently } \\
\text { being planned. }\end{array}$ & $\begin{array}{l}\text { Decision to undertake com- } \\
\text { pensation measures, but } \\
\text { specific activities still being } \\
\text { designed. No cost estimates } \\
\text { are available at present. }\end{array}$ \\
\hline
\end{tabular}




\begin{tabular}{|c|c|c|c|c|}
\hline Country & Project & Cost per hectare ${ }^{a}$ & Compensation type & Notes \\
\hline Germany & $\begin{array}{l}\text { Brandenburg } \\
\text { habitat banking }\end{array}$ & $\begin{array}{l}\text { EUR } 40,000- \\
150,000\end{array}$ & & $\begin{array}{l}\text { Experience from Branden- } \\
\text { burger Flächenagentur }\end{array}$ \\
\hline Australia & $\begin{array}{l}\text { (not-project } \\
\text { specific) }\end{array}$ & $\begin{array}{l}\text { EUR } 31,000- \\
134,000\end{array}$ & $\begin{array}{l}\text { Credits under BushBroker } \\
\text { Scheme (2006-2009) }\end{array}$ & \\
\hline France & $\begin{array}{l}\text { (not-project } \\
\text { specific) }\end{array}$ & $\begin{array}{l}\text { EUR 30,000-over } \\
100,000\end{array}$ & $\begin{array}{l}\text { Cost per hectare of offsets in } \\
\text { pilot habitat banks }\end{array}$ & $\begin{array}{l}\text { Most compensation in France } \\
\text { is done case-by-case, rather } \\
\text { than through banks. The cost } \\
\text { structure is different, espe- } \\
\text { cially land acquisition. As a } \\
\text { result, compensation is often } \\
\text { less costly than pilot habitat } \\
\text { banks suggest. }\end{array}$ \\
\hline $\begin{array}{l}\text { Nether- } \\
\text { lands }\end{array}$ & $\begin{array}{l}\text { (not-project } \\
\text { specific) }\end{array}$ & EUR 20,000 & Habitat restoration & $\begin{array}{l}\text { Land acquisition costs } \\
\text { can be high, up to } \\
\text { EUR } 200,000 / \text { ha }\end{array}$ \\
\hline UK & $\begin{array}{l}\text { (not-project } \\
\text { specific) }\end{array}$ & EUR 30,000 & Upland restoration & $\begin{array}{l}\text { Based on conservative esti- } \\
\text { mates and excludes profits to }\end{array}$ \\
\hline UK & $\begin{array}{l}\text { (not-project } \\
\text { specific) }\end{array}$ & EUR 60,000 & Wetland & $\begin{array}{l}\text { providers. Other suggest EUR } \\
37,000 \text { to } 100,000 / \text { ha. }\end{array}$ \\
\hline US & $\begin{array}{l}\text { (not-project } \\
\text { specific) }\end{array}$ & EUR 63,000 & Conservation Banking credits & $\begin{array}{l}\text { Per hectare values vary signif- } \\
\text { icantly, driven by land values, } \\
\text { credit scarcity and demand }\end{array}$ \\
\hline US & $\begin{array}{l}\text { (not-project } \\
\text { specific) }\end{array}$ & $\begin{array}{l}\text { EUR } 80,000- \\
300,000\end{array}$ & Wetland banking credits & $\begin{array}{l}\text { Considerable variation } \\
\text { EUR } 6,000 \text { to } 1.2 \text { mill. per } \\
\text { hectare }\end{array}$ \\
\hline
\end{tabular}

\footnotetext{
${ }^{a}$ The scope of what is included in compensation costs varies considerably across projects and countries and therefore these data should be seen as only a rough illustration.

Source: Conway et al. 2013; Moksnes 2015; pers. comm. Martin Szaramowicz, Compensation Agency Brandenburg, Germany, pers. comm. Leif Strinnholm, Trafikverket, Sweden.
}

However, another way of conceptualizing costs is to consider the total cost of implementing a compensation project as a percentage of the overall project development costs. In reviewing international compensation experiences we find that this may vary from less than 1 to $5 \%$ (Table 3.3). This is based on anecdotal evidence, literature reviews, informal discussions and feedback from our reference group. These estimates are, however, difficult to compare since cost measurement varies across countries and projects, with some including "compensation design" costs and others focusing exclusively on "land purchase and ecological engineering" costs. Further, the costs of project delays are often hard to capture in these estimates. 
Table 3.3: Cost of compensation related to total cost of development project

\begin{tabular}{|c|c|c|c|}
\hline Country & Project type & $\begin{array}{l}\text { Cost of compensation } \\
\text { (\% of development cost) }\end{array}$ & Source \\
\hline Germany & Traffic infrastructure projects & $2-5 \%$ & $\begin{array}{l}\text { Ministry of Environment } \\
\text { Brandenburg (2013): } \\
\text { Presentation on the applica- } \\
\text { tion of the Impact Regula- } \\
\text { tion in Brandenburg. (Un- } \\
\text { published) }\end{array}$ \\
\hline England & $\begin{array}{l}\text { Various Projects (anecdotal } \\
\text { evidence) }\end{array}$ & $1-3 \%$ & $\begin{array}{l}\text { Pers. comm. Ian Dickie, } \\
\text { eftec, November } 2014^{\text {a }}\end{array}$ \\
\hline UK & Various projects & $0.1-0.8 \%{ }^{\mathrm{b}}$ & Rayment et al. (2011) \\
\hline The Netherlands & $\begin{array}{l}\text { Road and railway } \\
\text { projects }\end{array}$ & $\leq 1 \%$ & Conway et al. (2013) \\
\hline $\begin{array}{l}\text { The Netherlands } \\
\text { and Spain }\end{array}$ & Ports and airports & Up to $4,5 \%$ & Conway et al. (2013) \\
\hline Sweden & $\begin{array}{l}\text { Harbor Expansion, } \\
\text { Gothenburg }\end{array}$ & $\sim 1 \%$ & $\begin{array}{l}\text { Pers. comm. Per } \\
\text { Moksnes, } 16 \text { Dec } 2014\end{array}$ \\
\hline Sweden & Railway Botniabanan & $\sim 3 \%$ & $\begin{array}{l}\text { Rough estimation from } \\
\text { Riksrevisionen 2011:22 }\end{array}$ \\
\hline Norway & $\begin{array}{l}\text { Various projects (literature } \\
\text { review of projects outside } \\
\text { Norway) }\end{array}$ & $<1 \%$ & $\begin{array}{l}\text { Rough estimation by } \\
\text { Hårklau et al. (2013) }\end{array}$ \\
\hline
\end{tabular}

${ }^{a}$ Based on knowledge of discussions with private project developers.

${ }^{b}$ Represents percent of the cost of all construction sector activity in the UK each year, rather than individual projects. Because construction frequently occurs on urban sites with relatively low biodiversity values (and few offset requirements), offsets in other areas are likely to be more expensive.

\subsection{Linking Benefits and Costs}

A comparison of the costs and benefits of compensation may be of interest to policy makers assessing the extent and scope of a compensation framework. For example, the total compensation costs incurred by society (i.e., the developer and ultimately the public) ${ }^{22}$ may be justified from a net welfare perspective if they are less than the total benefits (assuming that a clear threshold for what constitutes a residual impact has already

22 While the developer pays for these costs in the short term, they represent opportunity costs to society in the long term as resources used for compensation are not available for other productive purposes, public or private. 
been agreed upon). One way of making this assessment is to monetize these impacts and compare them in a Cost-Benefit Analysis. ${ }^{23}$

In theory, the total cost of environmental damage should include not only the financial costs associated with assessing and repairing it (described above), but also the social and environmental costs that arise during the time the environment is injured (see "interim loss" chapter 2.3 and "economic damages" chapter 1.1). These social and environmental costs represent the economic damages that come from the loss of habitat, species, recreational enjoyment, etc. These losses may be permanent (or temporary, if future restoration is $100 \%$ successful), represent significant value, and may be difficult to measure. Nonetheless, the EU reported that the annual cost to the EU of biodiversity loss is EUR 450 billion (or 3\% of GDP, see EC 2011). Braat and ten Brink (2008) have written an influential report that estimates the cost of not meeting the 2010 biodiversity target. They have argued that if terrestrial biodiversity loss continues to proceed at the current pace, the marginal loss in value of global ecosystem services may be as high as seven percent of estimated global GDP in 2050.

To accurately compare costs and benefits of compensation we would need, among other things, information on (1) the monetary value of all financial costs from chapter 3.1 ; $(2)$ the monetary value of total benefits from chapter 3.2; and (3) the monetary value of the social and environmental damages. Further, the costs of avoiding or minimizing damages are likely to indirectly affect the financial costs of compensation. ${ }^{24}$

Although a formal Cost-Benefit Analysis is beyond the scope of this analysis, two important messages nonetheless emerge for policy makers. First, the cost of compensation as a percentage of total project development costs suggest that for a relatively small cost society can make a significant investment in the provision of biodiversity and ecosystem services by requiring compensation. Further, the compensation investment represents a significant improvement over the "business as usual" approach where nature exploitation is essentially free (Quétier et al., in

\footnotetext{
${ }^{23}$ Although cost-benefit analysis (CBA) is frequently applied to assess the net benefits of development projects affecting the environment, it is generally not applied to the case of compensation to determine, for example, the appropriate extent or scale of compensation. This peculiarity has been noted in the literature (Cole 2013, Atkinson and Mourato 2008).

24 Developers and authorities face costs related to minimizing, avoiding or rehabilitating environmental damage within the mitigation hierarchy. For example, an assessment of compensation costs necessarily assumes that costly measures have been taken to avoid damage (e.g., cleaning up or removing hazardous substances, removing wounded or killed wildlife) or to minimize impacts (e.g., re-routing a road to minimize impact on wildlife). These costs are difficult to quantify and will vary from country to country and from site to site, depending on regulatory interpretation of "avoidance" vs "minimizing" vs "compensating".
} 
press). Second, even if the compensation investment does not fully offset the costs of environmental damage (i.e., it may only internalize a portion of the external costs imposed on society), it nonetheless represents a step in the right direction. In some cases it may be cheaper for society to require compensation than not, i.e., compensation will have positive welfare impacts if the value of environmental restoration benefits is higher than the cost of carrying out compensation and the opportunity costs of alternative land uses of compensation sites. This argues for (1) better understanding the impact of environmental injuries on ecosystems and the resulting impact on human welfare and (2) reducing the cost of carrying out compensation.

There are several important caveats:

- There may be significant variation in costs depending on the type of biodiversity damaged. But this facilitates the dynamic benefit discussed above by harnessing incentives: development can and should be encouraged on sites with low biodiversity value and moved away from high value sites.

- Costs and benefits are likely to vary together so that higher costs of compensation link to higher benefits, as both tend to vary with scale of projects.

- Compensation will lead to distributional impacts on society, as there will likely be "winners and losers." For example, some local communities may be affected by ecological and/or human use losses that are compensated offsite as part of a regional conservation plan. These stakeholders may view the benefits of this compensation different than those in the community where the compensation is provided. ${ }^{25}$ When planning for benefits, it is important to consider a fair and equitable sharing of benefits. When distance between impact and compensation area is relevant, e.g. in urban areas with focus on recreational values, this may argue for on-site compensation to ensure that people living closer to a development project receive priority in terms of benefits. Such impacts should be considered in the scaling process to ensure equitable compensation.

- Further, compensation may have distributional impacts on a larger societal level, but these (macro) impacts are intentional. That is, the primary motivation for requiring compensation is to re-align the current distributional impacts associated with environmental 
damage from one where the public "pays" (via welfare losses from un-repaired damage) to a more equitable outcome where "polluters" face these costs (in the short term) and thus have an incentive to avoid or minimize them.

\subsection{Addressing risks}

There are several potential risks associated with compensation that should not be underestimated:

The focus on environmental compensation may provide a distraction from tackling the underlying causes of biodiversity loss, e.g. the impacts of agriculture, forestry, fisheries and energy and transport infrastructure development (EEB 2014).

Environmental compensation might be seen by decision makers as an easy way to deal with land use conflicts and hence be expected to speed up approval processes.

Certain actors may abuse the intention of the policy, sometimes referred to as a "license to trash" (EEB 2014). Note that in some cases a developer may not be "abusing" the system intentionally, but simply reacting rationally to a system that is characterized by a market failure, where external costs are not easily considered in the private decisionmaking process.

Compensation project selection may focus too heavily on the potential costs of compensation such that the "cheapest" offset option is repeatedly chosen.

Some types of environmental injuries are difficult or impossible to offset, such as to rare or endangered habitats and species (Pilgrim et al. 2013).

The likelihood of restoration success is uncertain. Several studies show that far from all restoration projects succeed in restoring structure, composition, or function (Sunding 2011).

Restoration itself can be uncertain. Ecological systems are complex and may develop in several different trajectories when restored, not necessarily leading to the exact same type of ecosystem that was intended: "When planning for and evaluating restoration we generally simplify the complex systems and do not take into account this type of uncertainty" (Hilderbrand 2005). Ecological recovery takes time and the regeneration ability of habitats vary. Older habitats (e.g. ancient woodlands, grasslands, etc.) take centuries to replace, while secondary habitats (e.g. secondary woodlands, grasslands, heathlands, etc.) may only take a few 
decades to replace in a best case scenario. Many offset schemes employ habitat restoration in one area to re-create biodiversity value that is destroyed elsewhere, assuming that recovery is timely and predictable. Recent research has challenged these assumptions and has shown that restoration implies long time delays and a low certainty of success. For old-growth forests, Curran et al. (2013) conclude that active restoration significantly accelerates the process for all indices, but that the inherently large time lags, uncertainty, and risk of restoration failure require offset ratios that far exceed what is currently applied in practice (see Quétier et al. [in press] for a discussion).

Even in cases where compensation successfully restores damaged habitats it will inevitably lead to changing landscapes, some of which may be valued in their pre-restored (non-compensated) state. For example, compensating for the loss of habitat $A$ by restoring an offsite habitat $B$ has unavoidable opportunity costs. That is, repeated conversion (restoration) of Habitat B to a landscape that resembles A may result in a decline over time in the baseline habitat provided in $B$ (which could be a problem if $B$ has distinct value). This may affect the provision of biodiversity and/or our enjoyment of the recreational services provided by $B$.

But there are several strategies for addressing these risks, for example:

A compensation framework can establish clear guidelines about what is accepted and what is not. For example, guidance from Swedish EPA (unpublished) ${ }^{26}$ aims to prevent the potential "slippery slope" in the permitting process introduced by compensation by including the following considerations:

- That all reasonable measures are taken to prevent, avoid or minimize residual impacts before a decision is made about the need for compensatory offsets, and even consider the option of establishing "no go" areas.

- That compensation should not lead to: (a) the approval of an alternative project site with worse environmental outcomes (Chapter 2, section 6 of the Environmental Code); (b) reduced environmental protection in the level of avoidance or minimization measures (Chapter 2, section 3 of the Environmental Code ); or (3) relaxed requirements in the permitting process itself (Chapter 2 , section 9 of the Environmental Code).

${ }^{26}$ Jörgen Sundin, Naturvårdsverket. Pers. comm. 
- That permit conditions related to preventing, avoiding, and/or minimizing impacts are established prior to the assessment of compensation for possible residual impacts.

The second BBOP principles (see Box 2.3) identifies limits to what can be offset in order to address the fact that biodiversity offsets cannot fully compensate for some residual impacts due to irreplaceability or vulnerability of affected resources.

In habitats with low regeneration ability, biodiversity loss should be avoided and development should be restricted to areas that can more easily be restored (Van Teeffelen et al. 2014).

In cases where the biodiversity affected is extremely vulnerable or irreplaceable, it would be impossible to offset the impacts concerned. In such places "no go" areas should be considered (Conway et al. 2013). No Net Loss planning should be integrated within broader planning and policy frameworks. Where possible, guidelines to identify "no-go" zones and areas of high biodiversity value suitable for conservation efforts through offsets should be identified as a matter of policy and not relegated to case-by-case decisions (BBOP 2014). 


\section{Environmental compensation in the Nordic countries}

\subsection{Drivers for environmental compensation}

\subsubsection{EU and other international regulatory drivers}

The Convention on Biological Diversity 27 (CBD) recognizes that the conservation of biological diversity is "a common concern of humankind" and is an integral part of the development process. The CBD states that conservation and sustainable use of biodiversity shall be attained through plans, programs, policies and legislation. A continued gradual degradation of biodiversity caused by human land use is not in line with the CBD.

The EU has approved the CBD in the Cartagena Protocol on Biosafety ${ }^{28}$ and as well as the Nagoya Protocol. ${ }^{29}$ The European Commission has since 2011 adopted a strategy to halt the loss of biodiversity and ecosystem services in the EU by 2020.

There are numerous international agreements on the protection of biodiversity in addition to the CBD, including the Ramsar Convention, which has explicit guidelines on compensation.

Several EC Directives support requirements for environmental compensation including the Environmental Impact Assessment (EIA) Directive, ${ }^{30}$ the Birds Directive, ${ }^{31}$ the Habitats Directive, ${ }^{32}$ the Strategic Environmental Assessment (SEA) Directive ${ }^{33}$ and the Environmental Liability Directive (ELD). Below, the focus is on the Habitats Directive and the Birds Directive, since these regulations have thus far been the

\footnotetext{
27 http://www.cbd.int

${ }^{28}$ Cartagena Protocol on Biosafety to the Convention on Biological Diversity, UNEP 2000.

${ }^{29}$ Nagoya Protocol on Access to Genetic Resources and the Fair and Equitable Sharing of Benefits Arising From Their Utilization to the Convention on Biological Diversity, UNEP 2011.

${ }^{30}$ Directive 85/337/EG on the assessment of the effects of certain public and private projects on the environment (afterwards codified to 2011/92/EU).

31 Council Directive 2009/147/EC on the conservation of wild birds.

32 Council Directive 1992/43/EEC on the Conservation of natural habitats and of wild fauna and flora.

33 Council Directive 2001/42/EC on the assessment of the effects of certain plans and programmes on the environment.
} 
most important in driving requirements for environmental compensation. However, the EU has noted the lack of legal requirements for compensation of unavoidable residual impacts on species and habitats that are not covered by nature legislation, i.e., areas not covered by the EU Birds and Habitats Directives and ELD.

The ongoing EU work on the concept of No Net Loss is therefore a key step towards changing the mindset regarding biodiversity and ecosystem service losses in everyday landscapes. This relates directly to the 2020 strategy and the international commitments in the CBD.

\section{EU EIA Directive, Habitats Directive and Birds Directive}

The EIA-, the Habitats- and the Birds Directive allow for the use of environmental compensation, but do not contain explicit and clear requirements. Although all EU countries are subject to these Directives, the legal formulations provide room for varying interpretations by each country (Samferdseldep 2013).

The Habitats- and the Birds Directive form the foundation of the Natura 2000 network of protected areas. The European Commission published guidelines ${ }^{34}$ on how to manage Natura 2000 sites, which includes guidance on development of compensation measures.

The Habitats Directive is primarily applicable in areas included in the Natura 2000 network, but member countries can and have also implemented the Directive in different ways.

The Habitats- and the Birds Directives state that significant impacts to the network Natura 2000 are prohibited. Only in exceptional cases, and if certain conditions are met, a developer may deviate from the ban. In these cases the effects must be compensated in relation to the damages caused to the network. It is important to emphasize that this type of compensation will not automatically be equated with No Net Loss.

The Habitats Directive also requires derogation for any impacts on protected species, including outside Natura 2000 sites. This is an essential trigger of compensation in many EU countries (Quétier et al. (2014)). The Swedish "Artskyddsförordningen" (Species Protection Ordinance) is one example of how the Directive has been implemented in national legislation.

Through articles 12 and 16, the Habitats Directive conditions the possibility of impacting protected species of plants and animals (those listed in Annex IV of the Directive) to a set of requirements: (i) that the impacting project be justified by reasons of overriding public interest,

${ }^{34}$ Managing Natura 2000 Sites - The provisions of Article 6 of the "Habitats" Directive 92/43/EEC. 
(ii), that no alternatives exist to the specific project, and that allowing the impacts does not preclude the reaching or maintaining of a favorable conservation status of the impacted species (European Commission, 2007a). The European Commission (2007a) guidance states that "the net result of a derogation should be neutral or positive for a species".

From this, it follows that maintaining a favorable conservation status of the impacted species fits the definition of NNL for that species, and offsets are in fact suggested by the guidance as a way of achieving NNL.

\section{EU Environmental Liability Directive}

Environmental liability with regard to the prevention and remedying of environmental damage establishes a framework based on the "polluter pays principle" to prevent and remedy (restore) environmental damage following chemical spills or other unanticipated events. The Directive defines environmental damage as "damage to protected species and natural habitats, damage to water and damage to soil". This is an important driver for compensation as it identifies who is responsible when damage occurs, although its applicability outside protected areas, i.e. in everyday landscapes, is open to some interpretation. Ex post compensation, as stated in the Environmental Liability Directive, has been a driver for developing methodologies and standards and can be seen as a benchmark for ex ante compensation.

\section{Other possible regulatory drivers}

The UN, the EU and many sovereign nations have issued directives and policy documents that clarify the responsibilities to remedy environmental damage. One important example is Best Available Technology (BAT), which in the Industrial Emissions Directive ${ }^{35}$ is defined as:

"the most effective and advanced stage in the development of activities and their methods of operation which indicates the practical suitability of particular techniques for providing the basis for emission limit values and other permit conditions designed to prevent and, where that is not practicable, to reduce emissions and the impact on the environment as a whole".

35 Directive 2010/75/EU of the European Parliament and of the Council of 24 November 2010 on industrial emissions (integrated pollution prevention and control). 
There is not always a clear line between mitigation measures and compensation. Since the use of BAT in some circumstances could be interpreted as compensation, it could also be considered a compensation driver. However, BAT has mostly been applied to gradually develop methods for better technology and methods, and to raise the demands on avoidance or mitigation measures. In this report, BAT is considered primarily as a driver for avoidance in the mitigation hierarchy.

Another example is the Water Framework Directive (WFD), which aims to ensure the quality of Europe's water resources. Similar to this is the Marine Strategy Framework Directive which is very much inspired by the WFD. In practice, the impact on water resources cannot prevent the reaching of "good ecological status" in waterbodies, which is assessed through the environmental permission process. At the same time, it is important to prevent a deterioration of the water resources concerning ecological status (cumulative impact). The WFD can thus, indirectly, provide support to make every business or activity responsible for its own impact. Development in fresh water and marine habitats can therefore require compensation measures, either to prevent deterioration or to improve status.

\subsubsection{Regulatory Drivers in the Nordic Countries}

The environment with its natural resources has created a solid ground for the economic development and social structures of the Nordic countries, and the legislation reflects this background.

With a growing awareness that developing activities result in a complex impact on ecosystems, Nordic legislation has targeted different types of restrictions and environmental conservation actions. This legislation has affected the location of environmentally harmful activities, particularly in important nature areas.

The mitigation hierarchy has been integrated in the legislation and regulations, but as shown in the following review, the degree of implementation of environmental compensation in Nordic countries varies. 
Table 4.1: Examples of implementation of mitigation hierarchy and compensation in Swedish legislation; Environmental Code (Miljöbalken)

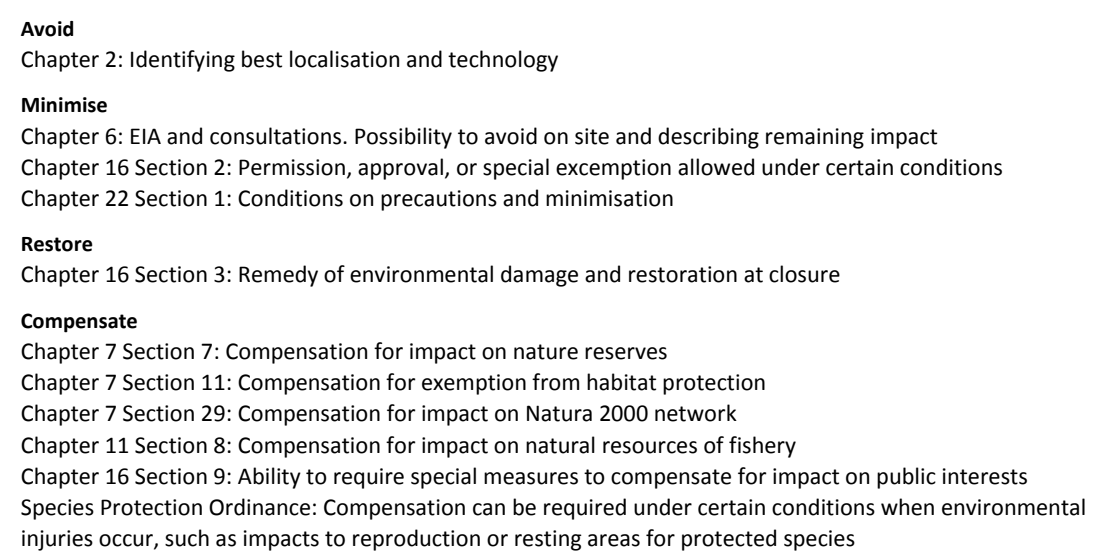

\section{Sweden}

As shown in Table 4.1 the basic logic behind the mitigation hierarchy is integrated in the Swedish Environmental Code, even if the concept itself is not directly quoted or cited in the law. For example, suitable locations must be found, the most relevant technology should be applied, and general environmental concerns should be considered before a permitting decision can be made. The purpose of the EIA process is to present information for the permitting authority to use as a basis in its decisionmaking. Legal practice says that EIA should present all measures according to each step of the mitigation hierarchy, which is the Swedish framework for avoiding the so-called "license to trash". The authority has the possibility to impose certain conditions that must be met before the project can continue and, in some cases, it can even require restoration at the end of the project life.

The overall situation concerning environmental compensation in Sweden is that this new tool is increasingly applied across various landscapes and activities (e.g., mines, roads). Environmental compensation is becoming a strategic policy focus for municipalities, and is receiving increased attention by the environmental courts. Still, the regulations are somewhat ambiguous.

It is important to emphasize that the starting points for compensation varies for the different statutory provisions (Table 4.1). It should be emphasized that compensation as applied today via these legal principles is not equivalent to No Net Loss. Compensation measures are required for impacts in protected areas, such as nature reserves, but also for other activities that are not compatible with Natura 2000 areas. In 
protected areas, the legal requirements are very clear and a specific guidance document has been developed (Naturvårdsverket 2003). However, a basic review by the Swedish EPA (Naturvårdsverket 2015), suggests that the possibility for requiring compensation for activities affecting nature reserves is seldom applied. The vast majority of activities that impact nature reserves do not require compensation, perhaps due to the fact that the impact itself is considered minor.

The Swedish "Species Protection Ordinance" plays a significant role in implementing the Habitats Directive in Sweden. Both the Directive and the EU's accompanying guidance provide a clear requirement for compensation. Although there is no explicit reference to Sweden's national implementation of the Habitats Directive in this Species Protection Ordinance, the Swedish EPA has nonetheless made it clear that compensation can be required under certain conditions, such as when negative impacts to reproduction or resting areas for protected species occur.

In the everyday landscape, habitats and species have a weaker protection. The Environmental Code enables a limited use of compensation in cases of project permitting. Regulation is found in the Environmental Code, Chapter 16, Article 9, and applies to a broad perspective of "common interests", i.e. species, habitats and recreational values. However, the regulation states that compensation can be requested, and is thus not necessarily required. Nonetheless, this regulation has been a driver in the last four years, having been applied to developments in the everyday landscape. The types of projects where authorities have demanded compensation have been smaller-scale projects with isolated impacts within a specific, small biotope protected area, which can be seen as part of the everyday landscape. In these cases, the developer has generally been required to conduct minor restorations, e.g., replacing cultural values lost from damaged historic stonewalls or birch alleyways. As infrastructure (roads, railways and power lines) and housing developments are not covered by the Environmental Code, the opportunity for compensation is lost. On the other hand, compensation can be required in certain cases when developments require permits for water infrastructure or will lead to impact on Natura 2000 areas or specially protected species.

Despite the lack of legal requirements for compensation related to housing development, the compensation question has become a strategic question for certain growth-oriented municipalities. Some municipalities are developing policies that developers can follow on a voluntary basis to compensate for lost environmental values resulting from urban development. 
Finally, in 2013, a government study on the values of ecosystem services in Sweden pointed to environmental compensation as a key policy tool that can and should be developed further, not least as it helps to raise awareness of the environmental values at stake (SOU 2013). Furthermore, a guidance document on the use of environmental compensation under the Swedish Environmental Code, is currently being developed by the Swedish EPA (see chapter 4.2.1).

\section{Finland}

Finnish legislation requires avoidance and minimization of environmental losses, and there are requirements for restoration. While there are compensation requirements based on EU directives (discussed in earlier chapters), few national statutes require compensation.

In large-scale projects, avoidance and minimization measures are examined in the EIA process. The legislation does not require compensation through the permitting process and compensation is only included in a few cases. However, there have been several cases of voluntary compensation measures to offset negative impacts.

The Nature Conservation Act of Finland (Luonnonsuojelulaki, 1096/1996) requires compensation if the coherence of Natura 2000 sites deteriorate. Deterioration of the network can only be accepted if the Government decides that the project or plan "must, in the absence of alternative solutions, be carried out for imperative reasons of overriding public interest". This requirement is based on the EU's Habitat Directive and damage only needs to impact the coherence of the Natura 2000 network. However, in practice, no permits have been applied for in Finland within the Natura 2000 network. Most of the Finnish conservation areas are included in the Natura 2000 network. Furthermore, in other sites regulated by the Nature Conservation Act rules for derogation of protected areas are strict.

The Act on the Remediation of Certain Environmental Damages (Ympäristövastuulaki, 383/2009) requires compensation after environmental damage in certain cases if on-site restoration is not possible. The Water Act (Vesilaki, 587/2011) includes some compensation requirements. For example, if a water resource management project causes damage to fish stocks or fishing, the party responsible for the project has to take measures to prevent or reduce the damage ("fisheries obligation"). A fisheries obligation may consist of the construction of a fish passage, river restoration, stocking or a combination of measures. A fisheries fee may be required to cover reasonable costs of these measures. However, we acknowledge that these types of measures may 
not be viewed as compensation as defined in this report, as they are not conducted within the mitigation hierarchy.

\section{Norway}

Norway's Nature Diversity Act ${ }^{36}$ contains provisions for requiring compensation. Compensation is not legally required in the sense that it is mandatory for all projects of a certain type. The provisions in the Act provide for a case-by-case assessment as to whether the conditions for requiring compensation are fulfilled or not. It is important to note that the Act explicitly refers to avoidance as a general requirement and impacts should be minimized. ${ }^{37}$ Compensation is reserved as a provision only under certain circumstances.

Chapter V in the Act, on protected areas, contains a provision for requiring compensation. The first paragraph of section 48 is concerned with exemptions from a decision to protect an area. An exemption can only be granted when it is not contrary to the purpose of the decision to protect and does not have a significant impact on the conservation value at hand. Alternatively, an exemption can be granted if safety considerations or important public interests make such an exemption necessary.

The second paragraph of section 48 explicitly deals with the potential compensation requirement in the context of an exemption and states that when weighing other important public interests against the interests promoted by the protected area, particular emphasis shall be placed on the importance of the protected area for the overall network of protected areas. There is a particular emphasis on whether a corresponding protected area can be established or developed elsewhere. The paragraph also states that the owner of a project may be required to bear reasonable costs arising from the safeguarding, establishment or development of such a corresponding area.

It is important to note that if there is an alternative way in which the public interest can be safeguarded, an exemption should not be given, and hence the compensation will not be required. For instance, if a nationally important highway or railway can be constructed along an alternative

\footnotetext{
${ }^{36}$ Act of 19 June 2009 No. 100 Relating to the Management of Biological, Geological and Landscape Diversity (http://www.regjeringen.no/en/doc/laws/acts/nature-diversity-act.html?id=570549).

37 See section 6 "General duty of care" in Nature Diversity Act which explicitly refers to avoidance. Several other Norwegian laws also refer to a duty to care and avoidance of impacts (for examples, see Miljøverndepartementet 2009). Further, section 7 of the Nature Diversity Act refers to principles for official decisionmaking, including principles such as having a good knowledge base for decision-making, the precautionary principle, an ecosystem approach and consideration of cumulative impacts as well as application of environmentally sound techniques and methods of operation (sections 8 to 12 in the Nature Diversity Act). These are all supportive of the essence of the mitigation hierarchy.
} 
route rather than through a protected area, the public interest may be handled in an alternative manner and one would not expect an exemption and potential requirement for compensation to occur.

In the case where a compensation measure is required, there is limited guidance on what is appropriate compensation. ${ }^{38}$ Priority should be given to identifying areas which allow the existing protected area to be expanded. Alternatively, other areas can also be considered. Impacts on Ramsar wetland sites normally include compensation, as the Ramsar Convention, which Norway has ratified, requires this. The guidance also stresses that the threshold for an exemption in a protected area should be high and that avoiding and minimizing impacts are prioritized over exemptions and associated compensation requirements.

In addition to chapter $\mathrm{V}$ on protected areas, the Act mentions that the scope for compensation can be one of the elements to consider when giving exemptions both for priority species in chapter III and selected habitat types in chapter VI. However, these parts of the Act are not legal provisions for requiring compensation, but rather simply refer to the option (as under Sweden's Chapter 16, Article 9).

The transportation sector in Norway has been important in exploring the potential use of compensation. A key policy document in the transportation sector, the Government White Paper on the National Transportation Plan prepared by Ministry of Transport and Communications, refers to exploring the use of compensation (Samferdselsdepartementet 2013). In 2013, the Ministry also commissioned studies related to the potential for compensation to play a role in Norway, based among other things on international experiences (Hårklau et al. 2014). A working group with representatives from the transportation, environment, and agricultural ministries and directorates recommended that compensation should be studied further in the transportation sector. In 2015, the transportation authorities have started work to identify potential pilot projects for compensation that can shed light on a variety of challenges and opportunities associated with compensation in the Norwegian context. The motivation of the transportation sector's engagement appears to be a combination of the desire to better protect biodiversity, to expand the tool box available in planning and constructing transportation infrastructure, and an interest in reducing the time required to implement such projects by more efficiently finding solutions acceptable to society as a whole. Compen-

${ }^{38}$ Guidance can be found in: Miljødirektoratet, 2014. Rundskriv om forvaltning av verneforskrifter. Veileder M106-2014. Miljødirektoratet, Trondheim (in Norwegian). 
sation may be such a tool if agreement on the infrastructure development can be reached sooner by considering compensation measures.

In 2013, a report on the values of ecosystem services in Norway touched briefly on compensation and recommended that further criteria for compensation be developed (NOU 2013:10). However, criteria have not yet been developed.

\section{Denmark}

In Denmark, legislation requires avoidance and minimization of losses to the environment, and environmental permits include restoration requirements. In large-scale projects, measures aiming to avoid and minimize are examined in the EIA process.

The Danish Environmental Protection Act (Lov om naturbeskyttelse) defines environmental damage. The Danish Act of Environmental Damage (Miljøskadeloven) states that the party responsible for an environmental damage or immediate risk of environmental damage is responsible to prevent or remedy the damage, and to cover all necessary costs. There is however nothing in the legislation referring to environmental compensation as a possible requirement for obtaining environmental permits.

\section{Iceland}

In Iceland restoration has been carried out for a long time across many different types of habitats, e.g. for halting soil erosion and for protection of soils and vegetation. However, Icelandic legislation and regulation regarding environmental compensation are not very strict (Barkarson, personal communication, November 2014, Aradóttir and Pétursdóttir 2011, Aradóttir et al. 2013).

The Nature Conservation Act (1999) defines conservation areas, ecosystems, geological formations and landscape features where conservation is more stringent (Barkarson, personal communication, November 2014). Development activities in these areas require a license from the Environment Agency and this license can include requirements for environmental compensation. For example, according to the Nature Conservation Act, wetlands should not be disrupted or damaged unless public interest demands so. If damaged, a condition that identical wetlands should be restored can be put in the development permit as a prerequisite for the development, preferably in the same area and within a certain time limit. However, these demands are not stated in the law. As an example, the National Road Administration has made reclamation of wetland damage from road construction a key part of its environmental policy. 
In addition to the Nature Conservation Act, the Soil Conservation Act (1965) also includes requirements for compensation. It states that "whoever damages land through development or any other way shall reimburse (pay)". In practice, if land is damaged there may be some requirements in the license to re-vegetate land, but this is not defined in law or regulation.

\subsubsection{Voluntary Drivers}

In addition to regulatory drivers, the link between business and biodiversity is slowly becoming a part of CSR. There is a growing level of awareness of the importance to consider biodiversity in business decision-making, and the biodiversity-related risks and opportunities to businesses. For instance, the Natural Capital Coalition ${ }^{39}$ initiative has identified biodiversity-related risks and opportunities for businesses and has worked with businesses to develop tools and approaches that integrate biodiversity considerations into business practice.

In Finland, an example of this kind of action is the Corporate Responsibility Network FIBS, ${ }^{40}$ which brings together companies, NGOs, researchers and public sector organizations to exchange information and experiences on best sustainability practices as well as to learn from each other. The network has currently over 230 members, most of them large companies. FIBS has a Business \& Biodiversity programme, which seeks to create public awareness about biodiversity and its importance, as well as to help companies identify and manage their own impacts on the environment. The initiative aims to encourage companies to integrate biodiversity and ecosystem services in all environmental and sustainability management systems and practices.

A recent article (LKAB Framtid 2014) ${ }^{41}$ stressed the importance of incorporating biodiversity in business decision-making: "Imagine if all companies with nature in the bottom of the value chain would say: Our business means that we have an impact on nature. That's a problem. But we'll make something good out of it - we'll give back at least as much."

At present, some companies are already voluntarily developing compensatory offsets to minimize their impact. However, compensation has great potential as a part of CSR. Although driven by somewhat less stable motivation that can fluctuate with public opinion, voluntary com-

\footnotetext{
${ }^{39} \mathrm{http}: / /$ www.naturalcapitalcoalition.org

${ }^{40} \mathrm{http}: / /$ www.fibsry.fi/fi/english/home

${ }^{41}$ http://www.lkab.com/Global/Documents/Tidningar/LKAB Framtid/2014/LKAB_Framtid_2014_Nr6.pdf
} 
pensation efforts nonetheless contribute to the increased use of compensation on the international level.

Voluntary compensation efforts are beginning to take shape in the Nordic countries. Below, we provide some examples of companies and projects carrying out voluntary efforts:

\section{The Port of Gothenburg}

The Port of Gothenburg is Scandinavia's largest and recently put forth plans for expansion to ensure competitiveness. The expansion will permanently damage two ha of eelgrass, which delivers several ecosystem services such as improved water clarity, fish production, and carbon sequestration. The Port's permit application for expansion led the Swedish Agency for Water Management ( $\mathrm{HaV})$ to recommend compensation measures ${ }^{42}$ to avoid additional loss of eelgrass, which has already declined significantly in the past 40 years due to costal development. ${ }^{43}$ The EU's No Net Loss Initiative and other regulatory drivers on the national level motivated the agency's recommendation. Besides these drivers there is also a voluntary effort from the port.

The compensation measures aim to reverse the historic decline of eelgrass through off-site eelgrass restoration. Further, the agency recommended methods for scaling seagrass compensation that are currently being developed in a research project and noted that the costs of such compensation likely represent a small fraction of the overall project expansion costs.

The proposed compensation comes with some risk, as it is based on building up a deep bottom bay (that previously did not support seagrass) to ensure the right light conditions for seagrass restoration. This replanting method has not been tested before in Nordic countries and thus requires some additional compensation to account for risk.

\section{LKAB}

In 2015 the Swedish state-owned mining company LKAB has adapted guidelines for sustainable land use that include a No Net Loss perspective on biodiversity. ${ }^{44}$ The guidelines provide the company with explicit management obligations to apply environmental compensation, together with efforts to manage and improve biodiversity after extraction. The

\footnotetext{
${ }^{42}$ see e.g., https://www.havochvatten.se/download/18.549ab516149e19df88f41541/1417532707280/ yttrande-mmd-m-4523-13-arendal-goteborg-hamn.pdf

${ }^{43}$ We consider this a voluntary measure because the Port has agreed to voluntarily abide by the recommendation, but ultimately the environmental courts may convert this to an obligation.

${ }^{44}$ Anders Furbeck, LKAB, Pers. Comm.
} 
guidelines on compensation were first applied to the newly established Mertainen greenfield mine in 2014, and resulted in the protection of ca 2,500 ha of old growth forests and wetlands through compensation measures (see Box 4.3). Interestingly, the compensation measures were originally part of a voluntary effort by the company, but their use has influenced the local authorities, who now require such compensation from other actors. This shows that, like the "chicken and the egg" problem, supply and demand is interacting.

\section{Case Rudus}

Rudus, a company processing rock material for construction work in Finland, has a special program that aims to safeguard biodiversity levels. Specifically, the company aims to ensure a higher level of biodiversity on their sites relative to pre-operation baselines. The program was started in 2014 and includes several pilot sites in different parts of the country.

\section{Financial mechanisms}

Connected to voluntary efforts are financial mechanisms and requirements from banks for development projects. This is often applied in developing countries, especially according to requirements from International Finance Cooperation Performance Standards, IFC PS6. Financial mechanisms and requirements have not yet influenced the development of environmental compensation in the Nordic countries.

\subsection{Experience and status of Environmental Compensation}

\subsubsection{Sweden}

Among the Nordic countries, Sweden has the most practical experience from both large and small compensation projects. The relatively recent Swedish experiences provide some interesting lessons and experiences, which cover all stages of the process, including planning, implementation, and long-term management. We highlight a few relevant experiences and activities below.

The Swedish National Rail Administration's (now Swedish Transport Administration) railway project Botniabanan next to the Natura-2000 area Ume River Delta resulted in a very large environmental compensation project undergoing licensing and completion during the years 2003 to 2009 (Banverket 2006). All stages of the mitigation hierarchy were 
implemented in this project, and the remaining damaged area was compensated by restoration of shore meadows, wetlands, temporarily flooded arable land and deciduous forests. The compensation covered about 500 ha. In the end of the project, The Swedish National Rail Administration formed a foundation with enough capital to finance the administrational and management costs of the compensation measures for 50-100 years. A large number of people from Sweden and other countries have visited the area to learn about environmental compensation.

During 2011, two national conferences were arranged with the aim to share knowledge and experiences of environmental compensation. ${ }^{45}$ The conferences were initiated by two consulting firms and financed by the Swedish Transport Administration. Practical advice was given during the conferences on how authorities can apply the relatively old (and rarely used) wording of environmental compensation from Chapter 16, article 9 in the Environmental Code. Officials from several authorities attended the conferences and they brought the message home and started to apply Chapter 16 Article 9. As a result, a praxis supporting environmental compensation in Sweden has slowly emerged. 46

In 2013, a government study received commission to analyze the measures and suggest ways and means to better evaluate ecosystem services (SOU 2013). One of the commission's proposals was greater and more consistent use of environmental compensation in the everyday landscape, i.e. outside protected areas.

The Swedish EPA (Naturvårdsverket 2015) surveyed the recent use of environmental compensation under the Environmental Code, covering all cases registered by the EPA from 2011 to 2014. The findings showed significant variation in the use of compensation across different cases, with similar environmental impacts leading to very different compensation requirements. For impacts affecting protected areas, the study found that compensation was only required in $1-2 \%$ of the 3,500 surveyed cases. $82 \%$ of the 1,080 cases that examined impacts to specially protected biotopes (forest and agrarian landscapes) required some form of compensation. The Swedish EPA report also covered cases concerning the Species Protection Ordinance, where compensation was required in $4 \%$ of the 486 cases. Compensation measures for nonprotected nature and species were very rare.

45 Enetjärn Natur and Enviro Economics Sweden 2011 (http://www.enetjarnnatur.se/site_specific/uploaded_files/10033/Sammanfattning.pdf). (http://www.enetjarnnatur.se/site_specific/uploaded_files/15108/Sammanfattning Ekologisk kompensation okt 2011.pdf)

${ }^{46}$ Enetjärn Natur 2011 (http://www.enetjarnnatur.se/static/sv/294/) 
Environmental compensation has also been applied in the permitting process for a number of complex cases regarding land use, like large-scale mining. These activities have increased in the recent few years. The Swedish Academy of Courts arranged training in environmental compensation during the spring of 2014, where representatives from all Swedish Land and Environment Courts took part.

The Swedish EPA is currently (March 2015) developing a guidance document for compensation, ${ }^{47}$ which is motivated by several events that have occurred between 2011 and 2014, including:

- Two national conferences on environmental compensation.

- Voluntary compensation initiatives developed by several municipalities in connection with urban development.

- Large-scale infrastructure projects that included compensation related to roads and railroads.

- A pilot project on compensation within the mining industry (case Mertainen, see Box 4.3) that was financed by the state-run organization Vinnova.

- Increased discussion of compensation in connection with several approval cases in the environmental courts.

- The governmental investigation on ecosystem services from 2013 (SOU 2013).

The Swedish EPA sees both risks and possibilities with compensation and hopes that their on-going guidance development will contribute with the following:

- More consistent use of compensation in the permitting process under the Swedish Environmental Code.

- Reduced risk that compensation is used as an excuse to reduce other environmental protection measures or allow development in sensitive areas (license to trash).

- Encourage voluntary compensation initiatives in different industry sectors.

- Better reach the national Environmental Quality Objectives related to increased biodiversity and ecosystem services. 
The Swedish EPA guidance development process will try to capture practical experiences from the use of compensation to address environmental loss in connection with the permitting process and to consider various solutions. Various stakeholders have been involved in the process and a key output so far from developers is the need to improve predictability within the decision-making process as this can lead to reduced costs. Another key discussion point was the need for compensation issues to be discussed early into the decision-making process regarding the permit and the need for flexibility ${ }^{48}$.

Person et al. (2014) surveyed compensation projects required for the Swedish Road and Rail infrastructure investments. They found 37 decisions between 2004 and 2012 that, based on the Environmental Code, required compensation. Most of the compensation decisions concern areas with strong biotope protection. The study focused on two of the larger compensation projects and found a need for better management and integration of compensation in the planning processes for both rail and railway planning, as well as a need for better regional coordination of compensation efforts.

The city of Helsingborg is one of the first municipalities in the Nordic countries that has applied environmental compensation in development projects. Although the Swedish Planning and Building Act does not explicitly give municipalities the right to require compensation, Helsingborg has established a principle of balancing environmental losses and gains. The city calculates a "balancing allowance" that varies with the size and quality of the impacted area and considers whether this is consistent with their comprehensive and green infrastructure plan. Exploitation on private land requires compensation measures close to the impacted area. Exploitation on public lands relies on the "balancing allowance" to generate credits that capture the value of natural and recreational use, which can then be applied elsewhere in the city. ${ }^{49}$

Residual impacts in the marine environment have received increased attention, including the impact of coastal development (e.g., docks, piers, dredging, etc.) and reduced water quality on seagrass habitat on Sweden's West Coast. Significant losses have been documented since the mid 1980s, with estimates ranging from 8,000 to 15,000 ha (up to $60 \%$ compared to 1980 ). To increase knowledge and improve the management of these coastal resources, a research project is currently

48 Johan Lindberg Pers. Comm.

${ }^{49}$ Jenni Wehrmann and Fredrik Bengtsson Pers. Comm. 
underway to help regulatory agencies to review future compensation proposals. Some of these are being proposed voluntarily by developers, while others are being recommended by the authorities. The interdisciplinary project ${ }^{50}$ involves marine ecologists, environmental legal scholars, and environmental economists and is funded by the University of Gothenburg, FORMAS, The County Administrative Board of Västra Götalands län and Swedish Agency for Marine and Water Management. The project will develop, among other things, a handbook for regulatory authorities in 2015 covering compensation in the marine environment, including technical methods for eelgrass restoration and planting), estimates of the economic value derived from eelgrass' ecosystem services, and legal guidance for implementing seagrass compensation under current regulatory regimes from the EU and Sweden.

Figure 4.1: Wetlands and meadows restored via temporarily flooded arable land in central parts of compensation area at Ume River Delta, with new railway Botnia Line through the area. This picture covers one of five new nature reserves.

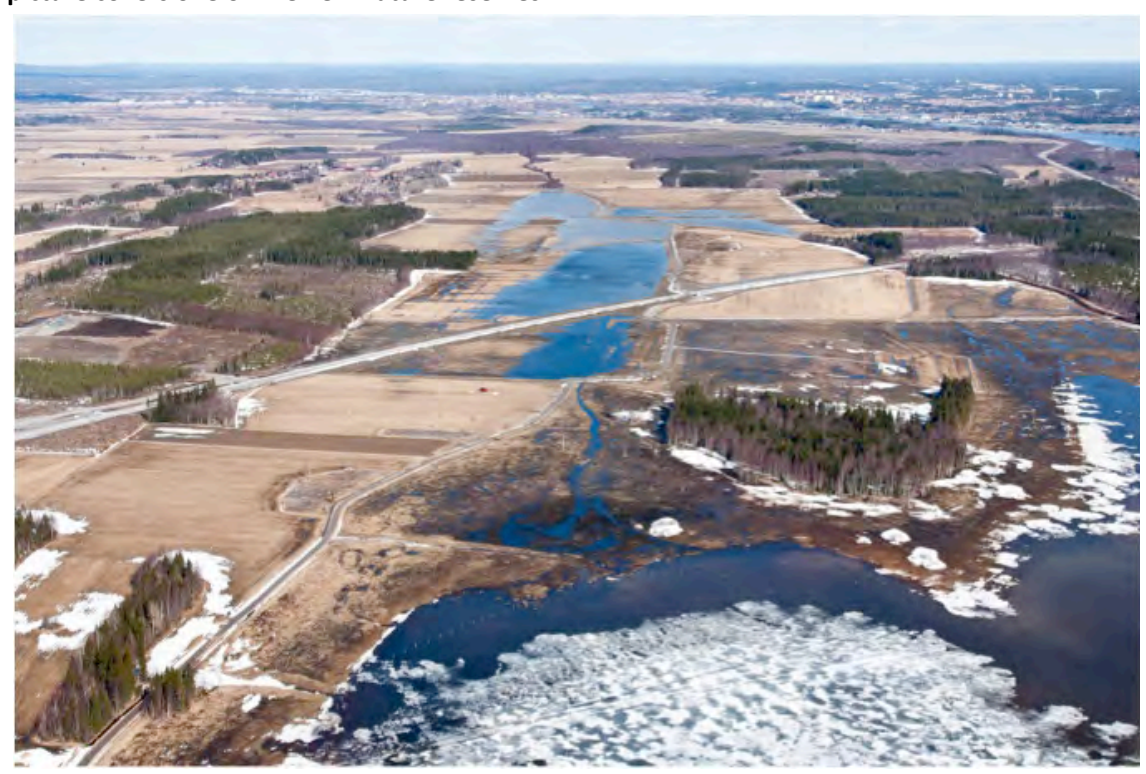

Source: Lars Lindh. 


\section{Box 4.1: Railway Bothnia Line, Ume River delta}

\section{Railway Bothnia Line, Ume River delta}

- Developer and project: Banverket, new railway.

- Location: Umeå, Västerbotten, Sweden.

- Impact: Impact on the Ume River delta Natura 2000 site (SCI and SPA) and Ramsar site, main impact on deciduous land upheaval forests and on arable land habitats for wetland birds.

- Regulatory driver: Habitats directive via Swedish Environmental Code on Natura 2000, (chapter 7 article 28, also referring to Species and Habitats Directive).

- Governmental body: County Administration, Naturvårdsverket, Environmental Court of Appeals.

- Stage of development and time line: Start of compensation design 2003, the very first compensation project in Sweden. Start of development project and compensation project 2008. Compensation measures completed and put under long-term operation and management 2009. Railway traffic started 2010. Planned duration of compensation management is $50-100$ years. Long-term monitoring and evaluation is following recommendations from The World Bank.

- Compensation measures: 500 ha divided, and long-term legally protected, in five new nature reserves, mainly on-site, all with either restored wetlands, temporarily flooded arable land, shore meadows or restored secondary deciduous forest.

- Equivalence: Main focus on maintaining number of Bean geese (goose-days, numbers of geese times days) during the migration period. Multipliers where used in scaling the compensation to account for risk of uncertainties about the compensation reaching its targets.

- Overall compensation costs: EUR 14,071 million (9\% transaction costs, 72\% investment costs and 19\% management costs). EUR 2,673 million of the overall cost was funded for 50-100 years long-term management.

- Cost per hectare: EUR 28,200.

- Results from monitoring: Compensation project is reaching all targets and reaching a net gain. First five years of long-term monitoring shows clear satisfactory results on compensation on wetland birds (Trafikverket 2014, unpublished).

- Challenges and solutions: Complicated permitting process, time delay, land acquisition were main challenges. Advantage was focus on habitats with relatively short time of delivery as well as progressive cooperation with County administration in land acquisition. 


\section{Box 4.2: Railway Bothnia Line, Öfjärden}

\section{Railway Bothnia Line, Öfjärden}

- Developer and project: Banverket, new railway.

- Location: Örnsköldsvik, Västernorrland, Sweden.

- Impact: Impact on small part of wetland habitat and protected area, 10 ha

- Regulatory driver: Environmental Code, chapter 7 article 7.

- Governmental body: Local municipality.

- Stage of development and time line: Management phase since implementation 2011. Planned duration of management is 20 years.

- Compensation measures: 20 ha of on-site restoration of wetland meadows and deciduous forests. Measures also include public access.

- Equivalence: No proper scaling. "Hands on quick solution". No clear compensation targets.

- Overall compensation costs: EUR 108,000 taken by developer, overall cost EUR 700,000.

- Compensation cost per hectare: EUR 5,400.

- Results from monitoring: No results yet.

- Challenges and solutions: NA.

\section{Box 4.3: Mertainen mine}

\section{Mertainen mine}

- Developer and project: LKAB greenfield iron ore mine.

- Location: Svappavaara, Norrbotten, Sweden.

- Impact: Old growth forest and wetlands, approx 550 ha direct impact, no formal protection.

- Regulatory driver: Voluntary initiative by developer, later provisioned by Environmental Code (Species Protection Ordinance).

- Governmental body: County administration and Supreme Environmental Court.

- Stage of development and time line: Development started 2014. Compensation plan confirmed 2014 and measures taking part winter 2015.

- Compensation measures: 2,571 ha of improved protection (averted loss) of on-site ( $5 \mathrm{~km}$ distance) forests and wetlands, measures to improve habitats (dead wood, forest fire, etc.). It is important to emphasize that 2,571 ha does not mean it is what is required in compensation. It may well be enough with less to balance the impact of the mine. 
- Equivalence: BBOP methodology being tested for calculating losses and gains, with focus on habitat hectares. Scaling was part of R\&D pilot project financed by Vinnova, Sweden's innovation agency.

- Overall compensation costs: Not public.

- Compensation cost per hectare: Not public.

- Results from monitoring: Not started.

- Challenges and solutions: Long time permission process. Challenge to argue for additionality with proposed nature protection in a region with a big amount of unprotected high natural value old growth forests. Advantage was that developers focused on maintaining biodiversity.

Figure 4.2: Felling of old growth forest in impact area of Mertainen mine. The retained trees will be removed separately and relocated to the compensation area to improve conditions for species depending on dead wood substrate

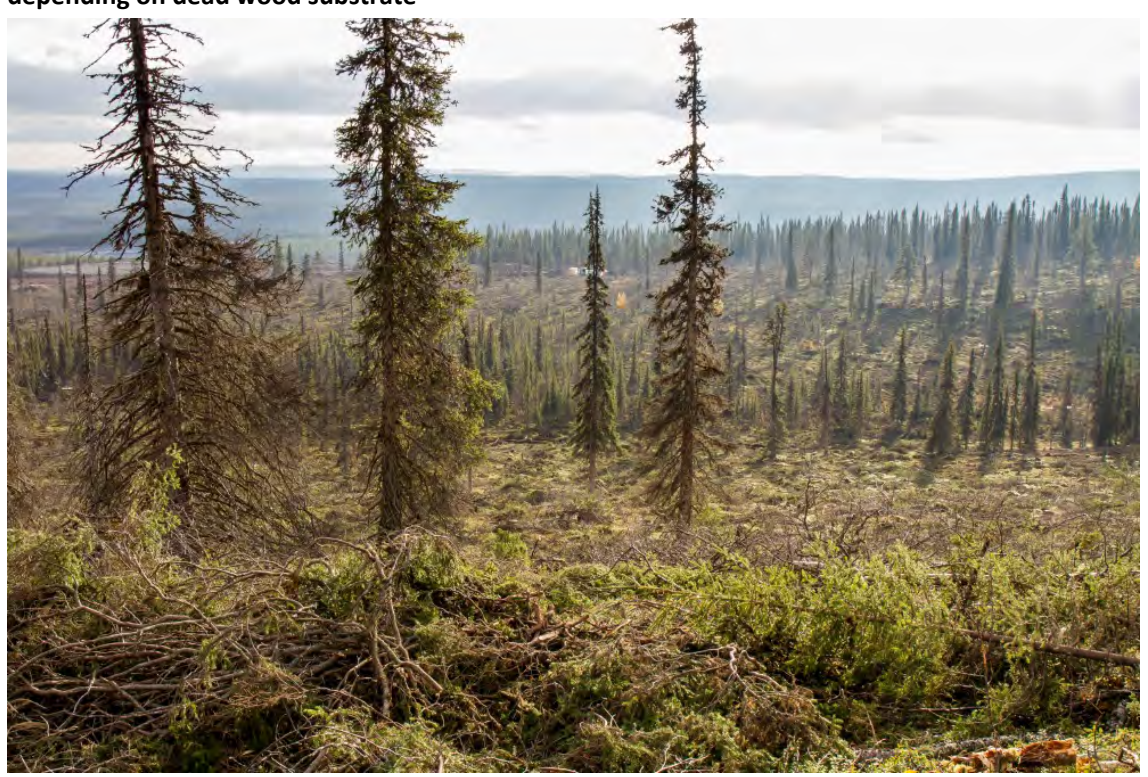

Source: Nic Kruys/N. 
Figure 4.3: Highway E45 and railway along river Göta Älv

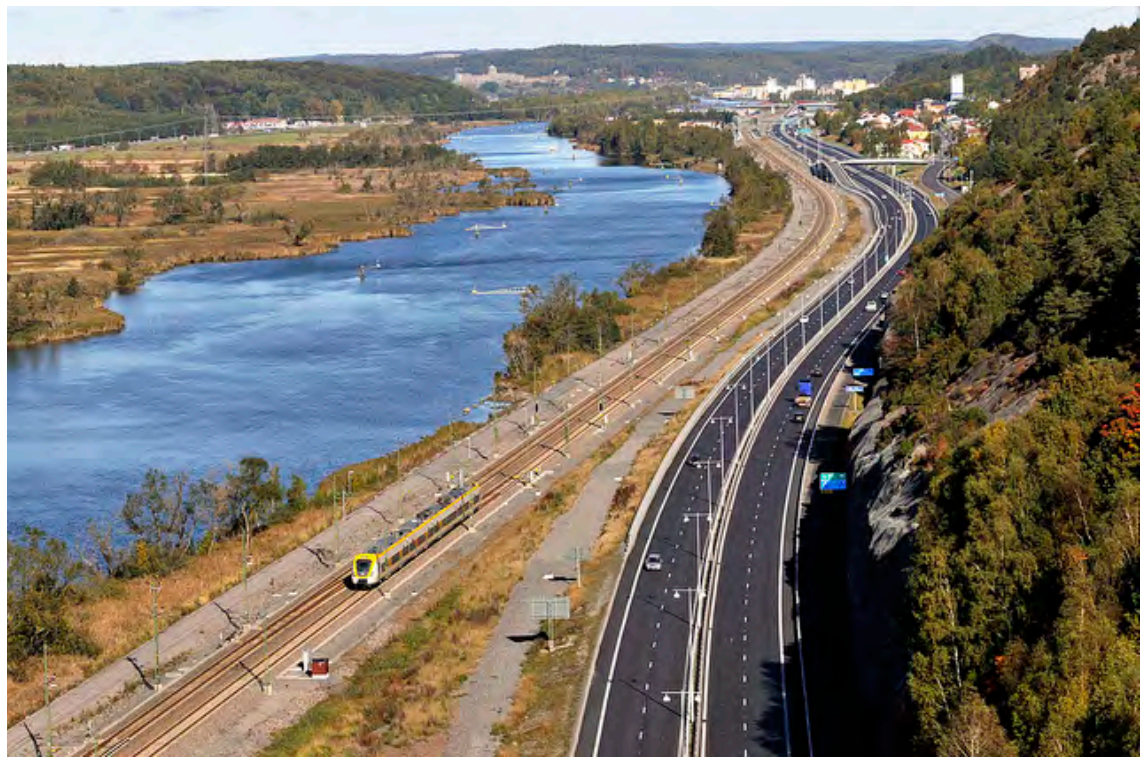

Source: Trafikverket.

\section{Box 4.4: New highway E45 and railway along Göta Älv River,}

\section{Gothenburg}

\section{New highway E45 and railway along Göta Älv River, Gothenburg}

- Developer and project: National Transport Administration (former Rail and Road Administrations).

- Location: Gothenburg, Västra Götaland, Sweden.

- Impact: The new highway and extended railway cut through 165 ha of valuable wetland meadows of national conservation interest along the Göta Älv River.

- Regulatory driver: The Railroad and Road administrations proposed compensation measures to limit the damage and prevent long-term ecological impact on the waterfront habitats and their fauna and flora. (pers. comm. Mats Lindqvist).

- Governmental body: County administrative board.

- Stage of development and time line: Restoration work and conservation measures to improve the biological status of the compensation areas were carried out 2008-2014. Followed by long-term management of the compensation sites.

- Compensation measures: The compensation area is approximately 320 ha, aiming to create species richness wetland and meadow habitats, on-site. 
Restoration and conservation measures involve cutting and mechanical removal of reed, mowing, extensive grazing by cattle, creation of ponds for amphibians and birds, and partial flooding of agricultural land.

- Equivalence: The compensation project started before the BBOP standard for biodiversity offsetting was developed.

- Compensation cost per hectare: EUR 14,000.

- Overall compensation costs: In total SEK 40 million of which SEK 25 million are allocated for long term management of the compensation area.

- Results from monitoring: Changes in species composition and increase in plant species richness on the meadows is a slow process. The set targets about in particular the reduction of reed have not yet fully been achieved. Two sites were newly restored in 2014 and results are not available yet.

- Challenges and solutions: A major challenge has been to ensure the longterm management of the compensation areas, to administer the money and manage the payments necessary for financing maintenance and conservation measures. Since the Bothnia Railway project, money allocated for compensation projects can no longer be administered by a foundation nor be paid out in a lump sum. Instead money for management of the compensation areas is paid out on an annual basis for the next 25 years.

\section{Box 4.5: New highway E12, Umeå}

\section{New highway E12, Umeå}

- Developer and project: National Transport Administration.

- Location: Umeå, Västerbotten, Sweden.

- Impact: Arable land with recreational values and migratory birds, inside Natura 2000.

- Regulatory driver: Environmental Code, chapter 16 article 9 (despite impact area was protected according to Natura 2000).

- Governmental body: County administration.

- Stage of development and time line: Development planned to start 2016. Compensation plan confirmed 2013 and measures taking part and finished early 2014, now start of management, duration 10 years.

- Compensation measures: Off site $(5 \mathrm{~km}$ from impact and in other part of the city) 6 ha, creation of small, new wetland, meadow, stream, sand and grazed habitats, measures for certain species (i.e. sand martin) and measures to improve recreational use and public access.

- Equivalence: No proper scaling, "hands on quick solution". No clear targets.

- Compensation cost per hectare: EUR 35,300. No cost for land acquisition. 
- Results from monitoring: No clear targets for monitoring.

- Challenges and solutions: Impact is partly on local recreational values but compensation benefits another part of the city population. Lack of targets and metrics made it difficult to decide level of compensation (scaling).

Figure 4.4: Compensation measures along new highway E12 aims to create several small wetland, meadow, stream, sand and grazed habitats between existing farmland to the north (right) and a stream to the south (left), as well as improve recreational use and public access

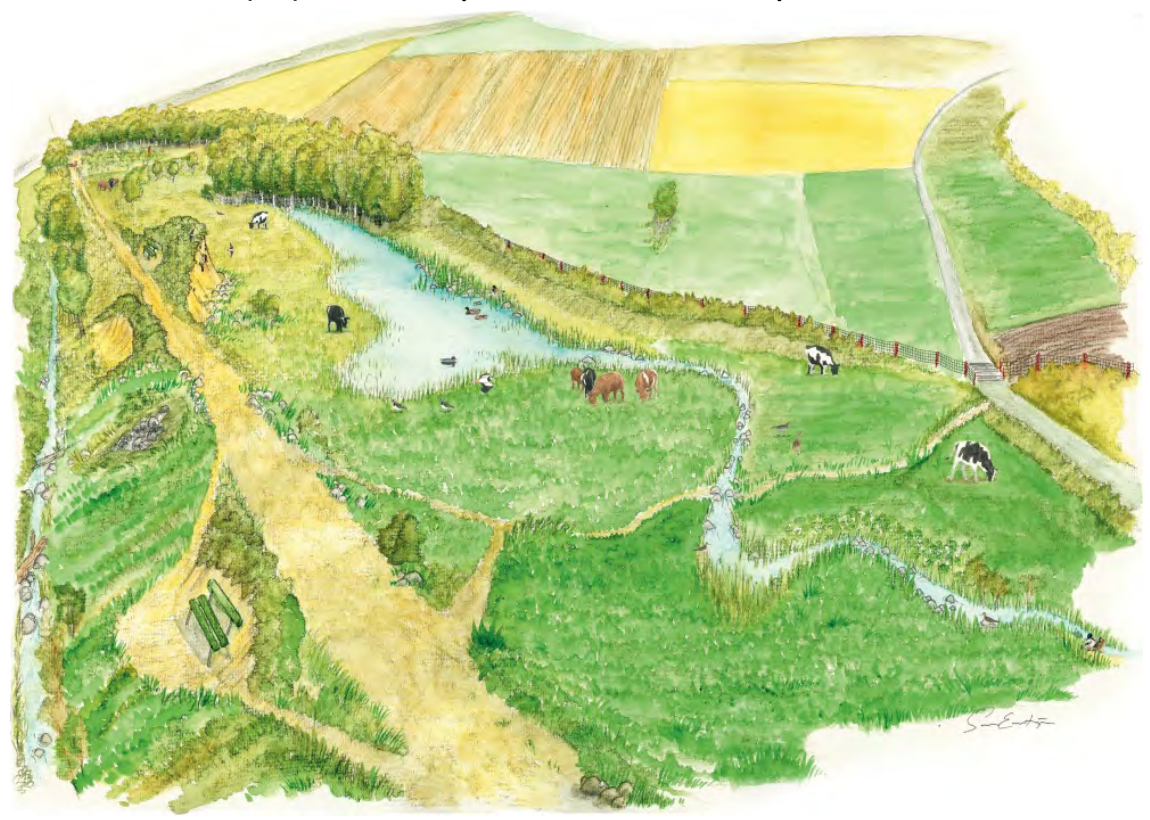

Source: Susan Enetjärn. 
Figure 4.5: Providing a new breeding habitat for sand martin is one of the compensation measures in the compensation plan for new highway E12

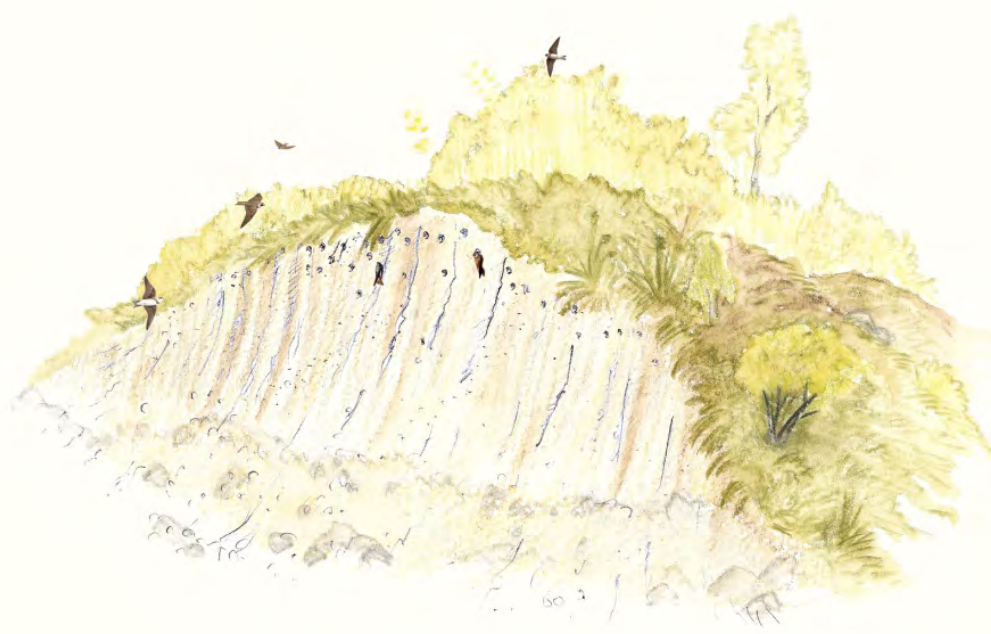

Source: Susan Enetjärn.

\section{Box 4.6: New tailings expansion, Aitik mine}

\section{New tailings expansion, Aitik mine}

- Developer and project: Boliden Mineral, mining.

- Location: Gällivare, Norrbotten, Sweden.

- Impact: Clearing of 250 ha of old growth forest and wetlands.

- Regulatory driver: Environmental Code, chapter 16 article 9.

- Governmental body: County administration, Environmental court.

- Stage of development and time line: Detailed compensation plan is to be completed in spring 2015. Losses will occur in steps and measures will be taken in those steps, probably with start during summer 2015.

- Compensation measures: An area of at least 250 ha older forest, suitable for habitat improvement (dead wood, nest boxes, possibly forest fire), will be restored and protected on-site, improving connectivity between two already protected areas. Dead wood (with species) will be moved from the exploitation site to the compensation site. 
- Equivalence: Focus is to provide the impacted species with a similar habitat suited for them, within a similar area. The restored area must be at least the same size as the area lost, 250 ha. The detailed compensation plan is still under development, but will contain quality goals for the improved habitat.

- Compensation cost per hectare: NA.

- Results from monitoring: Not started.

- Challenges and solutions: One of first large scale European compensation projects due to losses in virgin forest.

Figure 4.6: Old growth dead wood debris, like the old log on the ground in this picture, is a key priority substrate that will be moved from the impact area to improve conditions in the compensation area

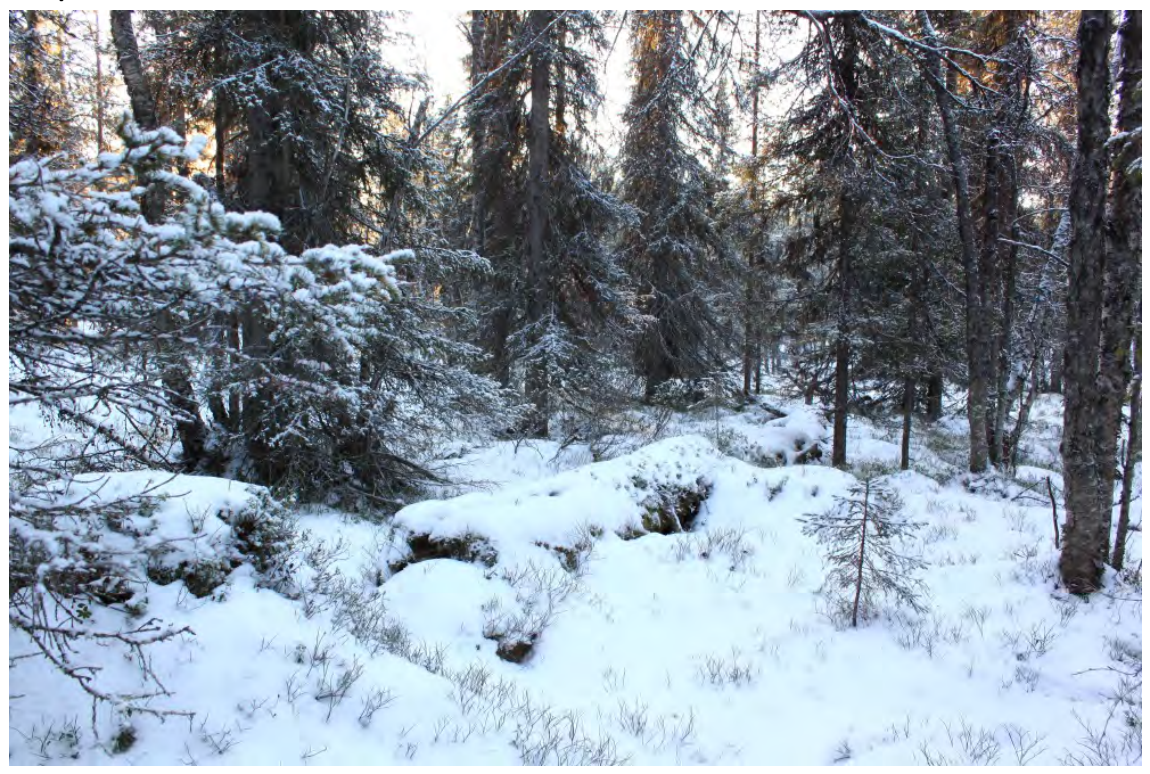

Source: Enetjärn Natur. 


\subsubsection{Finland}

Environmental compensation is not yet widely used in Finland. However, based on the Water Act, impacts from hydropower stations on fish stocks or fisheries require compensation. Hydropower plants have had significant environmental impacts, especially on trout in the northern parts of Finland and compensation can be carried out by e.g. charging fisheries a fee which is later used for fish planting or building fish passages. This kind of compensation has been carried out in several places in different parts of the country.

Furthermore, voluntary compensation activities are occasionally occurring, and e.g. Rudus, which is a company processing rock material for construction work, has a special program that aims to guarantee that the biodiversity level on the sites they are using is higher after operations than it was before operations. Pilot projects are also carried out in a highway construction (E18) between Hamina and Vaalimaa.

Even if not directly related to environmental compensation, largescale ecosystem restoration activities are carried out in the state-owned forests by Metsähallitus. As a part of the METSO forest conservation program, approximately 13,000 ha of state-owned forests and tree covered peatlands are restored in 2009-2016. In addition, by using EU Life funding, thousands of hectares peatland have been restored. However, the restoration activities that occur in peatlands, which earlier were drained for forestry purposes, compensate for economic activities carried out decades ago and should not be considered as ex ante environmental compensation.

The interest to develop compensation mechanisms has increased in Finland. Already in 2006, Suvantola (2006) suggested changes to the Finnish Nature Conservation Law so that it would demand compensation. In addition, practical frameworks for compensations in infrastructure construction (roads, railroads) have been examined by e.g. Nyrölä et al. (2011) and Ketola et al. (2009).

Furthermore, Kniivilä et al. (2014) assessed the feasibility and relevance of habitat banking and environmental compensation for the Finnish Ministry of the Environment. The study recommended piloting habitat banking in Finland in different ecosystem types, e.g. in heritage landscapes, which can be developed in a relatively short time, and in mires already partly restored. In addition, sites that fulfill the criteria of METSO programs were presented as a potential supply pool. The report also suggests combining habitat banking with production of other ecosystem services, e.g. carbon sequestration. Despite some exceptions, the current legislation does not mandate the use of compensation (see chap- 
ter 4.1.1). This is seen as one of the major restricting factors for the future use of environmental compensation in Finland. On the other hand, the existing extensive scientific and practical knowledge on restoration and the potential interest of private forest owners to supply compensation areas, is supporting the use of environmental compensation.

\section{Box 4.7: New highway E18 Hamina-Vaalimaa}

\section{New highway E18 Hamina-Vaalimaa}

- Developer and project: Construction of new highway E 18 HaminaVaalimaa, 32 kilometers.

- Location: Hamina-Vaalimaa region in South-East Finland.

- Impact: Impacts on several habitats and species; environmental compensation will be applied to the habitats of flying squirrel (protected by the Habitats Directive) and xerothermic habitats (sun exposed southern slopes). Also lost cultural ecosystem services will be compensated.

- Regulatory driver: Nature Directive (and Nature Conservation Law) forbids destruction of habitats of flying squirrel.

- Governmental body: Regional Centre for Economic Development, Transport and the Environment.

- Stage of development and time line: Construction of the highway will start in 2015.

- Compensation measures: Habitat creation for different species. This example suggests that compensation can, to some extent, be triggered for impacts on protected species (as per the Habitats Directive).

\section{Box 4.8: Merikoski hydro power station}

\section{Merikoski hydro power station}

- Developer and project: Oulun Energia, Merikoski hydro power station (construction work finished in 1954).

- Location: City of Oulu, northern Finland.

- Impact: Prevents fish migration.

- Regulatory driver: Water Act.

- Governmental body: Regional Centre for Economic Development, Transport and the Environment.

- Stage of development and time line: continuous process, yearly stocking obligation. 
- Compensation measures: Fish stocking, yearly release of 26,200 Atlantic salmon offspring, 4,550 sea trout, 15 million whitefish hatchlings, 50,000 lamprey, 4,250 $\mathrm{kg}$ of fishable rainbow trout. Later also fish passage has been built (in 2003).

- Overall compensation costs: Yearly costs of fish stocking EUR 150,000.

- Note: This project can rather be described as mitigation and not compensation, but it is an example of implementation of existing water related compensation legislation in Finland.

\section{Box 4.9: Rudus - voluntary nature conservation program}

\section{Rudus - voluntary nature conservation program}

- Developer and project: Rudus, nature conservation program (LUMO). The aim is that biodiversity level in the site is after compensation measures at least as high as it was before earth moving operations.

- Location: Several pilot sites in different parts of the country. E.g. Porvoo, Oulu and Lappeenranta.

- Impact: Removal of soil; gravel and sand pits.

- Regulatory driver: Voluntary compensation.

- Governmental body: Rudus (this is voluntary, i.e. there is no responsible governmental agency).

- Stage of development and time line: The program was started in 2014.

- Compensation measures: Ecosystem creation for different species.

\subsubsection{Norway}

Compensation connected to development projects is just beginning to evolve in Norway, particularly in the transportation sector. Norway has neither a substantial pool of experience from projects concerning compensation nor an extensively developed framework to regulate and guide compensation. No explicit compensation project is in the field implementation phase yet.

The transportation sector has since 2013 been exploring compensation as a tool to minimize damages to the environment. The first explicit compensation project, related to the expansion of the existing E6 highway through a lowland nature reserve and Ramsar site (Åkersvika), is currently in the design and planning phase. This project is likely to be implemented in the near future. In 2015, the transportation sector will 
assess the opportunity to initiate additional compensation projects to test compensation as a tool in roads, railways and aviation projects.

It is important to note that the mitigation hierarchy is in general well established in Norway and is currently being applied across a number of important sectors where impacts on ecosystems are substantial. Therefore, mitigation measures that reduce the extent of negative impacts are widely applied and typically appear as a condition for approval of projects by a number of authorities. However, the physical compensation for any residual impacts once mitigation has been carried out remains a rare exception in Norway.

It is also worth noting that in a mountainous area, much of which is about 1,000-1,100 meters above sea level, there is a major restoration project ongoing in a previous armed forces training field (165 sq. km). This is most likely the largest restoration project in Norway and has been going on for more than a decade. The project could be considered a form of ex post compensation for the development of a new training field for the armed forces.

Norway has about 1,500 hydropower stations with an aggregated installed capacity of about 31,000 MW, making Norway one of the largest hydropower producers in the world. Associated with hydropower development, there have been large investments in mitigation measures. Several hydropower licenses have been issued with certain conditions that require compensation earmarked for various environmental measures to improve fish and fishing conditions, wildlife areas or recreational areas. There is no clear distinction between mitigation measures and other measures that might resemble compensation, in part because of a lack of an explicit compensation framework within which such measures could be developed. While many in Norway would consider these measures as a form of compensation, most of these measures would qualify as mitigation measures according to the mitigation hierarchy rather than as compensation. 


\section{Box 4.10: Highway E6 expansion Hamar}

\section{Highway E6 expansion Hamar}

- Developer and project: Åkersvika Highway (E6) expansion, Hamar and Stange Municipalities.

- Location: Hamar and Stange Municipalities, Hedmark County, SouthEastern Norway.

- Impact: Åkersvika Nature Reserve and Ramsar Site.

- Regulatory driver: Provision in section 48 of Nature Diversity Act not applied. Reference made to Ramsar Convention.

- Governmental body: Norwegian Public Roads Administration (Statens vegvesen).

- Stage of development and time line: Design and planning of compensation. 2013 to present.

- Compensation measures: Not determined yet. The following are discussed as on-site measures: Expansion of Nature Reserve, restoration of previously impacted areas inside and outside the Reserve, more active management including removal of invasive alien species. Potential measures off-site: Protection of another wetland area.

Figure 4.7: Northern part of Åkersvika with existing highway E6 and suburbs of city of Hamar prior to the proposed expansion of the highway and associated compensation

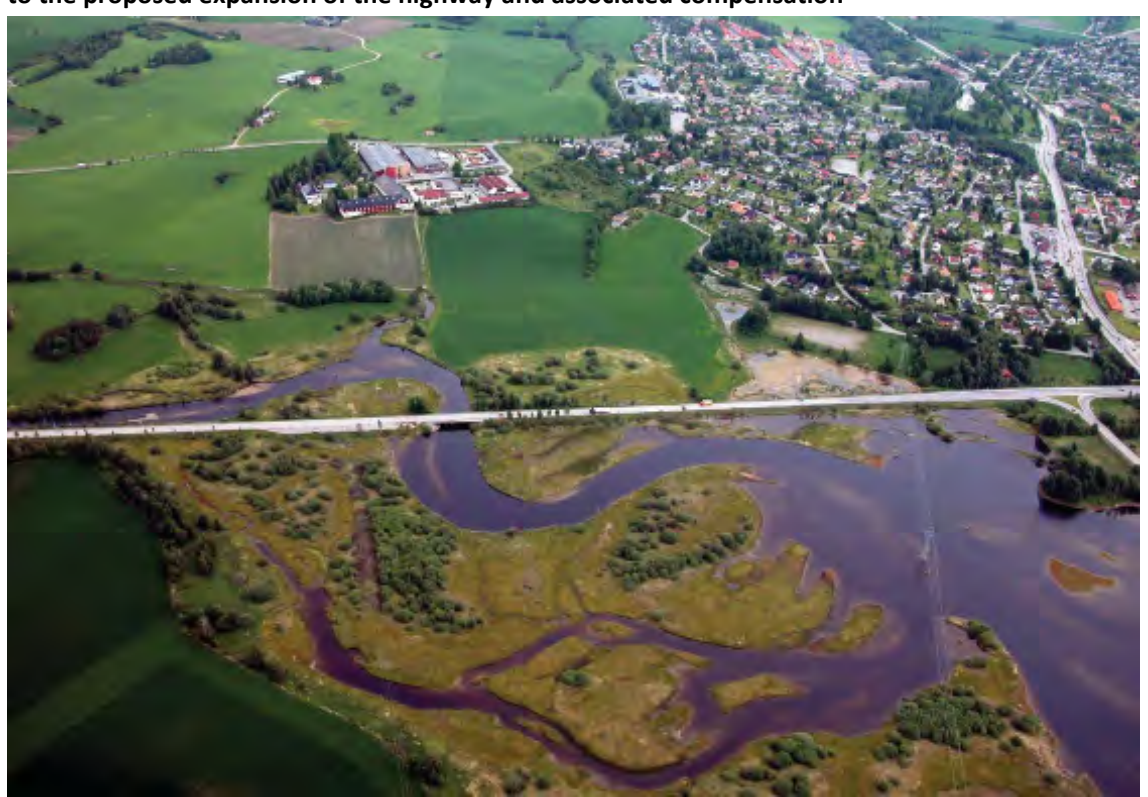

Source: Fylkesmannen. 


\section{Box 4.11: Various hydro power projects}

\section{Various hydro power projects}

- Developer and project: Various hydropower projects by various power companies.

- Location: Countrywide.

- Impact: Mainly freshwater ecosystems.

- Regulatory driver: No compensation provision applied. Typically included as license conditions for license by the Norwegian Water Resources and Energy Administration. Case-by-case assessment of residual impacts and how local communities and affected interests can be compensated.

- Governmental body: Norwegian Water Resources and Energy Directorate (Norges vassdrags- og energidirektorat).

- Stage of development and time line: Ongoing and some completed.

- Compensation measures: Both financial and physical compensation, typically to improve conditions for fish fauna and fishing, wildlife and recreation.

\section{Box 4.12: Armed forces training field}

\section{Armed forces training field}

- Developer and project: Norwegian Defence Estates Agency (Forsvarsbygg).

- Location: Various.

- Impact: Mountainous ecosystems at higher altitude $\left(165 \mathrm{~km}^{2}\right)$.

- Regulatory driver: No compensation provision applied. Parliamentary decision to restore previous training field when new one was being developed.

- Governmental body: Norwegian Defence Estates Agency.

- Stage of development and time line: Duration 2000-2020. Advanced implementation and monitoring of restoration measures.

- Compensation measures: Removal of physical infrastructure and restoration of substantial impacted areas.

- Comment: This project might rather count as "restoration after use" than environmental compensation. 


\subsubsection{Denmark}

Although there are Danish success stories regarding restoration and habitat creation, we have not identified any specific compensation project related to the mitigation hierarchy. Positive impacts on ecosystems may, however, be included in the overall assessment for a project, e.g. additional protected forest when the Billund Airport was extended. In addition, we have not found any specific discussions regarding balancing offsets on biodiversity or ecosystem services between locations. However, there are examples of voluntary environmental compensation to offset negative impacts and to carry out large-scale restoration.

As environmental compensation is linked to different needs and plans for ecological restoration, we provide a short overview of the Danish policy on restoration.

According to the recent evaluations of the environmental objectives the Danish forest area is increasing, in particular those with high biodiversity values. The national forest program is currently under revision (2014).

The policy objectives primarily concern restoration of forests with high biodiversity values and establishment of a network of ecological connections between habitats. This focus is due to the country's relatively small forest areas, lack of old growth forests, and that the majority of landscapes are agricultural. 51

The national forest program from 2002 sets six overall objectives. Two of these concern forest ecology and biodiversity. The first objective, which is implemented by the EU LIFE program, is that $10 \%$ of the forest area $(40,000 \mathrm{ha})$ shall have biodiversity as the primary objective before 2040. This includes natural forests, old growth forests and forests with ancient management forms. The second objective (originally set by the Danish Parliament in 1989) is to double the forest area to $20-25 \%$ of the land area within 80-100 years (a generation of trees).

The largest and most famous of the Danish large-scale restoration projects is the restoration of River Skjern 1999-2002. The project included the establishment of $40 \mathrm{~km}$ new watercourses and a couple of lakes, removing vegetation and restoration of the natural hydrology by removing dams and land reclamation pumps. As with Finland and Norway (see earlier chapters), this type of Danish restoration is not part of an ex ante compensation scheme within the mitigation hierarchy.

${ }^{51}$ Nordic Council of Ministers 2004. 


\subsubsection{Iceland}

Restoration activities are currently carried out in Iceland, and in some cases compensation is demanded. One illustrative example was found in this study, see box 4.8 below.

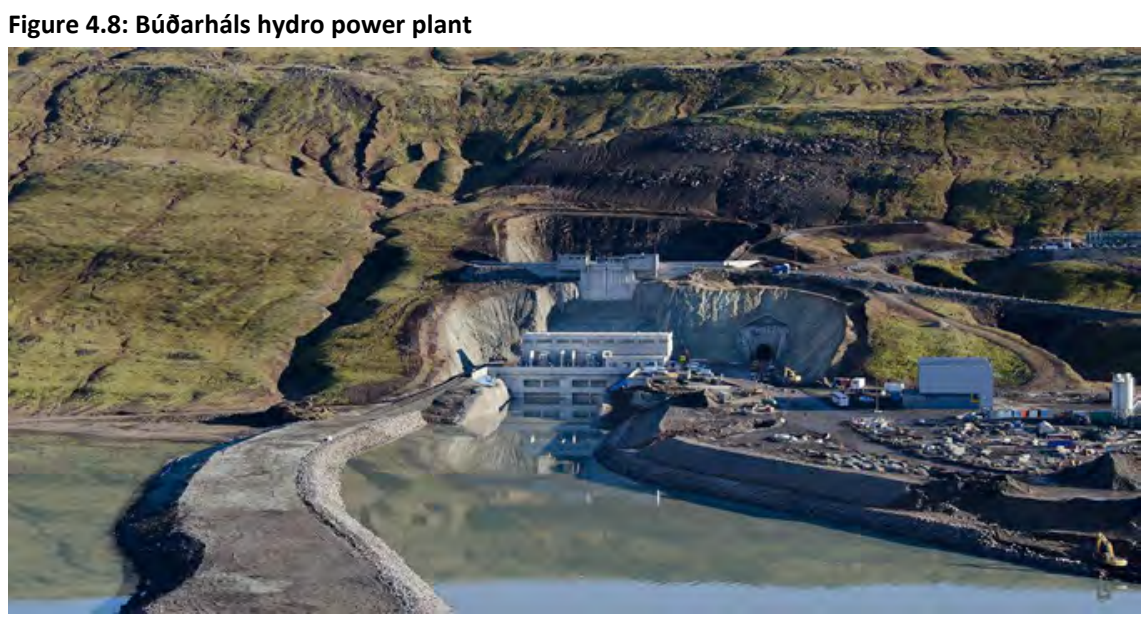

Photo: Landsvirkjun.

\section{Box 4.13: Búðarháls hydro power plant}

\section{Búðarháls hydro power plant}

- Developer and project: Energy company Landsvirkjun, building new hydropower plant and dam.

- Location: Búðarháls, south central part of Iceland.

- Impact: The reservoir is $7 \mathrm{~km}^{2}$, of which $2.1 \mathrm{~km}^{2}$ covers well vegetated land.

- Regulatory driver: The Icelandic National Planning Agency's environmental impact assessment opinion and municipality conditional permitting.

- Governmental body: Landsvirkjun. It has contracted the Ásahreppur municipal, and the Soil Conservation Service of Iceland (SCSI) to carry out the restoration measures. SCSI is responsible for planning, monitoring and consulting whereas the Ásahreppur performs the activities.

- Compensation measures: Landsvirkjun will compensate for loss of vegetated land by restoring $6 \mathrm{~km}^{2}$ eroded land nearby with the aim of increasing vegetation cover, decreasing soil erosion, and restoring function and structure of these ecosystems.

- Equivalence: NA.

- Overall compensation costs: Not public.

- Compensation cost per hectare: NA. 
- Results from monitoring: In 2009, soil erosion, amount of stones on the surface (assessment of machinery accessibility) and vegetation cover were mapped on almost $19 \mathrm{~km}^{2}$ with the purpose of assessing the conditions of the area and for selecting suitable areas for restoration. Five years later, in 2014 , the mapping was repeated on almost $8 \mathrm{~km}^{2}$ land. The restoration activities have initiated processes resulting in less soil erosion and increased vegetation. Other indications, such as patches of biological soil crust and distribution of native willows plants in the restoration area imply restoration progress.

- Challenges and solutions: Factors that limit these eroded ecosystems to recover include surface instability (frost heaving), and low moisture and nutrient retention, thus restoration measures need to overcome these thresholds. The task is to initiate natural processes through restoration measures such as fertilizing and seed augmentation. The compensation project is viewed as a long term task, and the period proposed is 40 years from 2009 to 2048.

\subsection{Key challenges}

This chapter describes lessons learned in Nordic compensation projects and the key challenges experienced.

\subsubsection{Sweden}

The Swedish compensation projects to date include more than 3,500 ha of land that has been or is about to be set aside. ${ }^{52}$ Even if there is a lack of figures on the amount of development, this suggests that compensation is a minor proportion of all land lost to human development.

The compensation projects are diverse, with some covering less than one hectare to others that cover several hundred. In one case, more than 2,000 ha were protected (see box 4.3 about Mertainen mine).

We believe that there are a lot of valuable Swedish experiences and conclusions that are relevant for other Nordic contexts. Compensation at a larger scale started in Sweden in 2003 (see case Botnia line in Box 4.1), and several large and medium compensation projects have been initi-

${ }^{52}$ Anders Enetjärn Pers. Comm. 
ated since. Further, small-scale compensation related to habitats, protected areas etc., has existed prior to 2003.

\section{Lack of clear guidelines}

The first projects in environmental compensation in Sweden and thus in the Nordic countries have been characterized by a lack of clear guidelines. The compensation projects have therefore been directed to test different solutions and construct their own method descriptions. In some cases, methods have been derived from international experiences, but in most cases the calculation of losses and gains have been conducted on a local case-by-case basis, which increases transaction costs (e.g., repeated meetings and consultations with authorities) and leads to project delays.

The case of the railway Botnia Line was also characterized by widespread protests from stakeholders. The reasons for the protests were not primarily the proposed compensation measures but rather the planning and the location of the new railway. Along the process, the protests also developed to be directed at the proposed compensation measures. The arguments were principal, meaning that losses of habitats for migrating wetland birds could not be compensated. For results of this compensation project, see Box 4.1.

\section{Low exchangeability}

The Swedish compensation projects are generally characterized by low exchangeability between different values, like habitats or species. As the process of designing the compensation is part of the permission process for the development, the county administrations often pinpoint certain species or habitats that strictly have to be compensated for. In some projects, there have been clear ambitions to simplify the processes through some flexibility in the design of compensation, but it has proven to be very difficult. Instead, complexity in terms of scaling and specific demands from the Species Protection Ordinance (see text about Sweden in chapter 4.1.1), have characterized the first generation of projects.

\section{Time delay}

One of the consequences of the uncertainties mentioned above is time delay of the development projects. Even if the Ume River Delta project covers a non-everyday landscape it deserves to be mentioned as it is often referred to as a project with major time delay for The Swedish National Rail Administration's (Banverket). The railway project's selected location was a sensitive area with strong existing environmental protection that attracted resistance from several NGOs and required four nego- 
tiations in the Environmental Court before the project and compensatory measures could be carried out. To implement compensatory measures, land acquisition through government-initiated protection of nature reserves on private land were required. This permission process caused a 2.5 years time delay for the railway project. ${ }^{53}$ Similar time losses have not occurred in other Swedish compensation projects.

It was not, however, the design and construction of the compensatory measures that caused the delay, but rather the legal trial. Natura 2000 legislation had recently been implemented in the Environmental Code when the Bothnia Line was designed and tested. This contributed to both the uncertainties and delays.

\section{High costs for compensation design}

The low degree of flexibility in compensation so far has resulted in high costs for scaling and selection of suitable areas and methods for compensation (see Table 3.1 and boxes chapter 4.2.1). However, the Swedish compensation projects performed thus far lack sufficient cost summaries.

\section{Clear targets to follow up}

The focus on individual species and habitats has resulted in clear outcome targets for several of the Swedish compensation projects and also, at least in some cases, an appropriate target follow-up.

\section{Land acquisition challenges}

In Sweden, there is plenty of land used for extensive agriculture and forestry, which can serve as potential compensation land. However, land access has been a major challenge in several of the compensation projects. Some of the compensation projects built on voluntary agreements with landowners have faced substantial costs due to the fact that supply has been very limited. These are a few of the main reasons why there is a growing interest among landowners in Sweden to start pilots to build a potential habitat bank. Further, there are legal uncertainties about whether developers can buy and own land for compensation/conservation purposes, as legislation on land ownership is mainly aimed at forestry and agricultural production.

${ }^{53}$ Marie Berglund, Pers. Comm. 


\section{Long delivery of habitats}

There are also challenges to using environmental compensation in boreal ecosystems where delivery times for many habitats are long. The Swedish compensation projects have in some cases included actions that primarily aim for nature protection (conservation) of older forests that would otherwise be at risk to be cut down, so-called averted loss. Some other compensation projects have dealt with habitats with short delivery times, e.g. Ume River Delta and "Bana Väg i Väst med".

\section{Experiences on long term management}

The compensation scheme for the railway Bothnia Line, Ume River delta, has built valuable experiences on long-term operation and management. The solution in this case was to set aside long term operation, management and monitoring to a fund with capital designed to last for 50-100 years. The amount set aside to the fund was calculated according to expected long-term management and monitoring costs and discounted to a net present value. The fund, with a strong connection to the county administration, has been in place for five years and has proved successful. The fund is run by a board with representatives from all stakeholders involved in the original compensation design process, i.e. the local municipality, landowners and farmers, local NGOs, regional universities and the Transport Administration, who was the developer.

\section{Lack of legislation for municipalities}

In Sweden, municipalities are planning for development of urban areas according to the Planning and Building Act. However, the legislation does not require compensation in the manner that other parts of the Environmental Code do. Some of the fast growing cities have introduced or are about to introduce requirements for compensation as part of planning process, but the legal support is weak and compensation is therefore often voluntary. In addition, the system becomes unpredictable when developers face different demands and requirements in different municipalities.

\section{Experiences not collected}

Today, there is no comprehensive experience feedback from the different compensation projects in Sweden. Already in 2011 at the national conferences on ecological compensation (see chapter 4.2.1), the importance of collecting experiences and best practices was discussed. 


\section{Competition distortion due to lack of consistency between sectors}

Compensation is slowly but increasingly required from land developers applying for permits according to the Environmental Code. Even if they include large extraction and infrastructural developments they represent relatively small developments at a landscape scale compared to large-scale industrial forestry that is reshaping the landscape. Extensive users of natural resources such as agriculture, forestry and fisheries are not affected by legislation to compensate residual loss but nonetheless have a broad impact on biodiversity, habitats and species. The housing development sector is another sector that today is not affected by legislation to compensate.

This lack of consistency between sectors contributes to a distortion of competition where some actors have to invest in compensation while others do not.

\subsubsection{Finland}

Current compensation-like activities in Finland are mainly related to the impacts of hydropower on fish stocks. Marttila et al. (2014) found that fish stocking requirements were found to be insufficient compensation for losses, i.e., compensation of Atlantic salmon stocks in the rivers of the Bay of Bothnia should be 5-7 times higher than current stocking levels. The report suggests that fish planting be considered one of several measures and that greater focus be given to other compensation alternatives.

Compensation of other ecosystem services other than fish production is not required, which suggests a need for compensation guidelines, best practices and improved legislation in Finland. For example, more flexible mechanisms could be for infrastructure development, which has caused impacts on nesting sites of the flying squirrel - a species protected by the Habitats Directive. Currently, construction permits are granted if negative impacts on the species can be avoided and minimized. However, this approach may not be optimal, neither from the point of view of species survival nor for infrastructure development. The use of compensation in certain cases might increase both economic and ecological benefits. However, possibilities for national decision-making on this compensation issue are limited.

As with Sweden land availability for compensation will be a challenge. Thus, special consideration should be given to the creation of incentives for private landowners to sell or rent land or act as habitat bankers. Most forests in northern Finland are stated-owned which sug- 
gests that organizations like Metsähallitus could play a significant role in ecological compensation (Metsähallitus is already now carrying out notable restoration projects).

\subsubsection{Norway}

Due to the very limited experience from compensation projects in Norway there are few specific results and challenges identified. The only explicit compensation project (expansion of E6 highway through Åkersvika Nature Reserve and Ramsar Site) has not yet entered into the implementation stage and thus there is a lack of results regarding biodiversity impacts.

A couple of challenges have been noted in the ongoing planning process in the Åkersvika project, One is related to land access for compensation and the other is related to the lack of a clear framework or guidance for the compensation procedure. However, it is important to note that this work is ongoing and no conclusion has yet been reached in terms of the final design of the specific compensation activities.

\section{Legal protection of cultivated areas}

Norway currently has a legal protection of cultivated areas. The agricultural areas are considered important in terms of the country's ability to maintain the current level of self-sufficiency regarding food supply. This means that for any development project, conversion of agricultural land should be avoided. The cumulative losses of such land in the past had led Norway to consider a system for physical compensation where cultivated areas are lost, alongside a system for environmental compensation. One road project (E18 Vinterbro) is currently testing compensation for the loss of agricultural areas.

The protection status for cultivated areas will also apply when seeking areas for compensation credits. Converting cultivated or agricultural land by restoring past ecosystems or establishing new ecosystems as a way to supply credits, is likely to be challenging in Norway. The interdepartmental working group on environmental compensation and compensation for agricultural areas recommended that valuable agricultural areas not be used for environmental compensation, and vice versa (Arbeidsgruppe kompensasjon for jordbruks- og naturområder, 2013). They suggested that alternative land should be found for environmental compensation. This effectively means that some of the most productive lowland ecosystems that in the past have been converted to agriculture are unlikely to see any substantial restoration or conversion to natural habitats with the current regulatory framework. 
The current compensation framework also affected the available options for the road expansion project in Åkersvika (i.e., the debit). The discussions of different alternatives for the highway expansion, of which several were outside the Nature Reserve, concluded that some of the options that were entirely outside the reserve were not feasible as these would result in loss of agricultural areas. During the ongoing planning and design, taking agricultural land for environmental compensation in Åkersvika is therefore strongly discouraged. This regulation also restricts the potential of restoration of agricultural areas that are currently inside the Nature Reserve and the Ramsar site.

\section{Lack of clear guidelines}

Another challenge experienced in the current compensation planning in Åkersvika is the lack of a clear framework or guideline for compensation in Norway. While the ongoing multi-stakeholder process is in itself useful, and so far appears to be productive, there are obvious future challenges in terms of ensuring consistency in planning of any future projects and predictability for developers, regulators and other stakeholders. The ongoing Åkersvika project presents good opportunities for learning and contributes to the development of knowledge for future compensation guidelines.

Figure 4.9: In all Nordic countries there is a need for clear guidelines for assessing damage and scaling compensation

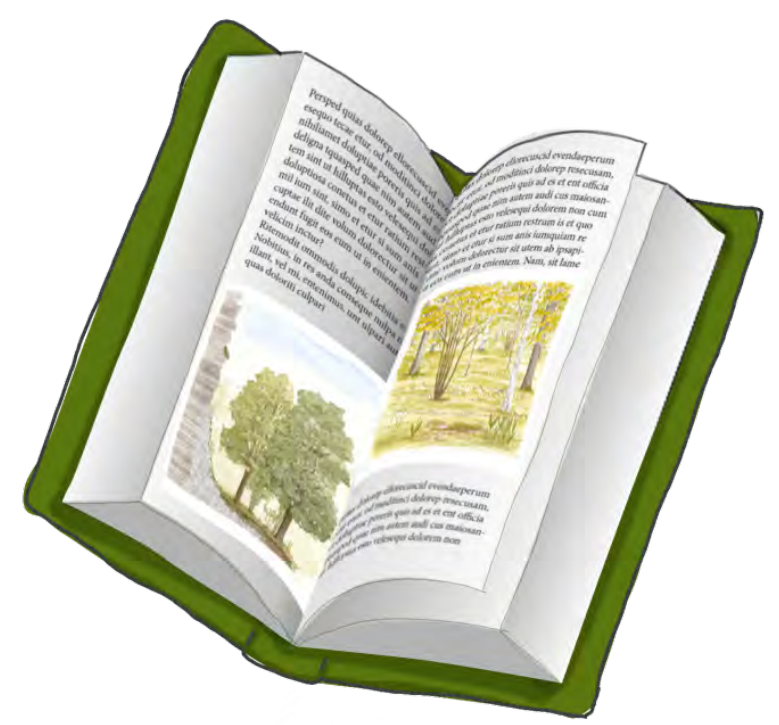




\subsubsection{Conclusion}

The Nordic circumstances vary with respect to compensation requirements and implementation. There is no specific Nordic legislation on the national level requiring proper offsetting or compensation for residual impacts on biodiversity and ecosystem services. However, there are opportunities to use the existing legislation to demand compensation in some Nordic countries. In practice, the current Nordic legislation is not designed to achieve No Net Loss of biodiversity and ecosystem services. Challenges that are shared by all Nordic countries are addressed in chapter 6.3 . 



\section{Key issues in developing a compensation framework}

A number of key issues need to be addressed in a compensatory framework if the future use of compensation is to increase in Nordic countries, whether that goal is No Net Loss of biodiversity and ecosystem services (i.e., the full internalization of external damage costs, as envisioned by the EU initiative) or some "acceptable level of loss" (i.e., based on some partial internalization of damage costs). We summarize these issues below and then recommend how best to address them in a cost effective manner in chapter 6 .

\subsection{Environmental compensation as part of the planning and regulatory process}

There is an important link between (1) the process for identifying, developing and agreeing on a compensation measure and (2) the local planning and regulatory review process for the (damage-causing) development project itself and the subsequent EIA.

Although the local planning and regulatory review process varies significantly across countries, a common thread is the need to assess environmental impacts of proposed projects and/or policies. More specifically, the vast majority of countries follow some variant of the mitigation hierarchy. As described in chapter 2.2, this suggests compensation as a "strategy of last resort" after other measures have been undertaken to avoid, minimize, and/or restore impacts. This important link suggests that any effort to improve the use of compensation should first address the context in which compensation takes place: (1) local spatial planning and (2) the EIA process.

The mitigation hierarchy is mentioned in one way or another in several Nordic regulations, but the degree to which the hierarchy is applied varies, and the last step, environmental compensation, is often ignored or used inappropriately in the existing planning and EIA processes. 
As noted, the Swedish EPA found in a survey that compensation was required in only 1 to 2 percent of 3,500 cases where the Environmental Code was applied (Naturvårdsverket 2015). Similarly, a recent UK report on planning system showed that most (95\%) of planning applications did not fulfill the requirements to consider biodiversity in planning. ${ }^{54}$ The results of these studies suggest that the effectiveness of the mitigation hierarchy is suspect, in part due to the weak implementation of environmental compensation as part of the general planning and regulatory process.

More consideration of environmental compensation early in the planning process (see figure 5.1 below) would create incentives for public authorities and developers to do more in preceding steps (avoidance, minimization and on-site restoration), and thus reduce costs for environmental compensation.

Figure 5.1: Environmental compensation should be considered when applying the mitigation hierarchy in all stages of the planning of a project, from public land use planning to de-commissioning. This would create incentives to improve avoidance, minimization and restoration

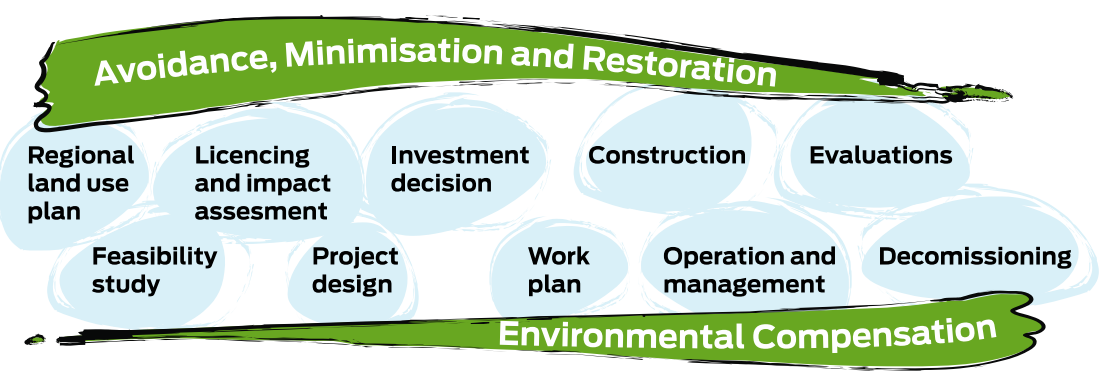

\subsection{Supply and Demand}

There are two pre-conditions for developing a functioning compensation framework: (1) demand for compensation based on a clear regulatory requirement that polluters pay to repair environmental damage and (2) a reasonable and accessible supply of compensatory credits for polluters to purchase, create, or otherwise obtain. Like the "chicken and the egg" problem, both supply and demand must be present from the beginning (see LKAB voluntary example in chapter 4.1.2).

${ }^{54}$ Ian Dickie Pers. Comm. 
The most powerful way to ensure demand for compensation is to establish a regulatory requirement and enforce it rigorously. Previous reports have shown that voluntary initiatives for compensation are unlikely to provide sufficient stimulus for demand (Cole et al. 2014). Simply put, the regulated community is unlikely to provide compensation if they are not required to pay to repair damage. The requirement can come from local, regional, and/or national authorities. Further, supranational governing institutions like the EU can support regulatory demand through broad initiatives that argue for compensation as a means for achieving key goals (e.g., NNL, Biodiversity strategy, etc.). Given recent EU efforts, it is now time for local, regional and national authorities to step up.

Information does not replace regulations but is an important complement. Hence, one way to stimulate demand is to spread knowledge about the values at stake from environmental damage. This will not only help support regulatory enforcement of compensation but may also bolster voluntary efforts by the private sector.

There are several factors that can stimulate supply. First, as with demand, strict enforcement of compensation requirements sends a signal to landowners that the regulated community will seek compensation in the future, which provides an impetus for landowners to see ecological restoration as a feasible future land use. The need to have competent service providers plays an essential role. This is analyzed in detail in the US context by Vaissière \& Levrel (2015). A successful example is the compensation broker Environment Bank of England ${ }^{55}$ whose contracts have gained access to a large number of possible landowners who each can serve as "provider".

Second, clear regulatory language provides a similar impetus as it informs potential suppliers on key points: what will be required? When? What is not acceptable? etc.

Finally, a price mechanism can be used to stimulate supply. For example, a market for the purchase and sale of compensation credits through e.g., habitat banking rewards landowners for improving the supply of credits by paying a fee to those who improve biodiversity and/or ecosystem services. This provides an alternative income for landowners. In Sweden, the large forest landowner Sveaskog is investigating opportunities to do business through ecological compensation as a complement to conventional forestry (Jessica Nordin, pers. comm.).

${ }^{55}$ Guy Duke, Pers. Comm. 
One conclusion in a Swedish scenario analysis about possible futures for habitat banking (Enetjärn Natur et al. 2015), strengthens the thesis that both supply and demand must be present from the beginning. The study concludes that the state alone will not push the issues. If the business community sees clear incentives for environmental compensation, the implementation will gain momentum. However, initially, a new system might have rules allowing a delay in compensation of maybe 2-3 years, to allow supply to "catch up." 56 Another option could be to focus less on estimating the debit in that initial period and focus more on ensuring the availability of credits

Figure 5.2: Like the chicken and the egg problem, both supply and demand must be present from the beginning. If the business community sees clear incentives for environmental compensation, the implementation will gain momentum

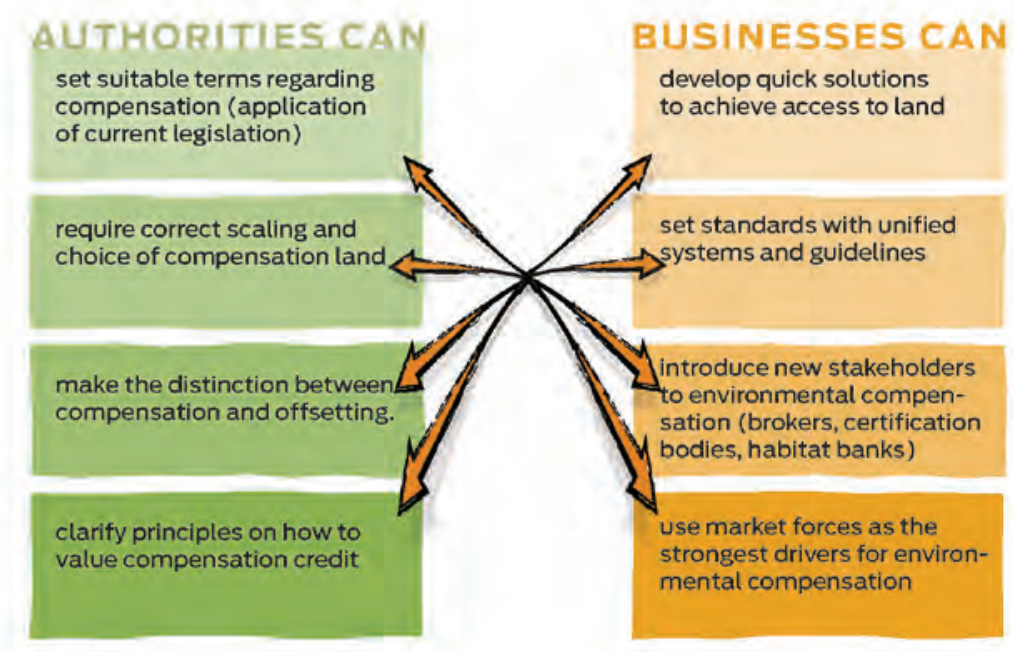

Importantly, both demand and supply are needed together. For example, it is challenging for policy makers to require compensation if they are uncertain whether a supply will develop in a reasonable timeframe. On the other hand, supply is unlikely to develop unless there are requirements for polluters to compensate for residual impacts.

56 Ian Dickie, Pers. Comm. 


\subsection{Cost-effectiveness considerations}

As noted in chapter 3.2 this report focuses narrowly on the financial costs of assessing and providing compensation, which are the most relevant costs in the sense that they can be affected in the design of a flexible and cost-effective compensation framework.

There are several strategies available for minimizing costs (i.e., transaction, scaling, investment, and long-term management costs) within a compensation framework. We describe these strategies below.

A few key starting points for this chapter:

- Flexibility. A compensation requirement per se is not flexible, as it imposes demands on actors. But these demands may be imposed in more or less flexible ways. This chapter identifies variables that can be adjusted within a compensation framework to reflect varying levels of flexibility and effectiveness.

- Cost effectiveness. An economist considers a policy measure to be more cost effective than another if it achieves the same objective at a lower total cost to society. This chapter considers the costeffectiveness of alternative approaches for reaching NNL, which requires consideration of transaction, scaling, investment, and longterm management costs. Any policy designed to minimize costs associated with NNL is inherently dependent on what constitutes NNL. The NNL objective is more difficult to define compared to other environmental policy objectives like reducing air emissions by a specific amount or reaching a defined environmental state. Given the imprecise definition it is difficult to separate the target from the means to achieve the target. The implication is that some strategies to minimize costs are associated with different views on what constitutes NNL. More flexible views on the interpretation of NNL may lead to greater opportunities for cost minimization.

- Relation to other compensation costs not included. There exists a trade-off between costs to avoid or minimize damage and the costs of compensating for residual damage. The more damages that are avoided or minimized in the earlier steps of the mitigation hierarchy, the less compensation will be needed, resulting in lower overall compensation costs. Finding the right balance between avoiding, minimizing and compensating is an important aspect of the costeffectiveness of environmental protection. However, this chapter focuses on exclusively minimizing financial compensation costs. 
Below we describe seven general strategies for minimizing compensation costs and summarize these in Figure 5.10. In general, the first five strategies aim to make the processes less time consuming and more predictable, while the last two (habitat banking and flexibility in key variables) provide a host of cost-reducing benefits across all compensation costs.

\subsubsection{Dissemination of experiences}

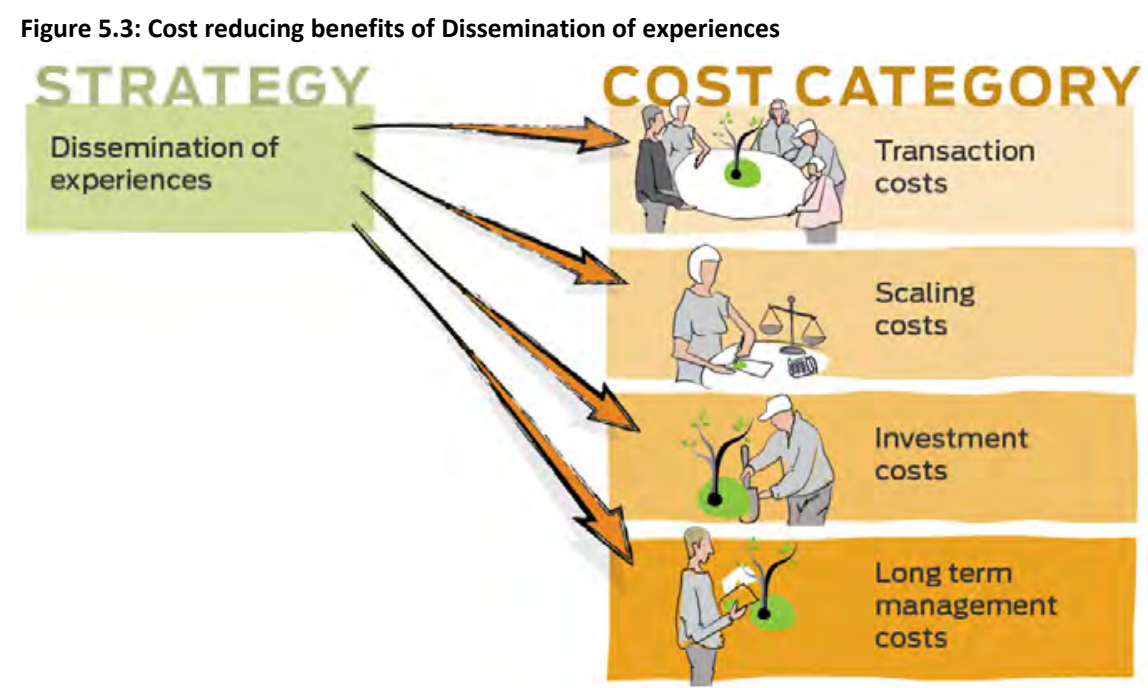

The development and dissemination of experiences is a crucial factor for minimizing transaction costs, by making actors more knowledgeable of the decision processes, developing best practices and legal praxis, etc. While this can be time consuming, efforts can be made to improve the dissemination, by creating networks, organizing workshops and seminars, developing guidance, collecting and sharing experiences in national or multinational databases etc. This implies that government, as well as NGOs and other interested participants, can play a key role by actively promoting information-sharing. 


\subsubsection{Regional management/Land use plans}

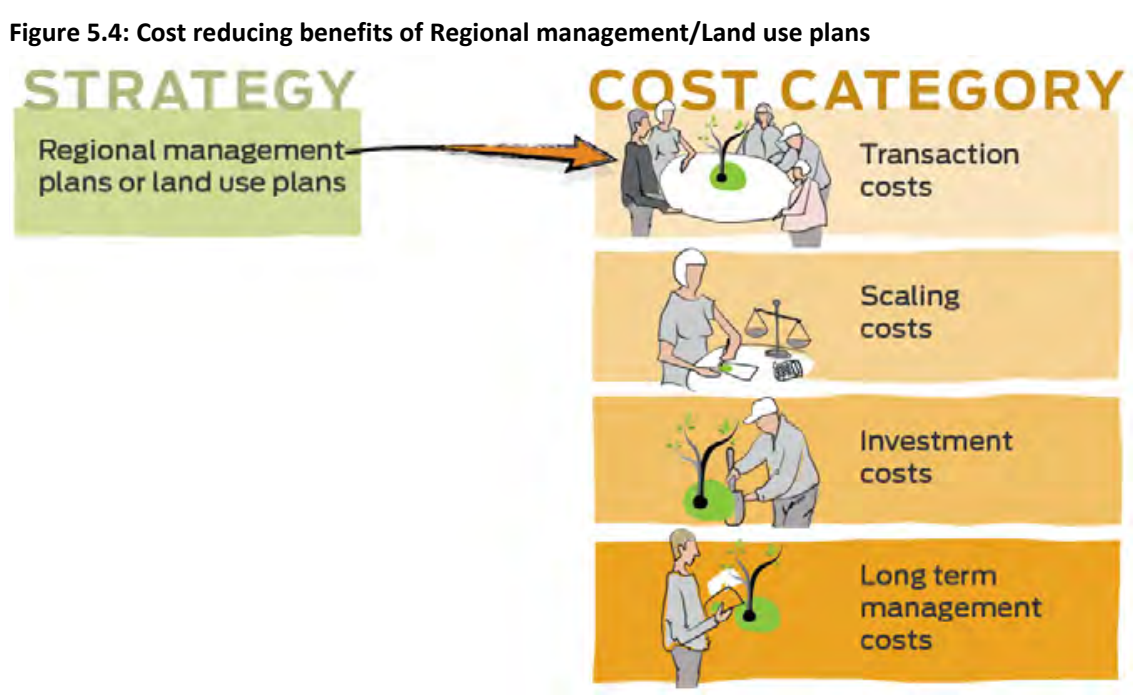

To make decision processes more predictable to developers and to make the administrative processes more efficient among the responsible authorities, regional management plans can be a practical tool. These instruments help identify geographic areas with particularly valuable biodiversity components and ecosystem services where impacts should be avoided and/or minimized (debit side). Further, these plans can identify priority areas for restoration, which can lessen search costs for developers associated with obtaining information on the location of biodiversity hotspots and the supply and value of ecosystem services (credit side) (Merkel, Keith, pers. comm.). This approach is in line with the Swedish EPA's ongoing work with regional strategies for Green Infrastructure (Jörgen Sundin, pers. comm.).

When developers and the authorities share a common view of general structures for environmental compensation, including key metrics in a region (which can help reduce scaling coasts), it is more likely that preliminary suggestions on compensation are in line with what the authorities will approve. Examples of such plans could be the spatial planning of a municipality, identifying areas of national, regional or local importance for different aspects. Such plans could play an essential role in improving the way cumulative impacts are dealt with in administrative systems. One example is the wetland planning of the municipality of Chamérby in the French Alps (Quétier et al., 2014). The restoration of 85 ha of wetlands around the city of Chamérby will be partly funded by developers through offsets for impacts on wetlands. 


\subsubsection{Administrative Systems}

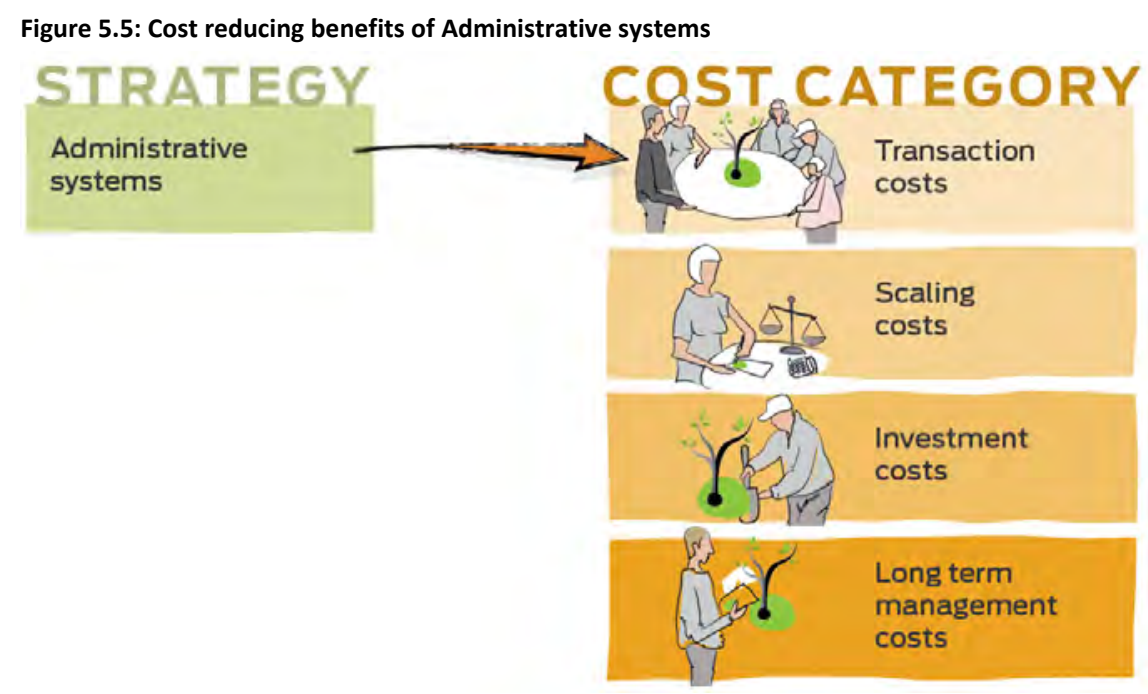

Efficient systems for administrating a compensation framework can reduce transaction costs. For example, well-developed administrative systems should ensure clearly defined responsibilities between different authorities, as well as between authorities and responsible parties. Further, they should ensure predictability and clarity within the compensation framework. Ambiguity regarding different responsibilities under compensatory demands (e.g., what is required of responsible polluters and who reviews and approves compensatory plans?) can drive up the overall cost of compensation by delaying the process and undermining trust in the system. This underscores the importance of establishing credible governing institutions to oversee the compensatory process.

Another important component of administrative design is to integrate compensation development and review into existing development planning processes on the local level, rather than establishing a separate and incremental layer of project review for compensation (see chapter 5.1). But compensation frameworks may also consider the counterargument: that compensatory scaling knowledge is best utilized when it is concentrated among a core group of experts to ensure innovation in identifying and scaling credits. 


\subsubsection{Clear guidelines for compensation}

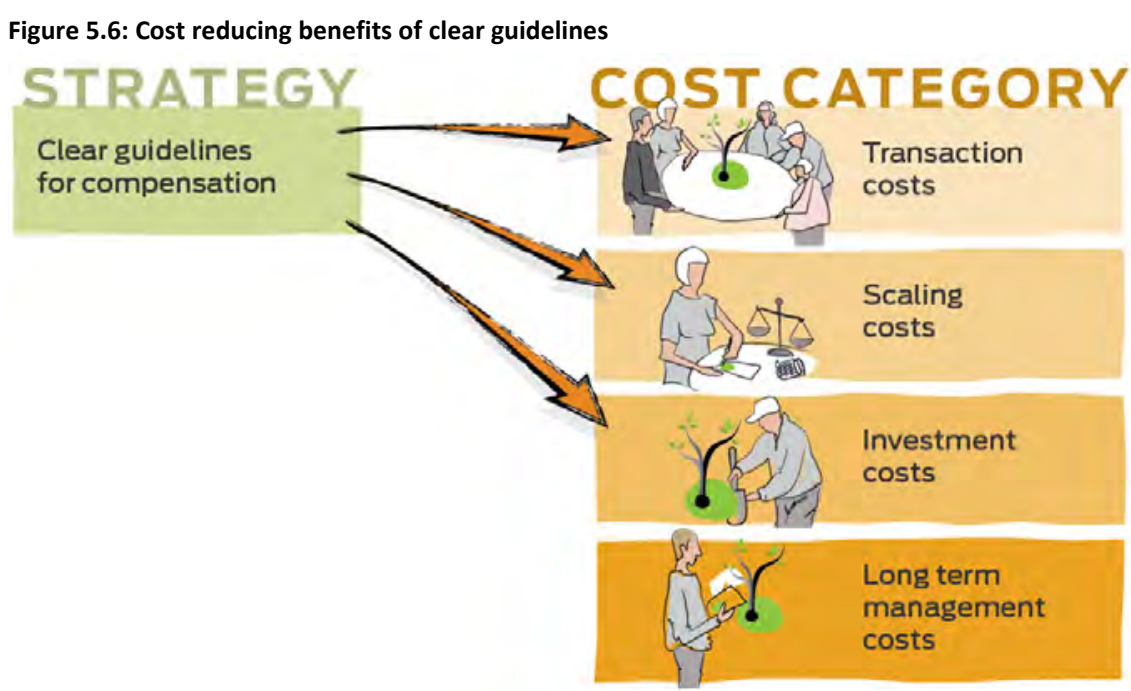

Clear guidelines from authorities help to minimize uncertainty with the process of assessing damage and scaling compensation. It can help reduce costs by making clear what is acceptable in terms of scaling methods and ensuring more predictability in the process (See chapter 4.2.1 about the Swedish EPA:s on-going efforts to develop guidelines).

\subsubsection{Best management practices for compensation projects}

Figure 5.7: Cost reducing benefits of Best Management Practices

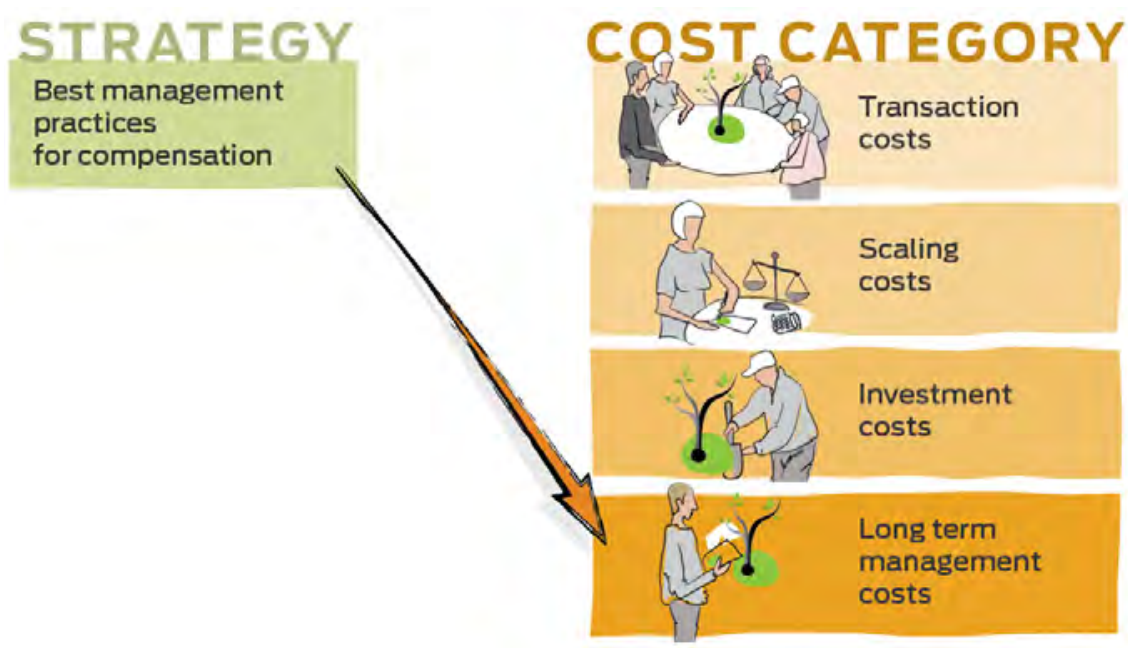


Long-term operation, monitoring and evaluation ("long-term management costs") is a necessary step in a compensation project that also demands resources. In order to ensure cost-effectiveness while securing "delivery" of biodiversity and ecosystem services over time (the objective of compensation), we recommend that long term management plans are clearly defined for any compensation project. The World Bank (1998) has the following recommendations for monitoring and evaluation of a biodiversity project (as supported by BBOP 2009):

- A clear set of objectives or goals, including clearly stated questions on how these objectives could be reached.

- A clear set of indicators to measure progress towards project objectives.

- Specific details on how and when monitoring and evaluation will take place, and who will undertake specific activities.

- Identification of any training, capacity-building or financial resources that will be needed to ensure necessary activities are adequately carried out.

- Identification of the intended audiences that will receive the results of a monitoring and evaluation plan.

- Specific details on how information and results from monitoring and evaluation activities will feed back into project management decisions.

- Identification of clear "decision points" when negative trends lead to corrective actions in project implementation (World Bank 1998).

Fulfilling these recommendations is likely to lead to cost effectiveness while securing good monitoring. As a Nordic example, the long-term management in the Ume River Delta compensation project fulfills the recommendations above on monitoring and evaluation set by the World Bank (see Box 4.1 and chapter 4.2.1 for description of this case). However, for small-scale compensation projects (e.g., related to Swedish habitat protection areas) it might be unreasonable to require advanced monitoring. 


\subsubsection{Flexibility in key compensation variables}

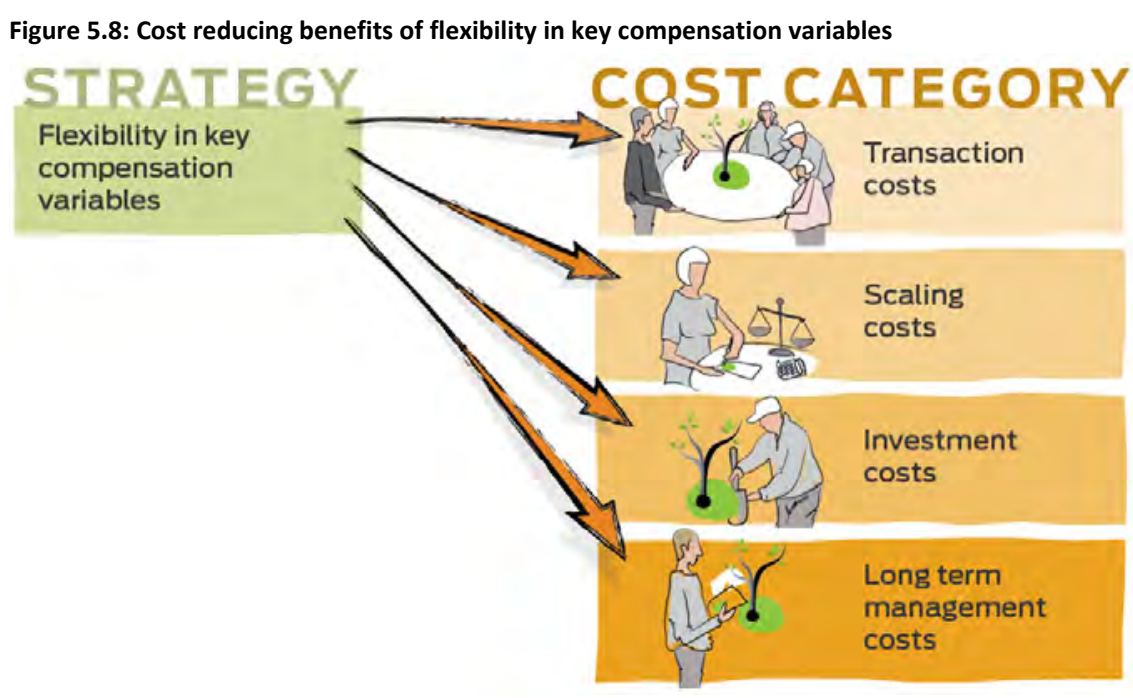

Ensuring flexibility in how the NNL objective is reached has the potential to reduce a variety of costs, including transaction, scaling and investment costs without reducing the overall environmental benefit, but its implementation may face some upfront costs.

The interpretation of the No Net Loss concept affects the scope for flexible solutions. The degree of flexibility in a system depends upon the ambition and policy targets. If the goal is to ensure No Net Loss in a strict scientific sense, there is probably little room for flexibility. However, if one is prepared to accept a greater risk of not achieving a strict interpretation of No Net Loss, the flexibility of the system can increase. Determining an appropriate balance in this question is beyond the mandate of this report.

In this report, we define flexibility as allowing a range of definitions for a key set of compensation variables, which can be adjusted for any given compensation context. The relationship between flexibility and cost effectiveness is important. Cost effectiveness can only be defined in relation to a specific objective: what are we trying to achieve and what is the least costly way of achieving it? In our case, it is challenging to define our objective because NNL can be interpreted in different ways. For example, a very strict interpretation of NNL might prevent all environmentally harmful activities and thus make a discussion of compensation meaningless. Therefore, flexibility is necessary in defining our objective and in defining alternative ways of reaching that objective. 
We assume that flexibility will ultimately allow more cost effective solutions. However, it is possible that over the medium term (while the system is being worked out and "tested"), flexibility may lead to a rise in disputes and different interpretations about the appropriate amount of flexibility (see "range of definitions" above). Consequently, scaling and investment costs might increase during this period. On the other hand, starting with inflexible and detailed requirements is likely to reduce the potential for cost minimization, and ultimately inhibit the level of innovation and the development of cost-effective compensation systems. One example of providing flexibility is to develop compensation schemes that focus more on habitats that provide beneficial structures for many species, rather than a strict focus on individual species.

Flexibility, in turn, requires subjective decisions about how to value different outcomes, i.e., trade-offs. Just as consumers assess the classic "price vs. quality" trade-off (should I buy a cheap car of questionable quality or an expensive and dependable one?) so too must policy makers consider a set of trade-offs in developing a compensation framework that fulfills NNL. ${ }^{77}$ Below, we identify five relevant trade-offs, and discuss alternative ways of interpreting them. Figure 5.8 provides an illustration including the implications for cost-effectiveness.

- Exchangeability. What type of resource(s) can be exchanged for what other type of resource(s) in everyday landscapes? And what types of resources are so important or rare that it is "too risky" to allow for exchanges?

- Location. Where can such exchanges take place relative to where the damage occurred?

- Amount. How much is enough compensation and how do units of measurement and definition of baseline affect this calculation?

- Time. How is the amount of compensation affected by the time at which the benefits from compensation accrue to the public (or the time it takes for a damaged environment to recover)?

- Framework complexity. How to balance quick and effective damage assessment with more sophisticated assessments when needed?

\footnotetext{
${ }^{57}$ Importantly, what is considered an acceptable trade-off will inevitably differ in everyday landscapes compared to protected landscapes, habitats or species.
} 


\section{Exchangeability of loss for gain}

The exchangeability criteria can range from strict to flexible. A strict view is that all environmental damage should be compensated with an identical resource, especially in the case of endangered or threatened species. ${ }^{58}$ For example, a specific type of lowland habitat might only be compensated through a credit that restores that same type of lowland habitat. But even this interpretation could have some limited flexibility, through provision of a wetland of similar characteristics, e.g., supports similar species. An even more strict form of exchangeability would focus on single species. This inflexible interpretation is sometimes called "likefor-like" compensation, and in some cases "like for like or better".

An alternative, and more flexible, approach might allow trade-offs between different resources types, i.e., "like for unlike" compensation. In this case, a certain wetland habitat might be replaced by another type of wetland habitat, e.g., trading reedbed with wet grassland. Allowing such flexibility can be challenging in terms of identifying metrics - i.e., if the debit and credit represent different resources, it can be difficult to agree on a metric for assessing fair compensation. Allowing flexibility and reducing costs might also improve environmental outcomes, if properly scaled. For example, a loss of deciduous forest habitat with birds and insects may be replaced with the restoration, protection and long-term management of a similar, nearby deciduous forest (see case Ludvika mine in chapter 2.4). In this case, we create the beneficial structures for the species rather than re-create the individual species themselves.

Yet another alternative for increasing flexibility might be to consider the use of so-called "ecosystem service" offsets rather than biodiversity offsets. An ecosystem services approach may provide a more flexible and cost-effective interpretation in some cases. The goal of this approach is to avoid a strict focus on the damaged and restored resources themselves (habitats or species), and focus instead on the underlying ecological function of these resources in terms of the benefits they provide society, i.e., ecosystem services. In this way, one might be able to replace certain underlying functions by restoring a different ecosystem service that still provides the same "end benefit" to society. For example, compensation in fast-growing urban areas should consider recreational values. In this case, it may be appropriate to complement a biodiversity offsetting approach with a broader ecosystem services assessment of recreational use (when, where, how often, what type, etc.) to ensure victims

\footnotetext{
${ }^{58}$ In most cases, damage to threatened or endangered species would be avoided or minimized and not allowed to be considered "residual" damage. But this may vary, especially in everyday landscapes.
} 
are fairly compensated. However, we do not suggest that these two approaches are inter-changeable, i.e., biodiversity benefits should not be substituted (or compensated for) through the provision of ecosystem services. Instead, we see ecosystem services as an additional criterion within a compensation framework that ensures social welfare is maintained. Further, note that this issue is being discussed within an EUsponsored project to better define No Net Loss. ${ }^{59}$

Most of the Nordic examples presented in this report (see boxes in chapter 4.2 and Ludvika example in chapter 2.4) represent a moderate rate of exchangeability, with a focus on broad definitions of habitats and seldom on single species. A relevant summary can be found in Table 1 in Quétier et al. (2014), which links different assumptions about exchangeability to different interpretations of "weak and strong" sustainability.

\section{Location}

A key trade-off is deciding where the compensation project should be located in relation to the debit. The anthropocentric basis for compensation suggests that equity plays a role, i.e., victims of damage should reap the benefits of the credit. A very strict approach would require compensation at the same location to the extent possible (i.e., within the same watershed or other natural boundary). The potential for flexibility arises from deciding how close to, or how far away from, the damaged site the compensation should take at place.

Decision-makers must consider gray areas: even when offsite compensation is considered acceptable, perhaps this might still require some reasonable geographical limitations? On-site compensation is not always possible and therefore requires some flexibility. Green infrastructure planning is one way of guiding this decision-making process as it relates to flexibility between on-site and off-site compensation.

\section{Amount - dealing with metrics, baseline, and uncertainties}

In addition to the distributional considerations for compensation (i.e., who gets the slice of pie?) there is the question of quantity (how big should the pie be?). Two key trade-offs for policy makers in this context is the selection of an appropriate metric for measuring loss and gain and the definition of baseline, both of which ultimately affect the amount of compensation.

${ }^{59}$ See Operational Potential of Ecosystem Research Applications (OPERA) Project Workshop on workshop on incorporating ecosystem services (August 2015). 
A flexible interpretation might allow a more generous and open judgment of the quality of different metrics, such as measuring the final benefits and ecosystem services, rather than the resource itself. A stricter and potentially more expensive approach might require specific metrics for certain types of loss (e.g., habitat loss can only be measured in quality-adjusted ha). Alternatively, it may require "trading up", i.e. providing credits that are of equal or higher value than the debit, to better safeguard NNL. Thus, decisions about appropriate metrics have direct effect on cost-effectiveness by influencing the amount of required compensation.

The definition of baseline - i.e., what would have happened to the damaged or compensated site in the absence of the development or compensation - also affects the amount of compensation. A strict "return to baseline" approach may seem reasonable but reaching baseline may not be technically feasible, may be feasible but expensive, or may no longer be relevant in a context of global climate change where new baselines are being established. A more flexible, and likely more costeffective, interpretation might see baseline as a moving target due to dynamic ecosystems, and allow more flexible measurements of debits and credits. A current debate in the restoration field questions the use of "rigid baselines" and suggests that society could spend less resources trying to restore identical ecosystems, especially if the alternative provides comparable value (Hobbs et al. 2009).

Other factors may affect the amount of compensation but are more difficult to influence in terms of cost-effectiveness. For example, compensation multipliers are sometimes used to account for risk or uncertainty (where realization of a credit is riskier than the expected loss) or to account for time lag (credit may be enlarged to account for late delivery). In these cases, the amount of compensation may be associated with risk predictions or economic measures of time preferences, rather than subjective trade-offs. In the Ume River Delta project multipliers where used to account for risk and uncertainty (see Box 4.1).

\section{Time}

Policy makers face decisions about when a compensation credit should be delivered relative to the debit and, if necessary, how to make adjustments when debits and credits occur at different times. Several timing issues may arise in a compensation case: How to assign value to a credit that takes 20 years to begin providing benefits? When can a habitat bank begin selling a slow-maturing credit? How long should a compensation project last, or be safeguarded? How to quantify a debit or credit for a project that will last forever (i.e., in perpetuity)? 
The key question is how time should affect the amount of compensation. A strict approach would require compensation credits to be in place and deliver benefits at the same time as (or even before) the damage. But this is un-realistic because (1) most credits take time to mature and (2) such demands can lead to significant delays for development projects and subsequently high economic costs for society (ex post compensation schemes can, by definition, only provide compensation after the damage has occurred).

A necessarily more flexible approach would allow a time difference between credits and debits, but take several precautions to ensure fair compensation. For example, one way of allowing flexibility with respect to time is to rely on the "interim loss" model (see Figure 2.2) that applies social discounting to the value of loss and gain. ${ }^{60}$ Economists use discounting to adjust the value of, and thus be able to compare, a loss or gain that occurs at different times (Cole and Kriström 2008). While it provides a useful methodological approach, the selection of an appropriate discount rate to use for assessing these types of social and environmental investments is inherently subjective. To address this problem, most countries point to economic guidance documents with specific discount rate suggestions to ensure consistency of project appraisals.

Another way of dealing with the inherent but necessary risks of allowing "time flexibility" is to require insurance for developers that can be applied if things go wrong in the future: i.e., bonds for compensation projects that fail or 3rd party verifications. Yet another way of dealing with time is to encourage developers in large-scale projects to implement pre-planned compensation measures, similar to habitat banking. For example, in the UK Thames Estuary port developments have preplanned compensation measures and implemented them, i.e., restored habitats and moved selected species to these new sites, without any delays. A similar example arises in California where port authorities were encouraged to "over-compensate" for certain dredging projects in order to have easy access to credits when dredging would be required again in the future (Robert Hoffman, NOAA, pers. comm. 2014).

${ }^{60}$ Note that discounting also provides an answer to the "forever" problem, as dividing the total value (i.e., the debit or credit measured in monetary or non-monetary terms) by the discount rate provides a "finite" measure of loss or gain (see e.g., Cole and Kriström 2008). 
Another trade-off related to time is deciding when to include compensation in the planning (see Figure 5.1). Late inclusion might raise costs but it encourages the project planner to include proper mitigation and avoidance. Early inclusion might lower costs and even steer development projects to less costly habitats, thus removing the need for compensation. Regardless of when compensation is included in the planning process, the simple existence of a compensation requirement imposes costs on developers, and thus creates a strong incentive for them to avoid and mitigate compared to a scenario without a compensation requirement.

\section{Framework Complexity}

A final trade-off to be considered is the complexity in the regulatory framework itself. A rigid approach may suggest a complex system of monitoring, verification, and administrative review to ensure that lost biodiversity and ecosystem services are adequately replaced. It might establish rules, specific guidelines, and several "checks and balances" in the regulatory system. But the development of complex institutions and additional rules raises transaction costs for both authorities and developers and - despite the best intentions - may not improve the actual chances of reaching NNL. A more flexible alternative might allow for streamlined review, simpler rules on exchangeability, and reduced administrative burden. This system would emphasize predictability so that small-scale damages can be compensated quickly and cost-effectively, but allow for increasing levels of complexity for large-scale damages. As an example, the ex post compensation system in the US categorizes damage assessment according to the level of sophistication needed to measure debit and credit: Type A assessments rely on standard computer models with simplifying assumptions, while Type B assessments are used for complicated damages that require a "case-by-base" approach. 61 Importantly, both types follow the same step-by-step process, but the former is more predictable and less time-consuming.

A third alternative (which describes the status quo) is to weakly enforce compensation requirements, but this is unlikely to reach the No Net Loss goal.

${ }^{61}$ See e.g., US Code of Federal Regulation for Natural Resource Damage Assessment under the Department of the Interior (43 CFR 11). 


\subsubsection{Supplying credits through habitat banking}

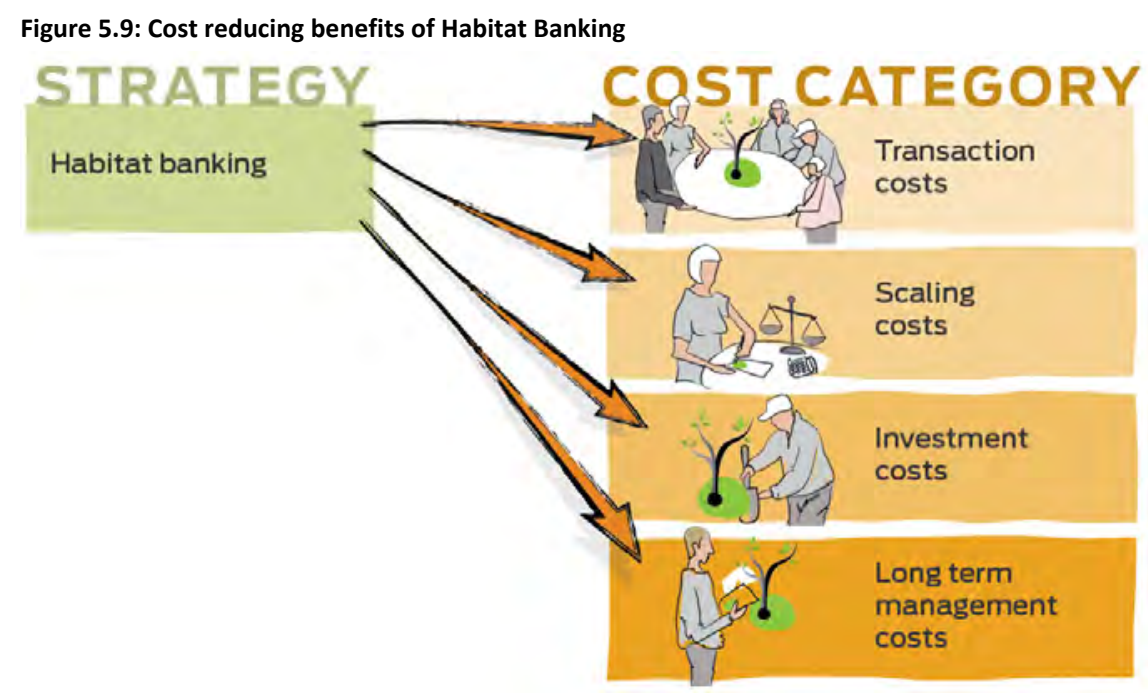

There are three ways of supplying compensation credits (see pros and cons in Box 5.3): (1) De novo (on a case by case basis), where developers propose and carry-out a compensation project on or off site for each specific development (this is the most common provision of compensation in Nordic countries today); (2) payment-in-lieu of funding, where developers pay a fee that is collected in a fund and used for future compensation actions; or (3) habitat banking, where a 3rd party invests in natural capital through e.g., restoration, preservation, etc. and sells these investments as credits to developers (see Box 5.1 and Nordic examples in Box 5.2).

All three approaches represent viable options for supplying credits but habitat banking is a promising option. Some of the key benefits of habitat banking include:

- Provides an easily accessible and cost-effective supply of compensation credits based on institutional knowledge and understanding of compensation requirements.

- Reduces the risk that other individual landowners utilize a monopoly position in being suppliers of land for compensation credits. The important aspect of a habitat banking system is that it keeps the costs of entry low to encourage several suppliers and ensure competition among them. 
- May increase likelihood of compensation success by concentrating expertise in institutions over the long-term and by the process of initiating and monitoring compensatory projects a priori (i.e., banks often have credits "up and running" before the developer arrives to buy them).

Habitat banking means cost effectiveness through the use of market incentives. The same environmental goal can often be achieved in several ways but environmental markets (such as carbon markets and habitat banking) provide a more cost-effective approach, provided the market regulations are properly set (Cole et al. 2014). For example, by establishing a bank, and then providing credits for sale at a specific price, this provides important price and quantity information to the market based on an actual offset. This may stimulate cheaper credit suppliers to come forward (on the supply side), while also providing important information to developers (demand).

In Finland, Rämö et al. (2013) conducted a mail survey for private forest owners participating in co-operation networks of METSO forest conservation program. About $40 \%$ of the respondents were found to be interested in acting as sellers of environmental values in a banking system. In Finland, like in the other Nordic countries, the majority of land is privately owned. In order to guarantee sufficient supply of suitable compensation areas, engagement of private landowners is essential. Families that own forests can often have strong emotional attachments to their forests and because of that, their willingness to sell forestland to companies needing land for compensation or to other entrepreneurs may be minor (Knivilä et al. (2014). For these private forest owners, more attractive alternatives might be to either act as habitat bankers themselves or renting the land for a habitat bank entrepreneur for a limited time period.

Habitat banking has become increasingly salient in Sweden. A recent article (MiljöAktuellt 2013) ${ }^{62}$ stressed the importance of incentives: "the only way to get different actors - both public and private - to increase the supply of natural capital is to do it on their terms. Ecosystem services need a price tag to ensure that it is costly to damage ecosystem services and profitable to provide them."

${ }^{62}$ MiljöAktuellt 2013-06-17 (http://miljoaktuelltidg.se/2.1845/1.512924/debatt-ekologisk-kompensationfar-inte-bli-exploatorernas-fribiljett). 


\section{Box 5.1: What is habitat banking?}

\section{What is habitat banking?}

Habitat banking is a potentially cost-effective way of delivering compensatory credits compared to a scenario where each developer creates his/her own compensatory gains "from scratch". It relies on market incentives to encourage entrepreneurs to invest in restoration (thus improving the supply of ecosystem services) in the hopes of earning a financial return in the future when they can sell "compensatory gains" to developers (buyers) who are required to offset their impacts (or, who do so voluntarily). The market structure provides an added benefit in meeting an environmental objective such as No Net Loss (NNL): it seeks the lowest cost option first, which ensures cost-effectiveness.

Habitat banking is defined as a market where credits from actions with beneficial biodiversity outcomes can be purchased to offset the debit from environmental damage. Credits can be produced in advance of, and without exante links to, the debits they compensate for, and stored over time (eftec, IEEP et al. 2010).

The motivation for developing habitat banks is to ensure that parties responsible for damaging activities pay for/restore the damage (by internalizing the cost of such damage, this may prevent such actors from causing damage in the first place). But it also rewards those who invest in conservation by putting a price on ecosystem services, as long as ecosystem services are part of the metrics. Habitat banks may also benefit from economies of scale in restoration, providing both ecological and cost-saving benefits compared to a fragmented approach to individual compensation projects.

However, there are potential risks. Some argue that it creates perverse incentives for developers by lowering the threshold, leading to a "license to trash", while others question whether it actually leads to "additionality" (i.e., will credits sold simply displace activity to do things that would have happened anyway?). (see also Box 5.2 below on Finland). 


\section{Box 5.2: Exploring habitat banking in Finland and Sweden}

\section{Exploring habitat banking in Finland and Sweden}

Enetjärn Natur and Kairos Future, in a 2015 report for Skogssällskapet, identified two considerations (uncertainties) that will affect the future development of habitat banking in Sweden:

- Degree of flexibility set by the legal framework in how biodiversity offsetting can be realized, level of detail in regulations and methods for balancing of biodiversity losses and gains.

- Extent of environmental awareness about biodiversity conservation targets.

Kniivilä et al. (2014) examined the applicability of habitat banking to Finland. However, the results can also be applied to environmental compensation in general. The authors list several factors that may support the implementation of habitat banking in Finland, including:

- Well-functioning institutions and governance

- Strong ecological knowledge for measuring sufficient compensation

- Significant experience in restoration activities in Finland, especially in Metsähallitus (organization governing state-owned forests).

- Private Finnish companies have expressed interest.

- Private forest owners may find habitat banking to be attractive based on positive experiences of the voluntary forest biodiversity conservation program METSO.

The authors also identify challenges and limiting factors:

- Finding compensation sites that are ecologically valuable and close to development sites.

- Lack of voluntary demand for compensation credits, suggesting need for legislative change.

- Uncertainty in potential future supply (and demand) to ensure economic viability. 


\section{Box 5.3: Alternatives to Habitat Banking: Pros and Cons}

\section{Alternatives to Habitat Banking: Pros and Cons}

De Novo. Developer provides compensation on case-by-base basis:

- Pro: Site-specific data collection ensures accurate picture of debit and credit.

- Pro: Compensation project can be linked to local management plans.

- Con: Costly compared to habitat banking due to high (and repeated) fixed costs for each compensation scaling.

Payment-in-lieu. Developer pays fee to a fund that is used for future compensation actions:

- Pro: Flexible if relevant compensation alternative cannot be readily identified in local area.

- Pro: Small compensation measures can be pooled and contribute more to common biodiversity or ecosystem services targets.

- Pro: The design can be cost effective compared to the case where each developer has start-up costs for compensation.

- Con: Money may become stuck if the fund managers lack incentives to spend resources.

- Con: May be difficult to ensure equivalence debit and credit if (1) time delay between payment of fee and use of restoration funds or (2) if fund lacks guidelines on when and how to use funds.

- Con: In theory the fee should cover the full value of biodiversity and ecosystem services, but often captures only a small portion of value. 


\subsubsection{Summary of strategies to minimize compensation costs}

There are various strategies for minimizing the different types of compensation costs (Figure 5.10). In some cases, a single strategy applies equally to several different cost categories. For example, habitat banking (1) reduces transaction costs by facilitating the matching of buyers and sellers; (2) reduces scaling costs by providing "ready solutions" as compensation credits; (3) reduces projects costs through economies of scale in project design; and (4) reduces management costs over time as profitdriven banks improve the efficiency with which they deliver long-term monitoring and evaluation.

Figure 5.10: Cost minimization strategies and their effect on the compensation cost categories

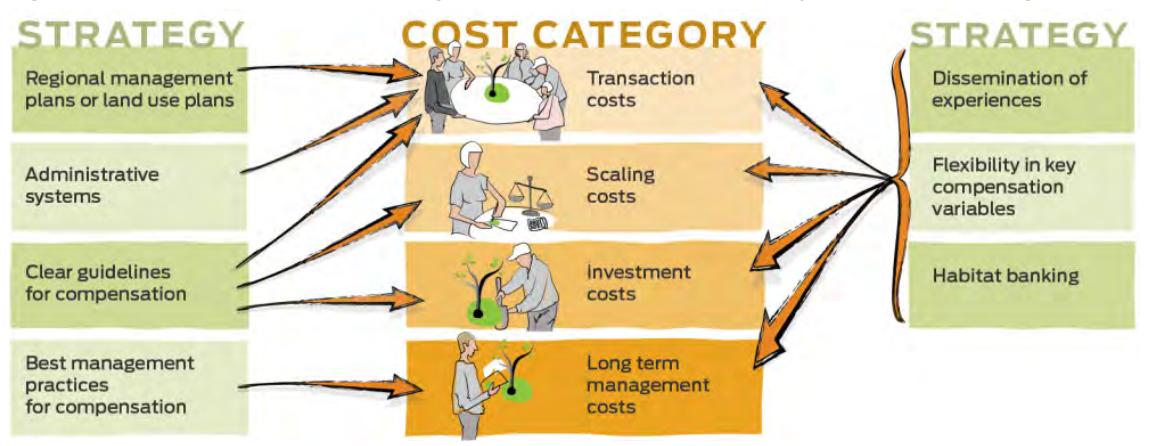





\section{Recommendations for increasing the use of environmental compensation in Nordic countries}

In recent years there has been an evolution in thinking about environmental values. While this shift may be driven in part by explicit changes in environmental regulations across countries, it also includes an implicit change in social norms about what is and what is not acceptable in terms of our impact on global ecosystems - and what we should do to repair or offset these impacts. One result of this change is increased requirements for environmental compensation in countries like the US, Germany, Australia, France, and England. More recently, this change in social norms on ecosystems can even be seen in the Nordic countries, in particular Sweden.

Changes in social norms tend to occur slowly over time, as can be seen in similar shifts in citizens' preferences or mindsets on issues like smoking in public places, child labor or wearing seatbelts. This shift in how we view biodiversity and ecosystem services can even be seen in the private sector. For example, at a recent conference on the environmental code in Sweden, a Boliden Mineral business representative suggested that "Environmental compensation is a reasonable and natural expectation when a company's development negatively impacts areas of high environmental value." 63

Below we make a number of recommendations for the Nordic Council of Ministers and decision-makers at the national level in Nordic countries on how to increase the use of environmental compensation. While the ultimate goal should be to reach No Net Loss of biodiversity and ecosystem services, we believe a realistic short-term goal of increasing compensation should be based on an "acceptable level of loss." The rec-

${ }^{63}$ Anders Forsgren, Boliden Mineral, at Miljöbalksdagarna (19-20 March 2015) "Ekologisk kompensation är rimligt och naturligt att genomföra vid anspråktagande av mark med höga naturvärden." (Environmental compensation is reasonable and natural to implement when developing land with high conservation values). 
ommendations incorporate international best practice and are applicable to all Nordic countries. The three main recommendations, which are detailed below, are:

1. Stimulate supply of, and demand for, compensation.

2. Clarify and supplement compensation guidelines and legal framework.

3. Strengthen strategic Nordic cooperation on compensation.

\subsection{Stimulate supply of, and demand for, compensation}

The current planning and regulatory systems in the Nordic countries are inadequate to reduce the cumulative losses of biodiversity and ecosystem services. To reduce and ultimately reverse these losses we recommend that Nordic governments take a two-part approach by implementing a strong regulatory driver that influences the decision-making of private actors and simultaneously easing potential challenges by facilitating the creation of an adequate supply of credits.

\subsubsection{Require compensation now to stimulate demand}

A regulatory driver is critical for creating a new status quo where compensation becomes the norm, rather than the exception. While voluntary compensation should be encouraged, obligatory compensation demands will do more to address environmental impacts and ensure consistent and transparent treatment of different sectors. National drivers will vary from country to country, but common regulatory drivers from the EU are relevant and applicable today.

For countries that favor a market-based approach for increasing supply, this regulatory driver is essential. Without it, market mechanisms like habitat banking cannot develop. But even countries aiming to increase supply through non-market approaches (or those who anticipate legal challenges to market-based approaches) will be equally dependent upon a consistent, replicable, and transparent compensation demand from all levels of government. This compensation demand is equally important for countries that wish to place the burden of creating credits on the developers themselves, rather than through a third party as in a habitat banking system.

Rather than waiting for changes in policy implementation or legal change, we suggest that national (and to a lesser degree local) decision- 
makers in Nordic countries apply a "soft start" where developers are required to provide compensation for any project affecting a certain threshold area, a key species, or over a certain project value in monetary terms. Such a start could be considered "soft" in the sense that these initial thresholds need not be strict. But then, through a gradual and transparent process, these thresholds can be "ratcheted up" over time based on existing, new or improved regulatory drivers. This will provide the most effective signal for ensuring a stable increase in the supply of compensation credits to match an anticipated demand.

Our key recommendation (1): Require compensation now to stimulate demand and concurrently develop guidelines to ensure predictable implementation.

\subsubsection{Establish pilot habitat banks to increase supply}

Facilitating the supply of credits is crucial for the system to work. Relying on individual developers to create their own supply on a case-bycase project basis is not only expensive, but does little to increase the confidence of other actors that the compensation system itself is capable of churning out the type of credits that will be legally required. Doing so requires creative solutions by all stakeholders, where governments will play a key role in stimulating discussion and coordinating initiatives.

We recommend that national (but also local) decision-makers in Nordic countries facilitate the establishment of pilot habitat banks by cooperating with landowners and landowner organizations. Creative solutions should harness the power of incentives to increase the supply of compensation credits. For example, landowners could enter into temporary contracts to lease their land or large-scale development projects could be encouraged to implement pre-planned compensation measures.

We believe that market-based approaches have the most potential. Development of such banks are common in the US and Germany and are actively pursued in EU countries that are ratcheting up compensation requirements (e.g., UK). This approach would likely receive support from stakeholders in Nordic countries. For example, Rämö et al. (2013) found that several private forest owners in Finland were interested in providing nature values by acting as sellers for a habitat bank. Habitat banking, or other market-based approaches, is particularly relevant in Nordic countries where small-scale private forest ownership dominates and landowner organizations are well established. Habitat banking will reduce the transaction costs associated with a high number of stake- 
holders and provide an alternative to state-owned land, whose supply is likely insufficient to meet future compensation demand.

Our key recommendation (2): Facilitate the creation of pilot habitat banks to increase supply of credits, lower costs for compensation, and to test and demonstrate credit measurement and registration systems.

\subsubsection{Develop compensation pilots using existing drivers}

In the short term existing drivers should be used to develop pilot compensation projects (similar to what is under way in Norway). This will build experience and capacity under different conditions and also support development of further guidance. To harness economies of scale, local expertise, and a potentially larger supply of credit providers, pilots should preferably be established in large development projects and around major Nordic cities. These should be complemented with smaller pilots to ensure valuable lessons from various scales. Pilot schemes have the potential to generate legal precedents that support future compensation requirements and also provide an opportunity to test and revise market-based approaches like habitat banking.

Our key recommendation (3): Develop compensation pilots using existing drivers.

\subsection{Clarify and supplement compensation guidelines and legal framework}

Environmental compensation is a relatively new concept to Nordic countries. To increase the use of cost-effective compensation measures in everyday landscapes we suggest that Nordic governments rely on - and clarify - existing legal and planning frameworks in the short-term, while improving compensation frameworks in the long-term. A flexible framework not only reduces the direct financial costs of compensation but can, in the long run, lead to improved economic growth by reducing the social costs associated with environmental damage, which benefits both private and public sectors. 


\subsubsection{First: Rely on existing legal frameworks and improve existing implementation}

In the short-term compensation demands should be based on existing legal frameworks. The aim should be to improve existing implementation based on international best practices and the cost-reducing approaches discussed in Chapter 5 .

A first step is to analyze the scope and applicability of existing legal provisions for compensation. Each country should study the relevant and useful existing legal frameworks and how their implementation can be improved. Our presentation of drivers in this study is a good starting point for such an analysis (chapter 4).

A second step is to develop and clarify guidelines based on existing legal frameworks, similar to what is under way in Sweden with a new EPA guidance on compensation. These guidelines may be relevant and helpful for other Nordic countries.

Key issues that should be addressed in guidelines include:

- What are reasonable requirements on avoidance and minimization before compensation is required? (i.e., guidance should not focus exclusively on compensation, but rather the mitigation hierarchy under which it is applied).

- Which impacts and values should be compensated and what is considered exchangeable? (i.e., clarify the primary focus on biodiversity and a secondary focus on ecosystem services in defining NNL).

- Which methods should be used to scale compensation?

- What are acceptable protocols for monitoring and evaluating compensation projects?

- How best to balance key trade-offs, in particular the unavoidable trade off between flexibility and risk discussed in Chapter 5 .

Our key recommendation (4): First, rely on existing legal frameworks and improve existing implementation.

\subsubsection{Second: Consider improvements to legal frameworks}

A key conclusion from this study is that countries with basic compensation requirements (e.g., Sweden) and those with minimal or uncertain support can all benefit from significant changes to their legal frameworks in order to reach the NNL target. For example, in Finland revision 
of Nature Conservation Act is currently under way that provides an opportunity to support increased compensation and thus better reach the NNL target.

In the long term, legal frameworks should ensure the fair and consistent application of environmental compensation independent of the sector causing the damage and it should cover all highly valued ecosystems in everyday Nordic landscapes.

Our key recommendation (5): Second, consider improvements to legal frameworks.

\subsubsection{Implement environmental compensation within existing spatial planning process}

The Nordic countries already have comprehensive regulatory processes for planning, implementation and monitoring of development projects (e.g., through local spatial planning and EIA). Compensation should not be presented as a stand-alone "addition" to this planning process but rather be integrated as much as possible. To maximize benefits and minimize costs, spatial planning should involve compensation as a new parameter, but do so in accordance with existing national and regional strategies for conservation and sustainable land use, including the mitigation hierarchy. One possibility is to develop a handful of pilot projects in different areas that suggest slightly different approaches for how to incorporate compensation and assess the results before developing nationwide guidance.

For example, regional planning authorities should clearly identify possible compensation areas based on existing spatial planning. This could be based on networks of protected areas and their connectivity or other high value nature areas identified in regional plans. Regional planning authorities should also be prepared to provide guidance for developers.

Our key recommendation (6): Implement environmental compensation within existing spatial planning processes.

\subsection{Strengthen Nordic cooperation}

Strategic Nordic cooperation on the implementation of compensation is highly relevant given a number of regional similarities including: regulatory frameworks, land ownership patterns, types of biodiversity and ecosystems, and common environmental quality standards such as natu- 
ral geographical regions and vegetation types. The Nordic countries also share functional cross-border regions of strategic importance, where a shared view on mitigation/compensation measures could promote sustainable development in transboundary projects.

These similarities suggest that strategies developed in one country are highly relevant in addressing common challenges in another country. This, in turn, underscores the importance of sharing experiences to reduce costs. Further, geography suggests that future transboundary development projects (e.g., infrastructure projects that are directly adjacent to, or cross, borders), could benefit from near-term collaboration in building similar frameworks to ensure consistent use of compensation.

\subsubsection{Share experiences and lessons learned}

Sharing experiences is a key way to reduce costs associated with compensation; in particular the non-productive yet inevitable transaction costs that arise. The emerging experiences and lessons in the Nordic countries supplement the comprehensive pool of experiences beyond the Nordic countries. We recommend that the Nordic Council of Ministers facilitate information exchange, outreach, and communication - and document this exchange - between Nordic countries. NCM will play a critical role in the following:

- Publications. NCM could create a web portal that centralizes information developed across different Nordic levels of government. This report could be the first example of such Nordic sharing of experiences.

- Harmonize terminology. NCM should ensure common use of terms and agreed-upon definitions of key concepts to ensure productive discussion between countries. As noted below, common understanding of the No Net Loss concept is key.

- Database. Document and share Nordic experiences and lessons in a common web-based database, e.g., info on past compensation projects and their success, local mapping of resources, relevant longterm management plans, etc.

- Outreach. An annual Nordic conference on compensation could be established with a start in Stockholm in 2016, which could highlight Sweden's early and ambitious efforts.

- Overseer. Although NCM does not have a regulatory role within Nordic countries it could perhaps create a "regulator's network" 
where best practices among Nordic countries are collected, summarized and made accessible for local planners and others charged with implementing compensation on a local level. To the extent that market-based approaches like habitat banking are established in several countries, NCM could help organize a common register for credits.

Nordic countries could benefit from developing this compensation knowledge base by promoting Nordic companies and exporting their know-how. This will help promote the environmental quality image of the Nordic countries, while also facilitating international information exchange. Nordic companies currently face (or will face) requirements from the International Finance Corporation IFC PS6 (see chapter 4.1.2) and must also comply with No Net Loss requirements from the EU. Our recommendation is therefore to consider building a common knowledge base on environmental compensation for international Nordic companies. Improving the capacity to manage these challenges at home can lead to a significant "first mover" advantages relatively to other countries, which can help keep the costs of compensation down.

Our key recommendation (7): Share experiences and lessons learned among Nordic countries and companies.

\subsubsection{Common Nordic interpretation of the No Net Loss concept}

The interpretation of the No Net Loss concept affects the scope for flexible solutions. The degree of flexibility in a system depends upon the ambition and policy targets. If the goal is to ensure No Net Loss in a strict scientific sense, there is probably little room for flexibility. However, if one is prepared to accept greater risk of not achieving No Net Loss, the flexibility of the system can increase.

Determining an appropriate balance in this question is beyond the scope of this report, but the development of a common Nordic interpretation of the No Net Loss concept is key, given the number of regional similarities among countries.

Our key recommendation (8): Outline a common interpretation of the No Net Loss concept for Nordic countries. 


\subsubsection{Start cooperation on transboundary development projects}

Given the likelihood of transboundary development projects in the coming years (e.g., roads, railways, hydropower, grid networks, etc.) and common conservation concerns for key habitats and ecosystems, we believe that early involvement across countries regarding common approaches to compensation is critical. Early discussion, including bilateral and even trilateral cooperation, can help reduce future transaction costs, ensure productive environmental outcomes, while also providing critical infrastructure to meet the needs of growing economies. This cooperation could develop within existing Nordic environmental forums rather than creating new ones.

Early and strategic cooperation in developing a common framework for compensation could add value to national efforts by providing structure and guidance to regulatory agencies on both sides of the border.

Our key recommendation (9): Start cooperation on environmental compensation in transboundary development projects. 



\section{References}

Aradóttir, Á. L., \& Pétursdóttir, P. (2011). Opinber stefnumótun og stjórnsýsluhvatar er varða vistheimt á Íslandi [Policies and incentives for ecological restoration in Iceland]. Pages 24-30 in Aradóttir, Á. L. \& Halldórsson, G. (eds.). Vistheimt á Íslandi [Ecological restoration in Iceland]. Landbúnaðarháskóli Íslands og Landgræðsla ríkisins, Reykjavík, Iceland.

Aradóttir, Á. L., Petursdottir, T., Halldorsson, G., Svavarsdottir, K. \& Arnalds. O. (2013). Drivers of ecological restoration: lessons from a century of restoration in Iceland. Ecology and Society 18(4): 33. http://dx.doi.org/10.5751/ES-05946180433

Arbeidsgruppe kompensasjon for jordbruks- og naturområder. (2013). Fysisk kompensasjon for jordbruks- og naturområder ved samferdselsutbygging. Rapport fra en arbeidsgruppe. Avgitt til Samferdselsdepartementet 3. juli 2013. Samferdselsdepartementet, Oslo. (in Norwegian).

Banverket. (2006). Kompensation avseende rastande fåglar i SPA-området vid Umeälvens delta och slätter. Botnia 2006:001. (in Swedish).

Braat, L. \& ten Brink, P. (eds.) and Bakkes, J., Bolt, K., Braeuer, I., ten Brink. B., Chiabai, A., Ding, H., Gerdes, H., Jeuken, M., Kettunen, M.,Kirchholtes, U., Klok, C., Markandya, A., Nunes, P., van Oorschot,M., Peralta-Bezerra, N., Rayment, M., Travisi, C. \& Walpole, M. (2008). The cost of policy inaction: The case of not meeting the 2010 biodiversity target. Report for the European Commission.

Business and Biodiversity Offsets Programme (BBOP). (2009). Business, Biodiversity Offsets and BBOP: An Overview. BBOP, Washington, D.C

Business and Biodiversity Offsets Programme (BBOP). (2012). Standard on Biodiversity Offsets. BBOP, Washington, D.C.

Business and Biodiversity Offsets Programme (BBOP). (2014). To No Net Loss of Biodiversity and Beyond. A Summary of Discussions at the Conference 3-4 June 2014.

Cole, S. G., \& Kriström. B. (2008). Annex 5: discounting. In Lipton, D. K., LeJeune, J. B. Calewaert, \& Ozdemirolgu. E. http://envliability.eu/docs/

D13MainToolkit_and_Annexes/D13MainToolkit.html Accessed 1 Jan 2013.

Cole, S.G. (2011). Wind Power Compensation is not for the Birds: An Opinion from an Environmental Economist. Restoration Ecology 19: 147-153.

http://dx.doi.org/10.1111/j.1526-100X.2010.00771.x

Cole, S.G. (2012). Environmental Compensation is not for the Birds: Assessing social welfare impacts of resource-based environmental compensation. PhD Dissertation. Swedish University of Agricultural Sciences, Umeå, Department of Forest Economics. ISBN 978-91-576-7665-8

Cole, S.G. \& Dahl, Espen Lie. (2013). Compensating White-Tailed Eagle Mortality at the Smøla Wind-Power Plant Using Electrocution Prevention Measures. Wildlife Society Bulletin. http://dx.doi.org/10.1002/wsb.263

Cole, S.G. (2013). Equity over efficiency: a problem of credibility in scaling resourcebased compensation? Journal of Environmental Economics and Policy, 2:1, 93-117. http://dx.doi.org/10.1080/21606544.2013.764616 
Cole, S.G., Aponte, Ana P., Hasselström, Linus \& Stavlöt, Ulrika (2014). Developing Payment for EcosystemServices: A synthesis of the approach and lessons-learned from a pilot project to protect mangrove forests in Vietnam. FORES Study 2014:3. ISBN: 978-91-87379-21-5.

Conway, Mavourneen, Rayment, Matt, White, Andy \& Berman, Sandra. (2013). Exploring potential demand for and supply of habitat banking in the EU and appropriate design elements for a habitat banking scheme. Final Report submitted to DG Environment. ICF GHK in association with BIO Intelligence Service, 2013.

Curran, Michael, Hellweg, Stefanie \& Beck, Jan. (2013). Is There Any Empirical Support for Biodiversity Offset Policy? Ecological Applications 24, no. 4: 617-32. http://dx.doi.org/10.1890/13-0243.1

Defra. (2013). https://www.gov.uk/government/consultations/biodiversityoffsetting-in-england

European Commission. (2011). Our Life Insurance, Our Natural Capital: An EU Biodiversity Strategy to 2020. http://eur-lex.europa.eu/legal-content/EN/TXT/ HTML/?uri=CELEX:52011DC0244\&from=EN

EC Working group on No Net Loss of ecosystems and their services. (2013). Scope and objectives of the No Net Loss initiative. (http://ec.europa.eu/environment/ nature/biodiversity/nnl/pdf/Subgroup_NNL_Scope_Objectives.pdf)

EEA. (2006). Urban sprawl in Europe. The ignored challenge. EEA Report No 10/2006

EEB. (2014). EEB Prioritites for 'EU No Net Loss initiative'. July. Available at: http://www.eeb.org/?LinkServID=AE82914E-5056-B741DB98744CF8393912\&showMeta=0\&aa

eftec, IEEP et. al. (2010) The use of market-based instruments for biodiversity protection - The case of habitat banking - Summary Report. http://ec.europa.eu/environment/enveco/index.htm

ELD. (2014). Directive 2004/35/Ce Of The European Parliament And Of The Council Of 21 April 2004 on environmental liability with regard to the prevention and remedying of environmental damage.

Enetjärn Natur, Kairos Future and Skogssällskapet. (2015). Habitat Banking - Framtider för marknadsbaserade lösningar för biologisk mångfald 2030 (in Swedish).

Enetjärn, Cole \& Hasselström. (2013). Ekologisk kompensation får inte bli exploatörernas fribiljett. MiljöAktuellt debatt 2013-06-17 (in Swedish).

English, E. P., Peterson, C. H. \& Voss, C. M. (2009). Ecology and economics of restoration scaling, final report for Coastal Response Research Center, Appendix C. URL http://rfp.crrc.unh.edu/projects/viewProject.php? PROJECT_ID=25

Freeman, A.M. III. (2003). The measurement of environmental and resource values. Theory and methods. Second edition. Resources for the Future. ISBN 1-891853-62-7.

Hilderbrand, Watts \& Randle. (2005). Perspective. The Myths of Restoration Ecology. Ecology and Society 10(1): 19.

Hobbs, Richard J., Higgs, Eric \& Harris, James A. (2009). “Novel Ecosystems: Implications for Conservation and Restoration." Trends in Ecology \& Evolution 24 (11): 599-605. http://dx.doi.org/10.1016/j.tree.2009.05.012

Hårklau, S.E., Arnoldussen, A., Colman, J., Flydal, K. \& Lied, A.B. (2013). Kompensasjon av jordbruks- og naturområder: Litteraturestudie med anbefalinger og vurderinger av kostnader. Rapport til Samferdselsdepartementet. Samferdselsdepartementet, Oslo. (in Norwegian). 
Johansson, P.-O. (1991). An introduction to modern welfare economics. Cambridge University Press, Cambridge, England, United Kingdom. http://dx.doi.org/10.1017/CB09780511582417

Jones, A. (2011). Presentation to 2nd Ecological Compensation conference, Stockholm, Oct 2011.

Jones, C. A. \& Pease, K. A. (1997). Restoration-based compensation measures in natural resource liability statutes. Contemporary Economic Policy 15:111-122.

ten Kate, K.., Bishop, J., and Bayon, R. (2004). Biodiversity offsets: Views, experience, and the business case. IUCN, Gland, Switzerland and Cambridge, UK and Insight Investment, London, UK. ISBN: 2-8317-0854-0.

Ketola, M., Malin, K., Nyrölä, L. \& Suvantola, L. (2009). Kompensaation mahdollisuudet liikennehankkeissa. Suomen ympäristö 18/2009. (in Finnish).

Ketola, M., Malin, K., Nyrölä, L. \& Suvantola, L. (2009). Kompensaation mahdollisuudet liikennehankkeissa. Suomen ympäristö 18/2009. (in Finnish).

Kniivilä, M., Kosenius, A.-K. \& Horne, P. (2014). Luontoarvopankkien hyödyt ja haitat sekä soveltuvuus Suomeen. PTT working papers 161.50 p. (in Finnish).

Kniivilä, M., Kosenius, A.-K. \& Horne, P. (2014). Luontoarvopankkien hyödyt ja haitat sekä soveltuvuus Suomeen. PTT working papers 161.50 p. (In Finnish with summary in English).

Lipton, J., LeJeune, K., Calewaert, J. \& Ozedemiroglu, E. (2008). Toolkit for performing resource equivalency analysis to assess and scale environ- mental damage in the European Union. Produced by the Resource Equivalency Methods for Assessing Environmental Damage in the EU (REMEDE) Team. Funded by the Sixth Framework Programme of the EC. September. URL http://www.envliability.eu/ docs/D13MainToolkit_and_Annexes/D13MainToolkit.html [accessed on 20 September 2009].

LKAB Framtid. (2014). Naturen kan skyddas på flera sätt. LKAB Framtid 6/2014. Anders Enetjärn (in Swedish).

Marttila, M., Orell, P., Erkinaro, J., Romakkaniemi, A., Huusko, A., Jokikokko, E., Vehanen, T., Piironen, J., Huhmarniemi, A., Sutela,T., Saura, A. \& Mäki-Petäys, A. (2014) Rakennettujen jokien kalataloudelle aiheutuneet vahingot ja kalatalousvelvoitteet. RKTL:n työraportteja 6/2014.96 p.

McCarthy, M.A., Parris, K.M., van der Ree, R., McDonnell, M.J., Burgman, M.A., Williams, N.S.G., McLean, N., Harper, M.J., Meyer, R., Hahs, A. \& Coates, T. (2004). The habitat hectares approach to vegetation assessment: an evaluation and suggestions for improvement. Ecological Management \& Restoration 5, 24-27. http://dx.doi.org/10.1111/j.1442-8903.2004.00173.x

Merkel, Keith. Biologist, CEO, Merkel Consulting, San Diego, CA. Personal Communication, 8 November 2013.

Miljøverndepartementet. (2009). Ot.prp. nr. 52 (2008-2009) Om lov om forvaltning av naturens mangfold (naturmangfoldloven). Miljøverndepartementet, Oslo. (in Norwegian).

Moknes Presentation, 4 feb 2015. Handbok för ålgräsrestaurering i Västerhavet. Conference on Marine Restoration.

Moksnes, Per. (2015). Presentation, Conference on Marine Restoration, Gothenburg, Sweden 3-4 February 2015.

Moksnes, Per. (2015). Personal Communication. 5 February 2015. 
National Oceanic Atmospheric Administration [NOAA]. (1999). Discounting and the treatment of uncertainty in natural resource damage assessment. NOAA Technical Paper 99-1. http://www.darrp.noaa.gov/library/pdf/discpdf2.pdf. Accessed 1 Jan 2013.

Naturskyddsföreningen. (2007). Kompensationsprincipens användning. Lägesbeskrivning och diskussionsunderlag. (in Swedish).

Naturvårdsverket. (2015). Tillämpning av miljöbalkens bestämmelser om ekologisk kompensation. (in Swedish).

Naturvårdsverket. Unpublished. Kompensation vid förlust av naturvärden. En prövningsvägledning. (in Swedish).

Naturvårdsverket. (2003). Natura 2000 i Sverige, handbok med allmänna råd (2003:9) (in Swedish).

Nordic Iron Ore. (2015 in press). Kompensationsplan Ludvika gruvor (in Swedish).

Norges Offentlige Utredning (NOU) 2013:10. Naturens goder - om verdi av økosystemtjenester. Rapport til Miljøverndepartementet. pp. 21, 361-363. (in Norwegian, English summary available).

Norwegian Finance Department [NFD]. (2005). Veileder i samfunnsøkono- miske analyser. Norwegian Government Agency for Financial Management. Accessed 1 Jan 2013. (In Norwegian).

Nyrölä, L., Erävuori, L., Junnilainen, L., Järvitalo, A.,Teerihalme, H. \& Väre, S. (2011). Kompensaation toteuttamisen reunaehdot tie- ja rautatiehankkeissa. Liikenneviraston tutkimuksia ja selvityksiä 52/2011.74 p. (in Finnish).

Nyrölä, L., Erävuori, L., Junnilainen, L., Järvitalo, A.,Teerihalme, H. \& Väre, S. (2011). Kompensaation toteuttamisen reunaehdot tie- ja rautatiehankkeissa. Liikenneviraston tutkimuksia ja selvityksiä 52/2011. 74 p. (in Finnish).

Parkes, D., Newell, G. \& Cheal, D. (2003). Assessing the quality of native vegetation: the "habitat hectares" approach. Ecological Management \& Restoration 4, S29-S38. http://dx.doi.org/10.1046/j.1442-8903.4.s.4.x

Pilgrim, J.D., Brownlie, S., Ekstrom, J.M.M., Gardner, T.A., von Hase, A., ten Kate, K., Savy, C.E., Stephens, R.T.T., Temple, H.J., Treweek, J., Ussher, G.T. \& Ward, G. (2013). A process for assessing the offsetability of biodiversity impacts. Conservation Letters 6(5), 376-384. http://dx.doi.org/10.1111/conl.12002

Quétier, F., Van Teeffelen, A.J.A., Pilgrim, J.D., von Hase, A. \& ten Kate, K. (2014). Biodiversity offsets are one solution to unmitigated biodiversity loss - a response to Curran et al. Ecological Applications, in press.

Quétier, F., Regnery, B. \& Levrel, H. (2014). No Net Loss of biodiversity or paper offsets? A critical review of the French No Net Loss policy. Environmental Science \& Policy 38: 120-131. http://dx.doi.org/10.1016/j.envsci.2013.11.009

Quétier F., Van Teeffelen, A.J.A., Pilgrim, J.D., von Hase, A. \& ten Kate, K. (2015). Biodiversity offsets are one solution to unmitigated biodiversity loss - a response to Curran et al. Ecological Applications, in press.

Riksdagen. (2010). Rapport från Riksdagen. Hållbara städer - med fokus på transporter, boende och grönområden. 2010/11:RFR3. (in Swedish).

Riksrevisionen. (2011). RiR 2011:22. Botniabanan och järnvägen längs Norrlandskusten - hur har det blivit och vad har det kostat? (in Swedish).

Roach, Brian \& Wade, William W. (2006). "Policy Evaluation of Natural Resource Injuries Using Habitat Equivalency Analysis.” Ecological Economics 58 (2): 421-33. http://dx.doi.org/10.1016/j.ecolecon.2005.07.019 
Rämö, A.-K., Horne, P. \& Primmer, E. (2013). Yksityismetsänomistajien näkemykset metsistä saatavista hyödyistä. PTT reports 241.107 p. (In Finnish with summary in English).

Samferdselsdepartementet. (2013). Meld. St. 26 (2012-2013). Melding til Stortinget. Nasjonal transportplan 2014-2023. Samferdselsdepartementet, Oslo. p. 221. (in Norwegian).

SEPA (Swedish Environmental Protection Agency). (2003). Konsekvensanalys steg för steg. Handledning i samhällsekonomisk konsekvensanalys för Naturvårdsverket (Impact assessment step by step. Guide to socio-economic impact analysis for the Swedish Environmental Protection Agency). Naturvårdsverket, Stockholm.

SIKA. (2009). Värden och metoder för transportsektorns samhällsekonomiska analyser - ASEK 4. SIKA Rapport 2009:3, Swedish Institute for Transport and Communications Analysis (SIKA), Östersund. (in Swedish).

SOU. 2013:68. Synliggöra värdet av ekosystemtjänster (in Swedish).

Suding, K. (2011). Toward an Era of Restoration in Ecology: Successes, Failures, and Opportunities Ahead. Restoration Ecology 2011. http://dx.doi.org/10.1146/ annurev-ecolsys-102710-145115

Suvantola, L. (2006). Huominen ei koskaan kuole - Luonnonsuojelun ja ympäristönkäytön kilpailutilanteen ratkaisemisesta. PhD thesis, University of Joensuu. Edita. 294 p. (in Finnish).

Suvantola, L. (2006). Huominen ei koskaan kuole - Luonnonsuojelun ja ympäristönkäytön kilpailutilanteen ratkaisemisesta. Ph.D. thesis, University of Joensuu. Edita. 294 p. (in Finnish).

Sterner, T. (2003). Policy Instruments for Environmental and Resource Management. Resources for the Future, Washington, DC.

Trafikverket/Enetjärn Natur. (2014). Opubl. Villkorsuppföljning fåglar vid Botniabanan 2010-2015. Årsrapport 2014. (in Swedish).

Vaissière, A.C. \& Levrel, H. (2015). Biodiversity offset markets: What are they really? An empirical approach to wetland mitigation banking. Ecological Economics 110, 81-88. http://dx.doi.org/10.1016/j.ecolecon.2015.01.002

Van Teeffelen, A.J.A., Opdam, P.F.M., Wätzol, F., Hartig, F., Johst, K., Drechsler, M., Vos, C.S., Wissel, S. \& Quétier, F. (2014). Ecological and economic conditions and associated institutional challenges for conservation banking in dynamic landscapes. Landscape \& Urban Planning 130: 64-72. http://dx.doi.org/10.1016/ j.landurbplan.2014.06.004 



\section{Sammanfattning}

Påverkan på natur och ekosystem ökar i takt med att samhällsutvecklingen, genom stadsutbyggnad, ny infrastruktur, materialutvinning $\mathrm{mm}$, tar natur i anspråk. Överutnyttjandet av de tjänster som naturen förser oss med - såsom biologisk mångfald och ekosystemtjänster - är ett direkt resultat av att vi misslyckats sätta ett pris på naturens gratistjänster. Att tillämpa ekologisk kompensation är ett sätt att ta itu med detta.

Ekologisk kompensation ger den som planerar ett ingrepp i naturen tydliga incitament att dels undvika skada, dels ersätta det som trots allt går förlorat. Det blir således inte längre samhället som ska bära de kostnader som följer med förluster av natur och ekosystemtjänster. Trots flera fördelar med ekologisk kompensation finns det också risker, t.ex. att kompensation blir ett sätt för exploatören att köpa sig fri.

Användningen av ekologisk kompensation varierar stort mellan de nordiska länderna. Ländernas lagstiftningar ger inte heller ett tydligt stöd för tillämpningen av ekologisk kompensation. Således är en slutsats att lagstiftningarna inte är utformade för att hejda nettoförlusterna av biologisk mångfald.

Internationella utblickar visar att kostnaden för att genomföra kompensation inom ramen för ett anläggningsprojekt kan variera från 1-5 \% av de totala projektkostnaderna. För en relativt liten kostnad kan ekologisk kompensation således leverera biologisk mångfald och ekosystemtjänster.

Syftet med den här studien är att ge Nordiska Ministerrådet och nationella beslutsfattare i de nordiska länderna en översikt över de viktigaste förutsättningarna för ökad, flexibel och kostnadseffektiv tillämpning av ekologisk kompensation. 
Studien ger ett antal rekommendationer för att öka användningen av ekologisk kompensation. Rekommendationerna bygger på nordiska och andra internationella erfarenheter och de är tillämpliga på alla nordiska länder. Rekommendationerna är samlade i tre huvudgrupper:

1. Stimulera utbudet av och efterfrågan på ekologisk kompensation.

2. Komplettera med tydligare legala ramverk och vägledningar om ekologisk kompensation.

3. Etablera och stärk strategiskt nordiskt samarbete om ekologisk kompensation. 
Nordic Council of Ministers

Ved Stranden 18

DK-1061 Copenhagen K

www.norden.org

\section{Environmental compensation}

Environmental impacts are increasing due to human activities. The overuse of the benefits nature provides us is the direct result of our failure to put a price on these benefits. One way of addressing this is to require environmental compensation.

The purpose of the study is to provide Nordic Council of Ministers and national decision-makers with an overview of key conditions for increased, flexible and cost-effective application of compensation.

The study shows that for a relatively small cost society can make a significant investment in the provision of biodiversity and ecosystem services by requiring compensation.

The study outlines three main recommendations on how to increase the use of environmental compensation:

1. Stimulate supply of, and demand for, compensation

2. Clarify and supplement guidelines and legal framework

3. Strengthen Nordic cooperation on compensation

TemaNord 2015:572

ISBN 978-92-893-4335-0 (PRINT)

ISBN 978-92-893-4337-4 (PDF)

ISBN 978-92-893-4336-7 (EPUB)

ISSN 0908-6692

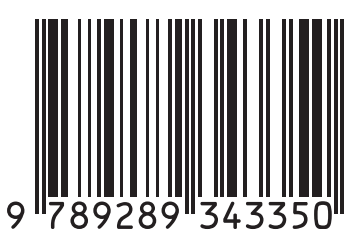

